\title{
DISTRIBUIÇÃO DO MARACANÃ-VERDADEIRO PRIMOLIUS MARACANA (PSITTACIDAE): PREFERÊNCIA DE HÁBITAT E FATORES QUE INFLUENCIAM NA MANUTENÇÃO DE SUAS POPULAÇÕES REMANESCENTES
}

\author{
MARIA FLÁVIA CONTI NUNES \\ Bacharel em Ciências Biológicas
}

\begin{abstract}
Dissertação apresentada à Escola Superior de Agricultura "Luiz de Queiroz", Universidade de São Paulo, para obtenção do título de Mestre em Ecologia de Agrossistemas, Área de concentração de Ecologia Animal
\end{abstract}

PIRACICABA

Estado de São Paulo - Brasil Agosto - 2003 


\title{
DISTRIBUIÇÃO DO MARACANÃ-VERDADEIRO PRIMOLIUS MARACANA (PSITTACIDAE): PREFERÊNCIA DE HÁBITAT E FATORES QUE INFLUENCIAM NA MANUTENÇÃO DE SUAS POPULAÇÕES REMANESCENTES
}

\author{
MARIA FLÁVIA CONTI NUNES \\ Bacharel em Ciências Biológicas
}

\begin{abstract}
Dissertação apresentada à Escola Superior de Agricultura "Luiz de Queiroz", Universidade de São Paulo, para obtenção do título de Mestre em Ecologia de Agrossistemas, Área de concentração de Ecologia Animal
\end{abstract}

PIRACICABA

Estado de São Paulo - Brasil Agosto - 2003 


\section{Dados Internacionais de Catalogação na Publicação (CIP)} DIVISÃO DE BIBLIOTECA E DOCUMENTAÇÃO - ESALQ/USP

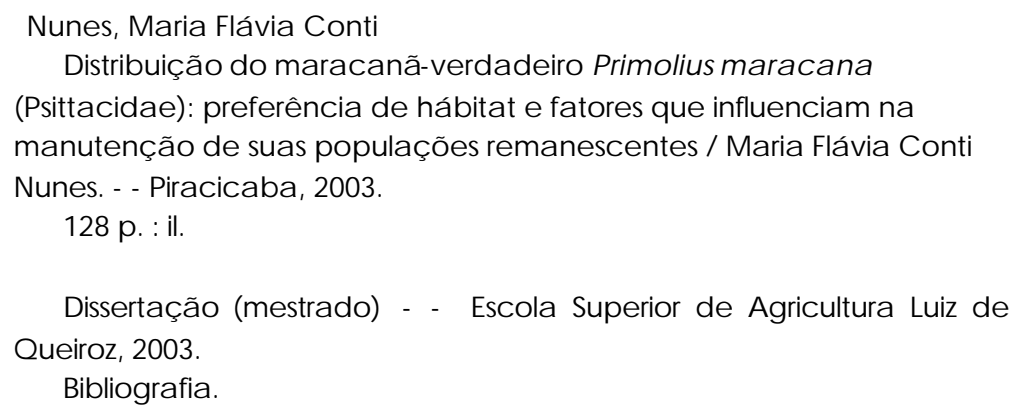

1. Aves 2. Biologia animal 3. Ecologia a nimal4. Ecossistema florestal 5. Habitat 6. População a nimal 7. Proteção a nimal 8. Psitac íformes I. Título

CDD 598.2913 
Á minha família pelo carinho dedicado por todos esses anos 


\section{AGRADECIMENTOS}

Sou muito grata pelo apoio financeiro/logístico da Fundação O Boticário de Proteção à Natureza- MacArthur Foundation, North England Zoo, Instituto Florestal (Estação Ecológica dos Caetetus), Departamento de Ecologia -Unesp e Laboratório de Ecologia Animal - Esalq.

Agradeço a Aninha, o Rubin, a Jane, a Anna, a Sandra e a Beth pela ajuda e companhia durante as "ralações" no campo, além de todo o pessoal de Caetetus, em especial, a Célia, que me deu muito carinho durante o meu longo período em Gália, e o seu Teodoro, que foi um grande parceiro de trabalho.

Agradeço ao meu comitê de orientação, Dr. Mauro Galetti, Dr. Marco Aurélio Pizo e Dr. Carlos Vetorazzi, pelas críticas, sugestões, apoio e paciência, tão importantes para a realização desse trabalho. Sem esquecer, é claro, do Luciano Verdade, do Dr. Marsden, do Gustavo beija-flor, da Kátia, do Silvio e da Roberta, e de todo o pessoal do LEA, que contribuíram de diversas formas durante o meu mestrado.

Agradeço ao IBAMA por toda a colaboração para o término da dissertação, e em especial as "pérolas” de Ariquemes: Zé, Márcia, Alan, Pati, Ricardo e Sérgio.

Por fim, agradeço de coração: às minhas grandes amigas e companheiras Marina, Laís e Júlia, pelo carinho e companheirismo. Ao meu namorado Horizonte, pela incomensurável contribuição nesse trabalho e em minha vida. E à minha família, Pai, Mãe, Laura e Cláudia, por todo apoio que vêm me dado, amo vocês! 


\section{SUMÁRIO}

RESUMO vii

SUMMARY ix

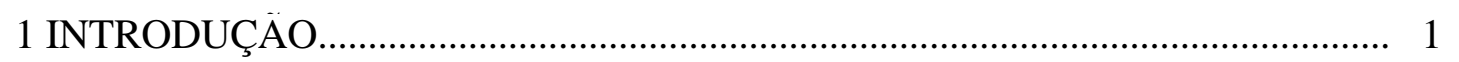

2 REVISÄO DE LITERATURA.............................................................

3 DISTRIBUIÇÄO GEOGRÁFICA E ESTATUS DO MARACANÄVERDADEIRO PRIMOLIUS MARACANA EM SUA ÁREA DE OCORRÊNCIA HISTÓRICA

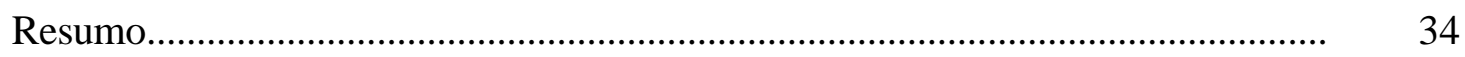

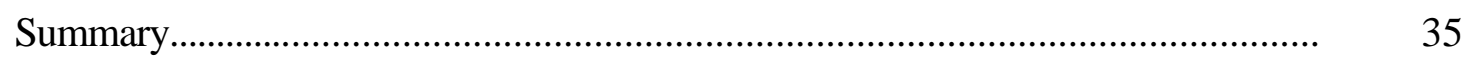

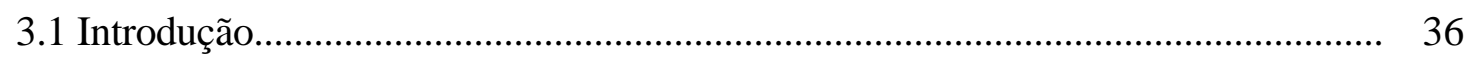

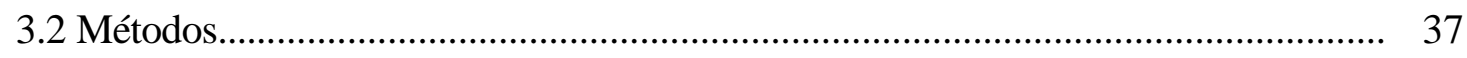

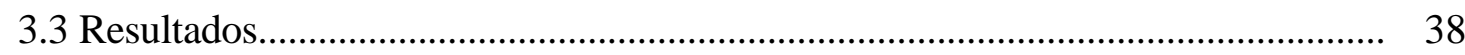

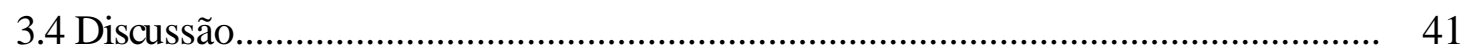

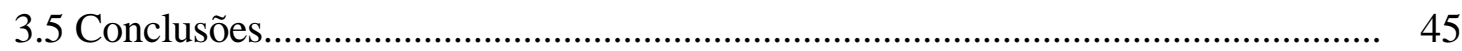

4 PREFERÊNCIA DE HÁBITAT E FATORES QUE INFLUENCIAM NA PERSISTÊNCIA DAS POPULAÇÕES REMANESCENTES DO MARACANÃVERDADEIRO PRIMOLIUS MARACANA EM ESCALA REGIONAL

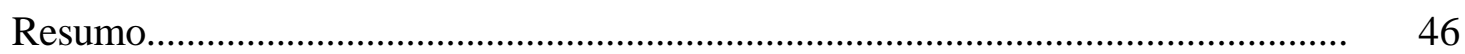

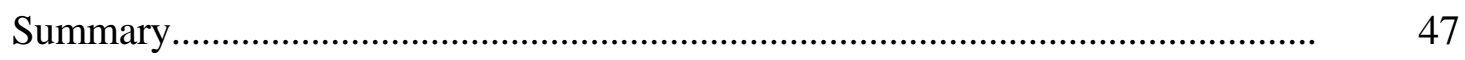

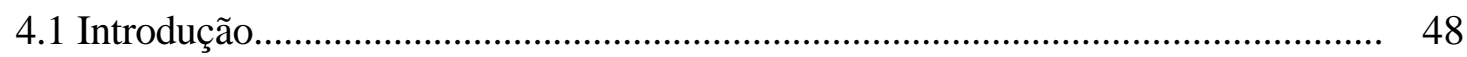

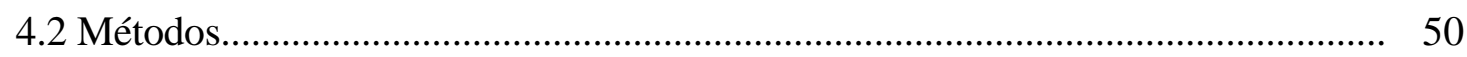

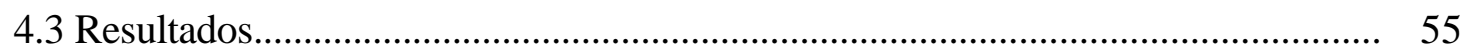




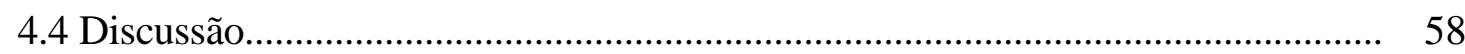

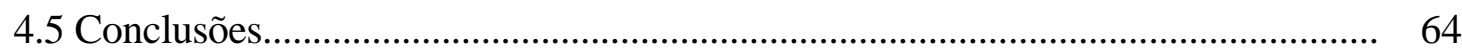

5 PREFERÊNCIA DE HÁBITAT E FATORES QUE INFLUENCIAM NA PERSISTÊNCIA DAS POPULAÇÕES REMANESCENTES DO MARACANÃVERDADEIRO PRIMOLIUS MARACANA EM ESCALA LOCAL.

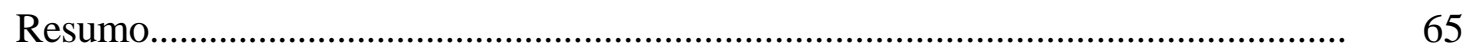

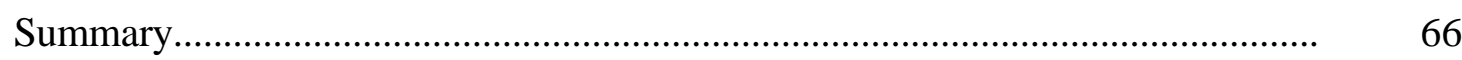

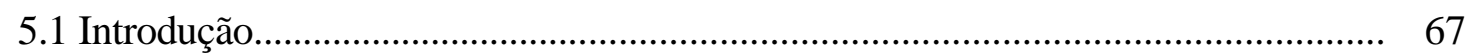

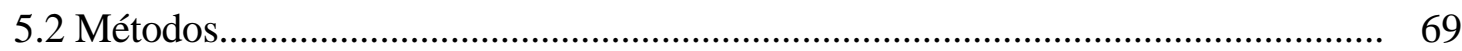

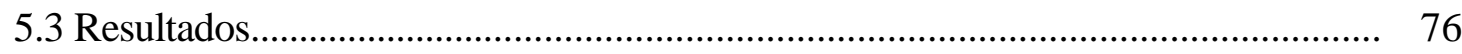

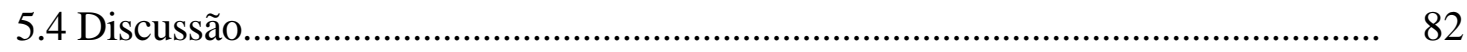

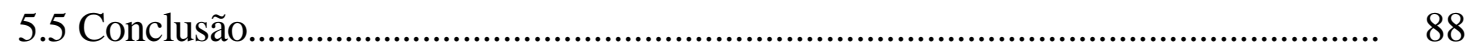

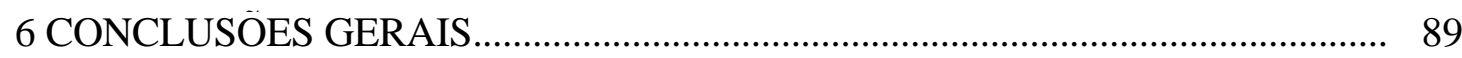

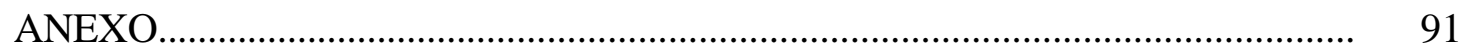

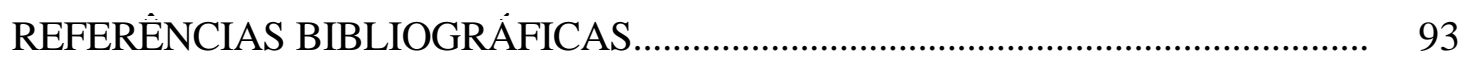

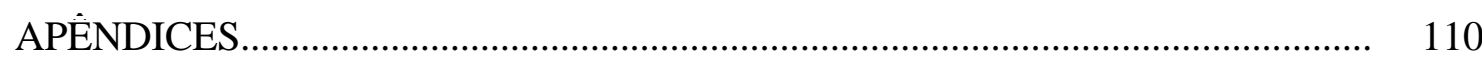




\title{
DISTRIBUIÇÃO DO MARACANÃ-VERDADEIRO PRIMOLIUS MARACANA (PSITTACIDAE): PREFERÊNCIA DE HÁBITAT E FATORES QUE INFLUENCIAM NA MANUTENÇÃO DE SUAS POPULAÇÕES REMANESCENTES
}

\author{
Autora: MARIA FLÁVIA CONTI NUNES \\ Orientador: Prf. Dr.. MAURO GALETTI RODRIGUES
}

\section{RESUMO}

O Maracanã- verdadeiro é um psitacídeo vulnerável a extinção, por estar havendo redução de suas populações em diferentes partes de sua área de ocorrência. Foi realizada uma revisão sobre a distribuição, histórica e atual, e o estatus da espécie através de dados de espécimes de museus e literatura. Foram reunidos 176 registros de localização do maracanã e comparadas as distribuições histórica e atual. Constatou-se, principalmente, uma contração dos limites ao sul da distribuição histórica da espécie. Dessa maneira, foi avaliado se nessa região a ocorrência do maracanã está associada a características da composição e estrutura da vegetação. Dados de ocorrência atual da espécie foram relacionados com a localização geográfica e índices de paisagem de 54 localidades, através da análise de regressão logística. Verificou-se que o "total de cobertura vegetal da paisagem" foi a única característica de paisagem significativamente relacionada com a ocorrência do maracanã $(\mathrm{p}<0,01)$, porém o poder explicativo da variável foi baixo. A variável "latitude" também foi altamente significativa $(p<0,001)$ e não foi relacionada com nenhuma das métricas de paisagem analisadas. Isso sugere a 
existência de um outro fator não avaliado, com estrutura espacial em clina latitudinal, que está afetando as populações meridionais do maracanã. Foi também estudado o padrão de ocorrência do maracanã em escala local, no entorno da Estação Ecológica de Caetetus (2178 ha). Essa reserva está imersa em um mosaico de paisagem constituído por pequenos remanescentes florestais que podem ser importantes para a conservação da espécie. Foram amostradas 36 destas áreas remanescentes, através do método de contagens em pontos estratégicos. Cada fragmento obteve um índice de visitas por maracanã que foram relacionados as suas características espaciais, através da análise de regressão linear. As características das paisagens no entorno dos remanescentes estudados explicaram mais a variação da frequiência de visitas pelo maracanã que as características dos próprios fragmentos. As visitas dos maracanãs foram diretamente relacionadas com a "distância do fragmento até a cidade mais próxima" $(\mathrm{p}<0,05)$ e o "tamanho do remanescente" ( $\mathrm{p}<0,05)$, e inversamente relacionado a "distância mínima do fragmento até um dormitório conhecido de maracanã" $(\mathrm{p}<0,01)$ e "distância mínima do fragmento até a E.E. dos Caetetus" ( $<<0,05)$. Todas essas análises indicaram que a conservação da paisagem como um todo parece ser fundamental para manutenção de populações do maracanã, em escala local e regional. Porém deve-se levar em conta a área dos fragmentos e sua configuração espacial, investindo esforços para a conservação das áreas de dormitórios. 


\title{
DISTRIBUTION OF BLUE-WINGED MACAW PRIMOLIUS MARACANÃ: HABITAT PREFERENCES AND FACTORS AFFECTING THE PERSISTENCE OF ITS REMAINING POPULATIONS
}

\author{
Author: MARIA FLÁVIA CONTI NUNES \\ Adviser: PROF. DR. MAURO GALETTI RODRIGUES

\section{SUMMARY}

The blue-winged macaw is a vulnerable psittacidae, which has been suffering a rapid reduction of its populations in different parts of its occurrence. Thus, it was carried a detailed revision on the, historical and current, distribution and estatus of the species through using literature and specimens in museums data. We gathered 176 records of blue-winged macaw sites and compared its historical and current distributions. We verified a range contraction in the south limit of blue-winged macaw's historical occurence. In this way, we evaluated if, in this zone, the blue-winged macaw's occurrence is correlated to composition and structure of residual vegetation. The current occurrence of the species was related to geographic coordinates and landscape indices of 54 localities, through the logistic regression analysis. The "total of vegetal cover of the landscape" was the only feature of the landscape significantly related to blue-winged macaw's occurrence $(\mathrm{p}<0,01)$, however its explicatory power was very low. The "latitude" was highly significant to predict blue-winged macaw's occurrence $(p<0,001)$, and also was not related to any analyzed landscape metric. This suggests the existence of another non-evaluated factor, with spatial structure highly related to latitude, affecting the southern populations of blue-winged macaw. Also we studied the occurrence pattern 
of blue-winged macaw in local scale, around of Caetetus Ecological Station (2178 ha). This reserve is placed in a mosaic of landscape, consisting of small remnants of native vegetation that may have some value to the specie's maintenance. We sampled 36 of these remaining areas through the method of countings in advantage points. Each remnant got a "blue-winged macaw's visit index" that was related to spatial remnants features and its surrounding landscape, through the linear regression model. The landscape features around of the fragments explained more the variation of the bluewinged macaw's visit index than the features of the fragments itself. The "index of visits of maracanãs" was directly related to "distance to the closest city" $(\mathrm{p}<0,05)$ and to "remnant size" $(\mathrm{p}<0,05)$, and inversely related to "distance to the closest known roost of blue winged macaw " $(\mathrm{p}<0,01)$ and "shortest distance to the Caetetus Ecological Station" $(p<0,05)$. All these analyses indicate that the conservation of the landscape as a whole seems to be critical for the maintenance of blue-winged macaw's populations, in local and regional scale. However the size of the remnants and its spatial configuration must be taken in account, besides the efforts for the conservation of the roost sites. 


\section{INTRODUÇÃO}

As relações das espécies com seu ambiente são refletidas na distribuição de sua abundância no tempo e no espaço (Brown et al. 1995). Porém, essas relações estão associadas à escala de análise (Karl et al., 2000), uma ferramenta de medição com a qual um fenômeno é percebido e quantificado (Hay et al., 2001). Isso porque as espécies são limitadas por diversos processos que operam simultaneamente em diferentes escalas, espaciais e temporais (Hay et al., 2001 e Karl et al., 2000), mas que podem se comportar de maneira não linear com a mudança de escala (Hay et al., 2001).

O maracanã-verdadeiro, Primolius [Ara] maracanã, é uma espécie de psitacídeo que vem sofrendo extinções de suas populações, tanto em escala local, com regional. Esses fatores responsáveis pelo declínio da espécie podem ser distintos em diferentes regiões de sua ocorrência e escalas geográficas. Dessa forma, procurou-se estudar a distribuição e o estatus da espécie, além de sua relação com o hábitat, atualmente fragmentado, em diferentes escalas geográficas. Para isso, a dissertação foi dividida em três capítulos. O primeiro capítulo contém uma revisão sobre a distribuição de Primolius maracana, que permitiu examinar a distribuição e o estatus da espécie, ao longo do tempo e em diferentes regiões de sua abrangência, e verificar áreas onde ocorreram extinções. Esse capítulo foi muito importante para complementar e sistemartizar o pouco conhecimento que se tinha sobre a ocorrência do maracanã e embasar as análises contidas na dissertação, porém trata-se de um texto um pouco dispendioso por ser uma compilação de dados referentes a pouco mais de cem anos de distribuição.

O segundo capítulo apresenta um estudo em escala local, que examinou a utilização e a preferência do maracanã por remanescentes de vegetação com distintas características em uma paisagem no entorno da Estação Ecológica dos Caetetus. Já no 
terceiro capítulo analisou-se a ocorrência da espécie em paisagens com distintas composições e estruturas dentro de uma região de Floresta Atlântica, que apresenta uma clina do estatus de Primolius maracana, contendo desde zonas de extinção até zonas de recolonização pela espécie.

O principal desafio do estudo foi examinar os padrões de ocorrência do maracanã em diferentes escalas espaciais, verificando de que forma as características dos fragmentos e das paisagens podem estar influenciando na distribuição e persistência da espécie. Além disso, procurou-se identificar áreas que possam ser importantes para a conservação da espécie em escalas local e regional. O entendimento dessas relações é necessário para que se possa desenvolver estratégias para deter ou reverter os fatores que mais estão afetando a manutenção da espécie.

Foram seguidas aqui as convenções no campo da Macroecologia (Blackburn \& Gaston, 1998), referindo-se às escalas amplas como regiões extensas, e não resoluções finas, e escalas reduzidas como regiões de pequena extensão. 


\section{REVISÃO DE LITERATURA}

Primolius maracana, o maracanã-verdadeiro, é um psitacídeo considerado vulnerável à extinção e está listado no Apêndice I da CITES (Convention on International Trade in Endangered Species) (Snyder et al., 2000 e Birdlife International, 2000). Nos últimos anos a abundância e a distribuição da espécie têm diminuído rapidamente, o que tem sido atribuído principalmente à perda de hábitat (Collar et al., 1994 e Juniper \& Parr, 1998). Porém, dados mais detalhados sobre o estatus de populações de Primolius maracana são escassos, apesar da sua đbvia importância para ações conservacionistas.

As poucas informações disponíveis sobre localidades de ocorrência e abundância da espécie são pontuais, não sistematizadas e muitas vezes desatualizadas, o que faz com que os estudos sobre seu estatus e suas distribuições, atual e histórica, sejam considerados prioridades para a espécie (Snyder et al., 2000 e Birdlife International, 2000). Dessa maneira foi realizada uma revisão sobre a distribuição de Primolius maracana, a fim de suprir uma lacuna importante no conhecimento sobre a espécie. Utilizaram-se livros e periódicos, a fim de reunir dados de listas de espécies da avifauna de várias localidades e averiguar se haviam registros da espécie. Informações sobre espécimes em museus, nacionais e internacionais, foram pesquisadas por meio de cartas ou visitas à instituições e também por consultas a boletins dessas instituições. Ornitólogos com atuação no Brasil também foram consultados, pessoalmente ou via correio-eletrônico, com o intuito de obter informações sobre registros da espécie e sobre listas da avifauna de certas localidades de interesse. 
Foram reunidos 176 registros de localização de Primolius maracana distribuídos em 19 Estados brasileiros, além de 7 Departamentos no Paraguai e 2 províncias na Argentina (Figura 2.1 e APÊNDICES 1 e 2).

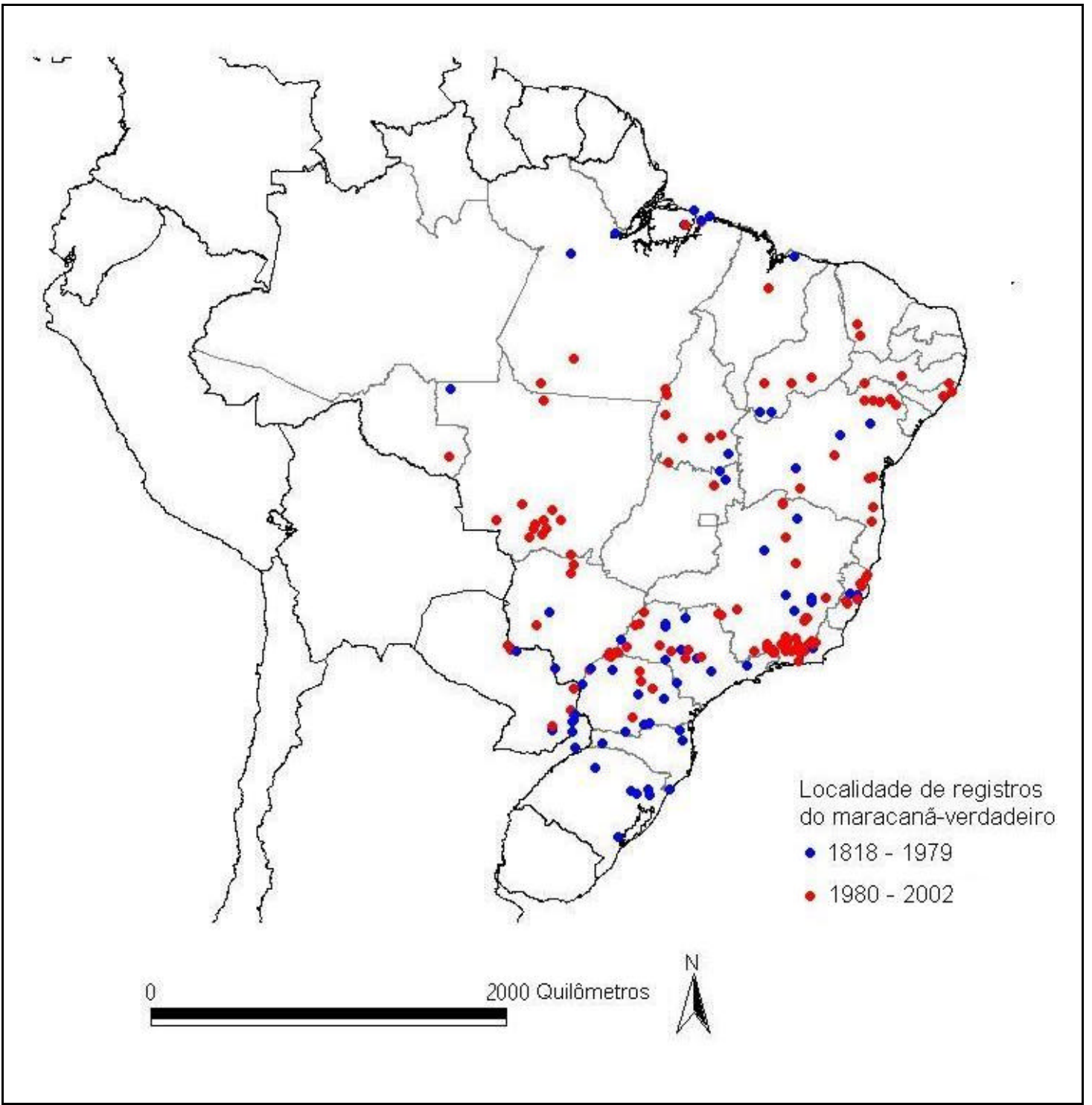

Figura 1 - Distribuição geográfica de todos os registros compilados de Primolius maracana referentes a diferentes datas 


\subsection{Revisão da distribuição do maracanã para cada Estado brasileiro, além de Argentina e Paraguai}

\section{Argentina}

Primolius maracana tem uma distribuição restrita na Argentina, tendo sido registrada na porção nordeste do País, nas províncias de Missiones e norte de Corrientes (La Penã, 1998). Muitos exemplares da espécie provêm de Missiones: no Departamento de Iguazú, foram coletados espécimes em Puerto Segundo (um exemplar de 1917), em Puerto Aguirre (três exemplares de 1920), em Iguazú (dois exemplares de 1947), em Arroyo Uruguai (11 exemplares de 1958) e em Salto de Iguazú (um exemplar sem data de coleta) (APÊNDICE 2). No Museu Argentino de Ciências Naturais encontra-se exemplares adquiridos em Santa Ana (Departamento de Candelária) e Eldorado (Departamento de Eldorado) (Navas \& Bó, 1998). Chebez (1996) também cita outros quatro Departamentos da Província de Missiones onde Primolius maracana já foi registrada: General M. Belgrano, Montecarlo, San Pedro e Guarani. Essa quantidade de exemplares coletados em Missiones pode indicar que a espécie tenha sido muito comum nas florestas da região.

O maracanã não vem sendo registrado na Argentina nas últimas décadas, sendo que existe apenas um registro confiável da espécie no País desde 1980 (Chebez, 1996). No início da década de oitenta, Nores. Correspondência eletrônica enviada para DaveCarper (BirdLife) em 20/04/2000, depositada no arquivo referente a espécie Primolius maracana, na Birdlife Conservation, em Cambridge, Inglaterra. já havia mencionado a dificuldade de encontrar o maracanã em território argentino e, no ano de 1989, Coentras considerou a espécie provavelmente extinta no País (López, 1992). ${ }^{1}$

\footnotetext{
${ }^{1}$ Correspondência enviada para Willan Belton em 14/08/1982; o documento está depositado nos arquivos da Birdlife Conservation, em Cambridge-Inglaterra, em pasta referente à espécie Primolius maracana.
} 


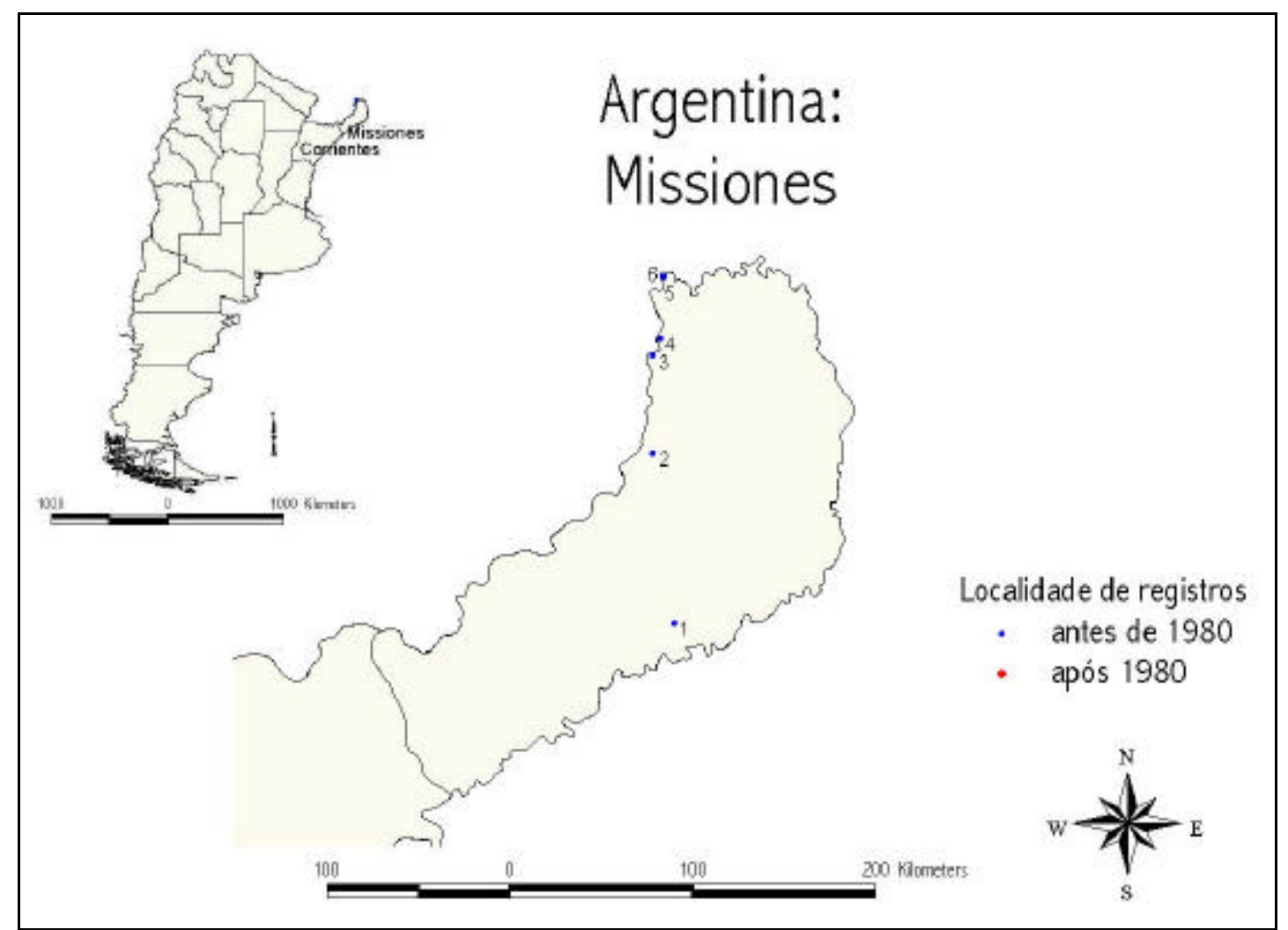

Figura 2 - 1. Santa Ana; 2. Eldorado; 3. Puerto Segundo; 4. Arroyo Uruguai; 5. Iguazú; 6. Puerto Aguirre

\section{Paraguai}

Há registros de Primolius maracana para toda a região do leste do Paraguai, exceto para o Departamento de Alto Paraguay. A espécie foi aparentemente comum nos Campos de Cerrado dos Departamentos de Amambay e Concepción. Há pelo menos oito exemplares coletados em 1938 nas proximidades de Capitán Bado, além de espécimes de 1931 provindos do Rio Apa (APÊNDICE 2 e Lopéz, 1992) e observações realizadas nas vizinhanças de San Lázaro na década de 40 (Poditiaguin, 1994). O maracanã também já foi registrado em florestas das regiões do Alto do Paraná e Paraguay Central (Hayes, 1995). Há um espécime de 1930 com indicação de coleta no Departamento de Presidente Hayes, região dos Baixos Charcos, no Rio Confuso, porém ele é considerado duvidoso por Hayes (1995). 
Nas últimas décadas Primolius maracana tem sido raramente registrada no Paraguai. Em 1978 dois exemplares da espécie foram coletados nas proximidades de San Rafael (Departamento de Itapuã) e, no início dos anos 80, um espécime foi adquirido no norte de Ygovy (Departamento de Canindeyú) (APÊNDICE 2; López, 1992). Nores (1982) também cita a presença, não muito freqüente, de maracanãs nas florestas do norte de Hernandarias, no Alto Paraná.

No final da década de 80 López (1989) visitou diversas localidades no Departamento de Concepción e registrou Primolius maracana em apenas duas ocasiões na Estância Primavera, nos anos de 1988 e 1989. Todavia, a espécie não foi avistada na mesma região durante um inventário realizado por R. Clay em $1999^{2}$. Posteriormente, entre os anos de 1992 e 1995, foram realizadas expedições em diferentes localidades ao leste do Paraguai, pelos projetos Canopy'92 e Yacutinga'95, e a espécie foi encontrada somente na Reserva de Itabó (Departamento de Canindeyú) sendo considerada rara na localidade (Lowen et al., 1996). Brooks e colaboradores (1993) já haviam mencionado o avistamento de um pequeno grupo de maracanãs no ano de 1992 na mesma localidade.

Outro registro atual da espécie foi realizado na Estância Tapytá, Departamento de Caapazá, onde foram observados apenas dois indivíduos (Clay et al., 1998). É provável que haja poucas populações de maracanã sobrevivendo no Paraguai e que essas sejam reduzidas e isoladas. Isso faz com que Primolius maracana seja considerada altamente ameaçada no País (Lowen et al., 1996).

\footnotetext{
${ }^{2}$ Correspondência eletrônica enviada para DaveCarper (BirdLife) em 20/04/2000; o documento está depositado nos arquivos da Birdlife Conservation, em Cambridge-Inglaterra, em pasta referente à espécie Primolius maracana.
} 


\section{Paraguai}

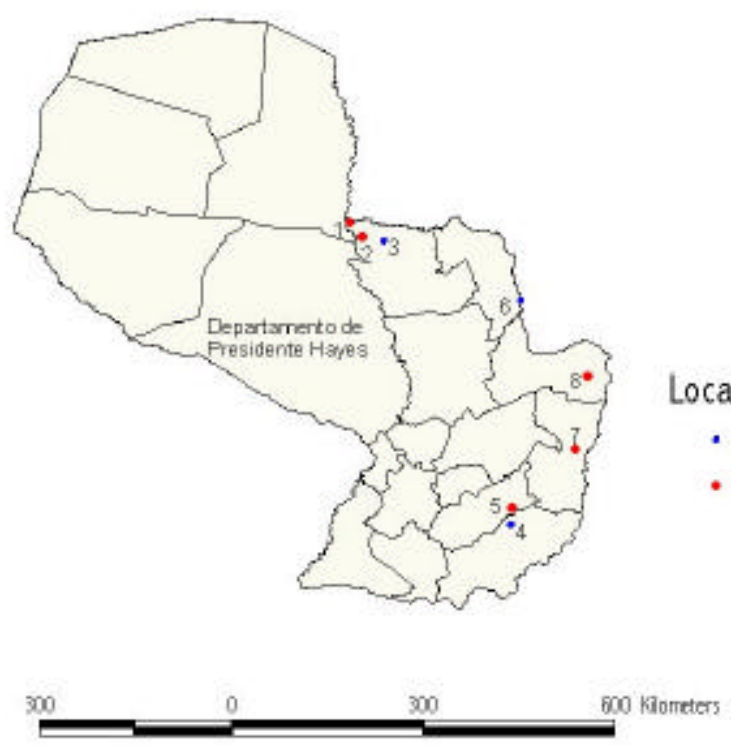

Localidade de registros

- $\quad$ antes de 1980

- após 1980

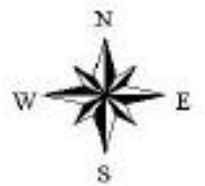

Figura 3 - 1. San Lazaro; 2. Estância Primavera; 3. Rio Apa (Departamento de Concepción); 4. San Rafael (Departamento de Itapúa); 5. Estância Tapytá (Departamento de Caazapá); 6. Capitán Bado (Departameto de Amambay); 7. Hernandarias (Departamento de Alto Paraná); 8. RNP Itabó (Departamento de Canindeyú)

\section{Rio Grande do Sul}

Primolius maracana foi provavelmente comum no Rio Grande do Sul, a julgar pelo número de registros e exemplares coletados no final do século IX e início do século $\mathrm{XX}$, principalmente nas áreas ao longo das escarpas ao noroeste do Estado (Belton, 1994). Berlepsh e Ihering (1885) mencionaram a coleta de nada menos que 20 exemplares em Taquara e arredores, entre 1882 e 1883, em florestas da base da Escarpa Serra Geral. Posteriormente, Ihering (1899) mencionou a espécie para São Sebastião do Caí e Gliesh (1930) fez registros em Poço das Antas e Canela, localidades nas 
proximidades das escarpas. Gliesh (1930) também observou a espécie na planície costeira de Torres, cidade no litoral norte do Estado.

Há outros exemplares provindos de localidades mais afastadas das escarpas, como um coletado por Gogaev em aproximadamente 1881 na cidade de Pelotas, sudeste do Estado, e outros dois reunidos por Garbe no ano de 1915 em Novo Wuttemberg (Cruz Alta) centro do Estado (APÊNDICE 2).

Desde, aproximadamente, a segunda metade do século XX, Primolius maracana não vem sendo registrada no Rio Grande do Sul, o que faz com que ela seja considerada provavelmente extinta no Estado (Belton, 1994). Nos últimos anos, levantamentos de avifauna vêm sendo realizados em localidades potenciais para ocorrência da espécie, como no Parque Estadual do Turvo (que é contíguo à Floresta do Iguaçu), no Parque Nacional da Serra Geral e no Parque Nacional dos Aparados da Serra, porém o maracanã continua sem registros atuais o Estado (Forrester, 1993; Belton, 1994 e Wege \& Long, 1995). 


\section{Rio Grande do Sul}
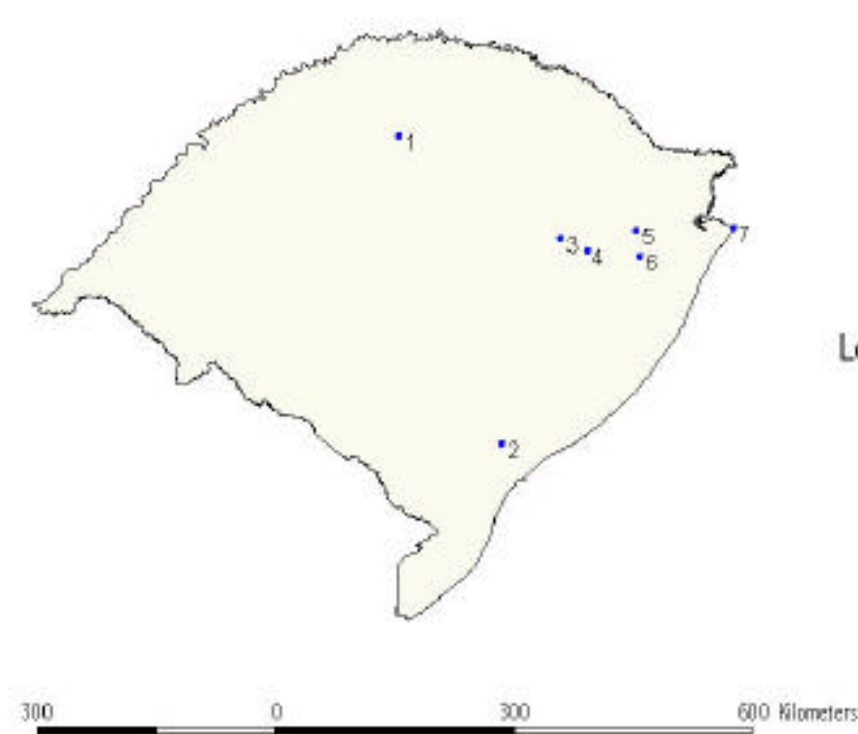

Localidade de registros

- antes de 1980

- após 1980

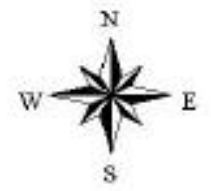

Figura 4 - 1. Novo Wuttemberg; 2. Pelotas; 3. Poços das Antas; 4. São Sebastião do Caí; 5. Canela; 6. Taquara do Novo Mundo; 7. Torres

\section{Santa Catarina}

Não há muitos registros de Primolius maracana no Estado de Santa Catarina. Rosário (1996) menciona dois espécimes coletados no Estado, um em Blumenau, região de Floresta Ombrófila Densa, e outro em Corupá, região de Floresta de Araucárias. Entretanto esses exemplares não possuem data de coleta e suas localidades por serem consideradas duvidosas. Há outro exemplar, coletado por Emil Kaempfer, no ano de 1929, em Palmitos, região sudoeste do Estado, próxima à Floresta de Missiones na Argentina (APÊNDICE 2). 
O maracanã está provavelmente extinto em Santa Catarina, pois nas últimas décadas a espécie não vem sendo registrada no Estado (Rosário, 1996), mesmo havendo levantamentos de avifauna em diferentes regiões catarinenses (Rauh \& Rosário, 1979; Bege \& Marterer, 1991; Zimmermann, 1993 e Albuquerque \& Brüggemann, 1996).

\section{Santa Catarina}

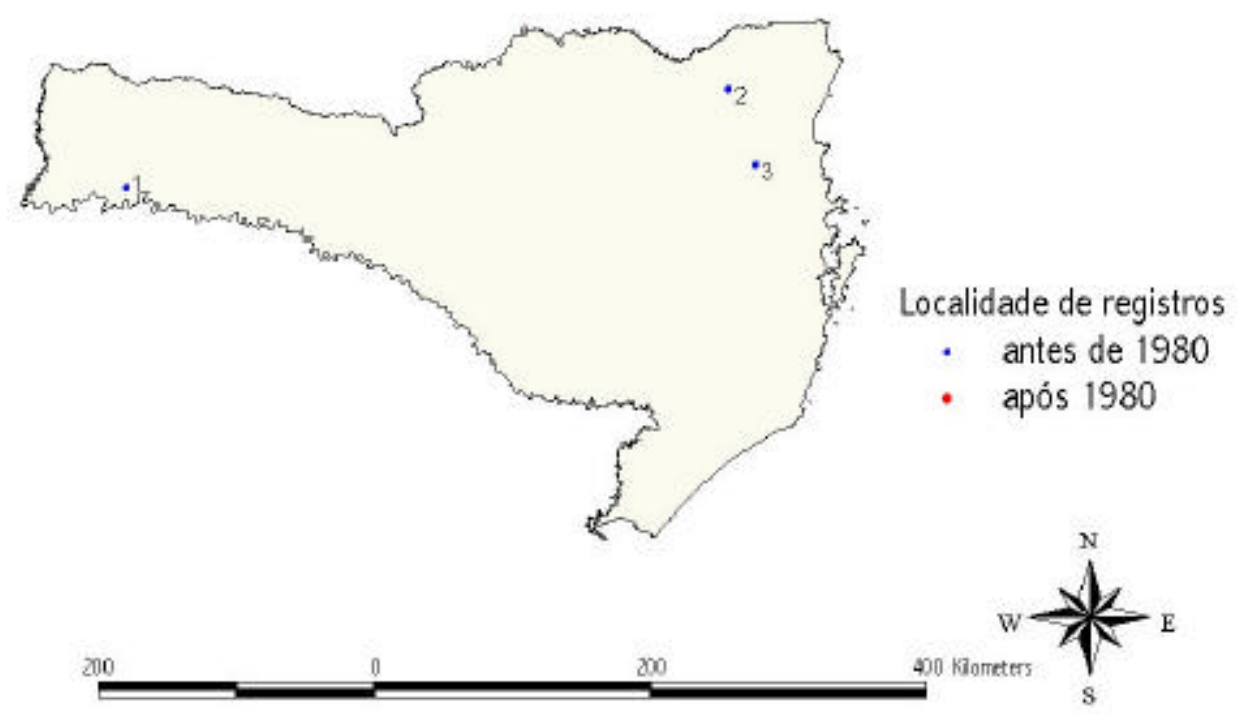

Figura 5 - 1. Palmitos; 2. Corupá; 3. Blumenau

\section{Paraná}

Há muitos registros de Primolius maracana reunidos até 1951 para toda a região planáltica do Estado do Paraná (Bornschein \& Straube, 1991). No início do século XX o naturalista polonês Chrostowski realizou coletas da espécie na região de Florestas Ombrófilas Mistas com Araucária ao sul do Estado, como nos municípios de Vera Guarani e São Domingos (Fazenda Concórdia) (Chrostowski, 1912 e Sztolcman, 1926). 
Há também outro exemplar provindo da mesma região, coletado por André Mayer na Fazenda Estância Nova, em Palmas, provavelmente nas décadas de 40 ou 50 (APÊNDICE 2).

Há espécimes de Primolius maracana provindos das Florestas Ombrófilas Mistas da parte central do Estado, como dois exemplares coletados por Garbe no ano de 1907 em Castro, e dois exemplares coletados por Steiger em Cândido de Abreu. Mayer também fez muitas coletas de Primolius maracana em regiões de Florestas Semidecíduas do noroeste do Estado, o que pode sugerir que a espécie foi muito abundante naquela região. O Museu de História Natural do Capão do Embuia mantém sete desses exemplares referentes ao Rio Piquiri, Vale do Rio Piquiri, Sertão do Rio Ivaí (dois exemplares), Vale do Rio Ivaí e Rio Paraná (dois exemplares) (APÊNDICE 2 e Straube \& Bonschein, 1989). A espécie também foi coletada em Foz do Iguaçu, em 1942, por Moojen.

Nos últimos anos foram realizados poucos registros de Primolius maracana no Estado do Paraná (Bornschein \& Straube, 1991). O maracanã não é mais avistado na parte extremo sul do Estado (Pichorim \& Bóçon, 1996 e D. Kajiwara, informação pessoal) e nas proximidades de Castro (Scherer-Netoet al., 1984; Straube, 1988 e Scherer-Neto et al, 1994). O noroeste do Estado, região onde foram realizadas muitas coletas por Mayer, hoje é composta, predominantemente, por áreas agrícolas e pastagens e os registros de Primolius maracana são raros (Straube et al., 1996). Essa região foi amostrada recentemente por Straube e colaboradores (1996) que avistaram o maracanã em apenas uma localidade, na Estação Ecológica dos Caiuá, em Diamante do Norte.

Nas últimas décadas, os registros da espécie no Paraná são raros (Bornschein \& Straube, 1991), em sua maioria de poucos indivíduos que estão em sobrevôo, aparentemente de passagem (E. Carrano com. pess.). Os registros foram realizados principalmente na porção noroeste do Estado, como na Estação Ecológica dos Caiuá (Straube et al., 1996), no Parque Nacional de Ilha Grande e no município de Terra Rica (APÊNDICE 1). Há também registros nas proximidades de Londrina, como no Parque Estadual dos Godoy (Anjos et al., 1997 e Anjos \& Shuchmann, 1997), em Mauá da Serra e em Telêmaco Borba (APÊNDICE 1). A espécie também já foi avistada nas 
adjacências do Parque Nacional do Iguaçu (Bornschein \& Straube, 1991) e na Usina Hdrelétrica de Segredo, no município de Pinhão (APÊNDICE 1). É intrigante a falta de um maior número de registros atuais para o Parque Nacional do Iguaçu (Koch \& Bóçon, 1994), que abrange uma área florestal de 170.086 ha e onde já foram coletados muitos espécimes nos lados brasileiro, argentino e paraguaio (APÊNDICE 2).

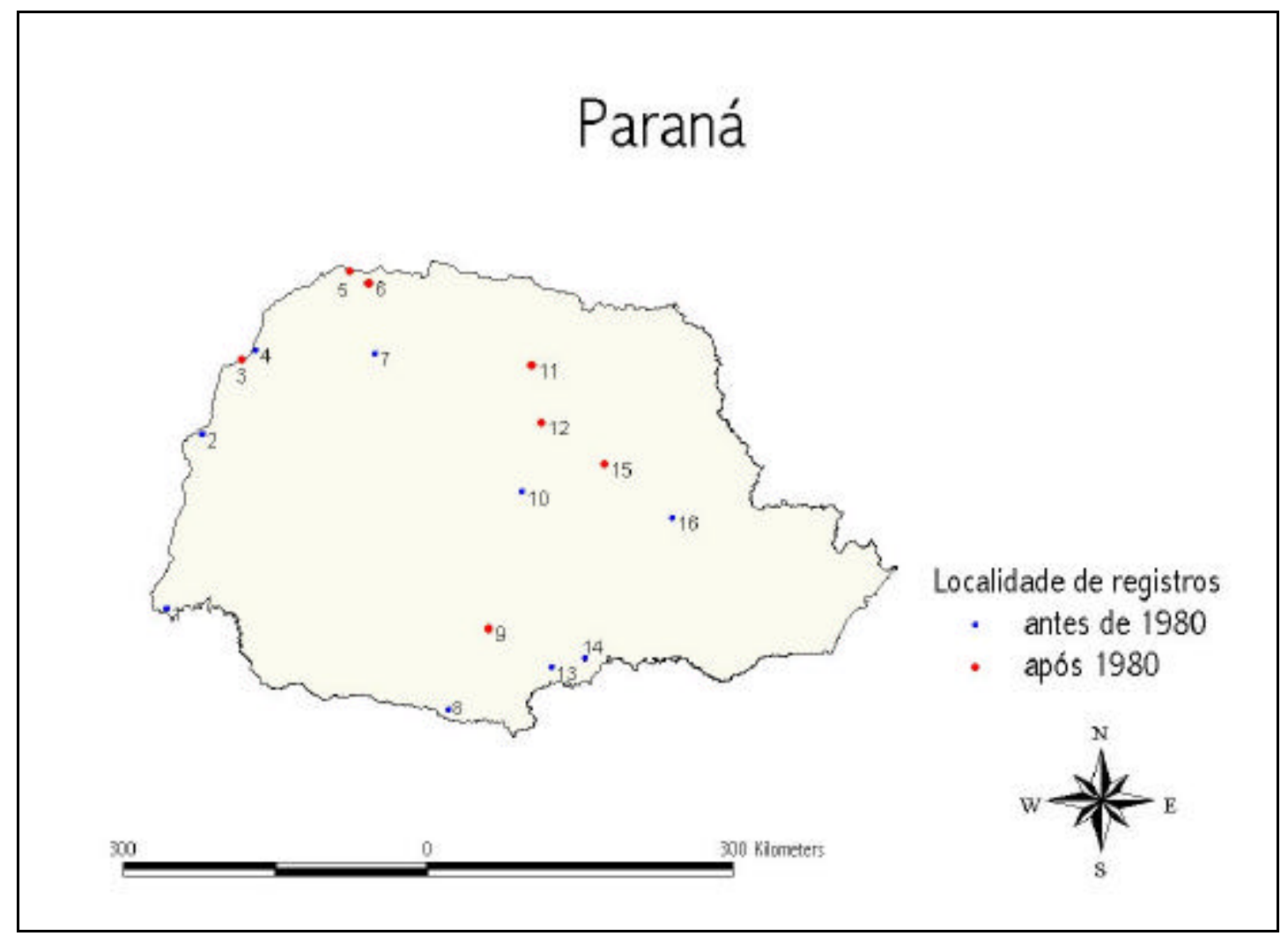

Figura 6 - 1. Foz do Iguaçú; 2. Rio Piquiri ou Vale do Rio Piquiri; 3. P.N. Iltha Comprida; 4. Vale do Rio Ivaí; 5. E. E. dos Caiuá; 6. Terra Rica; 7. Sertão do Ivaí; 8. Palmas; 9. Pinhão; 10. Cândido de Abreu; 11. P. E. Mata dos Godoy; 12. Mauá da Serra; 13. São Domingos; 14. Vera Guarani; 15. Têmaco Borba; 16. Castro 


\section{São Paulo}

Muitos registros históricos de Primolius maracana foram realizados no interior do Estado de São Paulo, principalmente em regiões de Florestas Semidecíduas e Áreas Florestais de transição ecológica. No início do século XIX o naturalista Natterer fez expedições no Estado e registrou maracanãs em Ipanema (localidade próxima a Sorocaba), em Mato Dentro (no vale do Paraíba), em Itararé e em Morungaba (Rokitansky,1957). Posteriormente, nos anos de 1902 e 1903, Hempel coletou três espécimes em Vitória de Botucatu e em Salto Grande (Fazenda Cayoá), na margem do rio Paranapanema (APÊNDICE 2). Aproximadamente na mesma época, Garbe trouxe para o Museu Paulista (hoje MZUSP) exemplares vindos das regiões de Bauru, de Olímpia, do Salto do Avanhandava e de São Jerônimo (arredores do baixo Tietê) (Pinto, 1938 e APÊNDICE 2). Na década de 40 a espécie foi registrada no extremo oeste de São Paulo em Porto Tibiriçá, hoje Presidente Epitácio (APÊNDICE 2).

Atualmente o Primolius maracana é incomum no Estado de São Paulo. Nas últimas duas décadas, grupos de maracanãs foram avistados em remanescentes de Florestas Estacionais Semidecíduas no extremo oeste do Estado, nos municípios de Nova Independência, Guaraçaí e Suzanópolis, e na região noroeste de São Paulo, em Patrocínio Paulista e Itirapuã (APÊNDICE 1). Há também registros realizados no centro-oeste do Estado, nos municípios de Pompéia, Lençóis Paulista, Pederneiras (APÊNDICE 1), Anhembi (Magalhães, 2000), Gália, Garça, Alvinlândia e Lucianópolis (ver Capítulo 2). O maracanã também tem sido raramente avistado no sudoeste do Estado, nos municípios de Rosana e Teodoro Sampaio e nas proximidades do Parque Estadual do Morro do Diabo (APÊNDICE 1).

Os registros de maracanã citados são, em sua maioria, de poucos indivíduos, indicando que suas populações são fragmentadas e reduzidas. O maracanã é abundante apenas na Estação Ecológica dos Caetetus e região, sendo provavelmente a população mais numerosa do Estado (Nunes, 2000). O Parque Estadual do Morro do Diabo é a maior área de Floresta Semidecídua de São Paulo (35000 ha), porém o maracanã não tem sido avistado em muitos levantamentos realizados na área (Willis \& Oniki, 1981; 
Vasconcelos \& Roos, 2000 e G. Bettini dados não publicados), sendo que para o local foi encontrado apenas um registro de três indivíduos da espécie, em novembro de 1999 (APÊNDICE 1).

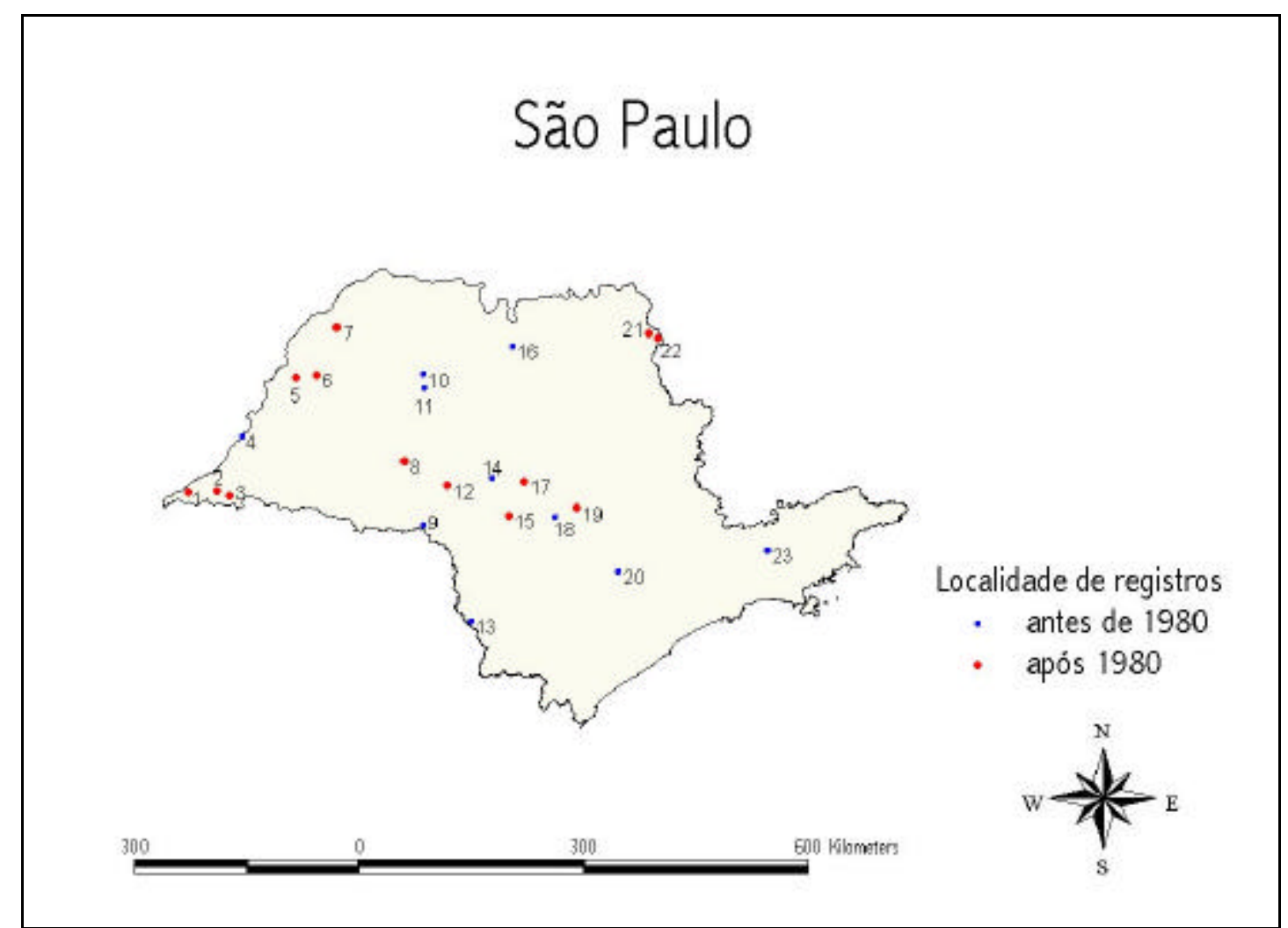

Figura 7 - 1. Rosana; 2. Faz. Tucano, Teodoro Sampaio; P.E. Morro do Diabo; 4. Porto Tibiriçá; 5. Nova Independência; 6. Guaraçaí; 7. Suzanópolis; 8. Pompéia, 9. Salto Grande; 10. São Jerônimo; 11. Salto do Avanhandava; 12. E. E. dos Caetetus; 13. Itararél Morungaba; 14. Bauru; 15. Lençóis Paulista; 16. Olímpia; 17. Pederneiras; 18. Vitória de Botucatu; 19. Anhembí; 20. Ipanema; 21. Patracíneo Paulista; 22. Itirapuã; 23. Mato Dentro 


\section{Minas Gerais}

Existem registros de Primolius maracana em diversas localidades de Minas Gerais, principalmente nas áreas de Florestas Estacionais Semidescíduas do Estado. Em 1847, o dinamarquês J. T. Reinhardt coletou a espécie em Lagoa Santa, pequeno povoado ao norte de Belo Horizonte (Pinto, 1952 e APÊNDICE 2). Posteriormente, em 1900, Godoy colecionou a espécie em Vargem Alegre, localidade vizinha a Mariana (Pinto, 1952 e APÊNDICE 2). Foram coletados outros exemplares de maracanã em locais não muito distantes dessa localidade, como em Raul Soares (em 1947), no Rio Matipoó (em 1939) e no próprio Rio Doce (em 1940) (Pinto, 1952 e APÊNDICE 2). Além dessa região, há exemplares de Primolius maracana coletados no norte e noroeste do Estado, como sete espécimes de 1949 provindo de Janaúba e um de 1937 provindo de Pirapora (APÊNDICE 2). Atualmente, a maioria dos registros de Primolius maracana é realizada nas porções leste e sudeste de Minas Gerais. O maracanã ainda é avistado nas proximidades do Rio Doce, sendo abundante no Parque do Rio Doce (Willis \& Oniki, 1991). Há também registros recentes para Caratinga (APÊNDICE 1) e para a região de Viçosa, como Cajuri e Paulo Cândido (Maldonato 1998).

Indivíduos de Primolius maracana também são freqüentemente avistados dentro e nos arredores do Parque Estadual de Ibitipoca (observação pessoal), como em Juiz de Fora (APÊNDICE 1) e Santa Bárbara do Monte Verde (Garske et al., 2001). Em junho de 2000, foram contados pelo menos 82 indivíduos pernoitando em dormitório no interior do Parque (Nunes, dados não publicados). Em regiões de baixas altitudes na Serra da Mantiqueira a espécie é comum, havendo registros realizados nas imediações de Baependi, Itamonte e Itajubá (APÊNDICE 1).

Alguns poucos indivíduos de maracanã também têm sido avistado no centro-sul do Estado, nas baixas altitudes do Parque Nacional da Serra da Canastra (Silveira, 1998 e APÊNDICE 1). Ao norte do Estado alguns indivíduos foram registrados no Vale do Peruaçú, nos municípios de Mocambinho, Itacarambí e Manga (Kirwan et al., 2000), e no Vale do Jequitinhonha, dentro do Parque Estadual do Rio Preto (APÊNDICE 1) e nas proximidades de Montes Claros (Forrester, 1993). 


\section{Minas Gerais}

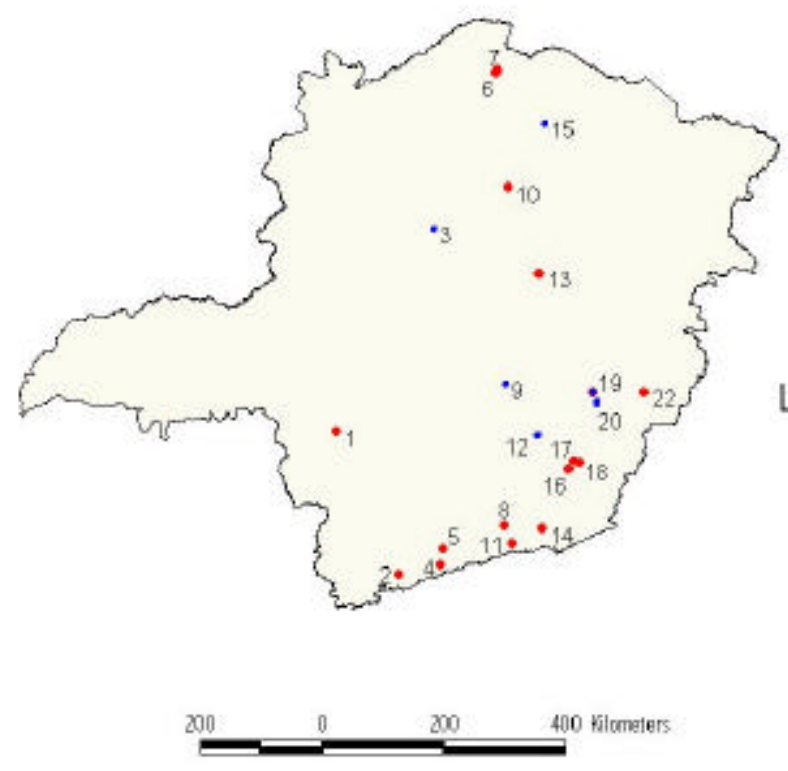

Localidade de registros

- antes de 1980

- após 1980

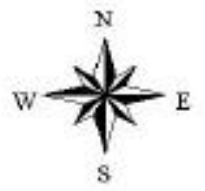

Figura 8 - 1. P.N. Serra da Canastra; 2. Itajubá; 3. Pirapora; 4. Itamonte; 5. Baependi; 6. Mocambinho; 7. Itacarambí/Manga; 8. P.E. Ibitipoca; 9. Lagoa Santa; 10. Montes Claros; 11. Santa Bárbara do Monte Verde; 12. Vargem Alegre; 13. P.E. Rio Preto; 14. Juiz de Fora; 15. Janaúba; 16. Paula Cândido; 17. Viçosa; 18. Cajuri; 19. Rio Doce e P.E. Rio Doce; 20. Rio Matipoó; 21. Raul Soares; 22. Caratinga

\section{Rio de Janeiro}

Foram encontrados registros históricos de coletas de Primolius maracana realizados em Nova Friburgo por Kaempfer (Naumberg, 1928). No século XX, a espécie não foi comumente observada no Estado porém, a partir do final dos anos 80, suas populações começaram a se recompor e um número cada vez maior de registros começaram a ser realizados (Pacheco et al., 1994). Na cidade do Rio de Janeiro a espécie já esteve provavelmente extinta (Del Hoyo et al., 1997) e nas últimas décadas 
houve uma recolonização de tal forma que atualmente ela é facilmente registrada até em áreas degradadas (M. Raposo, informação pessoal).

Atualmente o maracanã é considerado comum no sul do Estado, no vale do Paraíba e Serra da Mantiqueira. Há registros realizados na região de Visconde de Mauá (Bauer \& Pacheco, 2000), em Resende, em Volta Redonda, em Barra do Piraí, em Vassouras, em Petrópolis e em Teresópolis (APÊNDICE 1). O maracanã também foi observado no Parque Nacional de Itatiaia (Parker \& Goerck, 1997), embora não tenha sido avistado em levantamentos históricos realizados na mesma localidade (Holt, 1928 e Pinto, 1951). Outros registros de maracanã foram realizados na região do médio Vale do Paraíba, nos municípios de Três Rios, Nova Friburgo, Carmo, Duas Barras, Cantagalo e em Pião, porém ele é menos comum que na parte sul do Vale (APÊNDICE 1).

\section{Rlo de Janeiro}

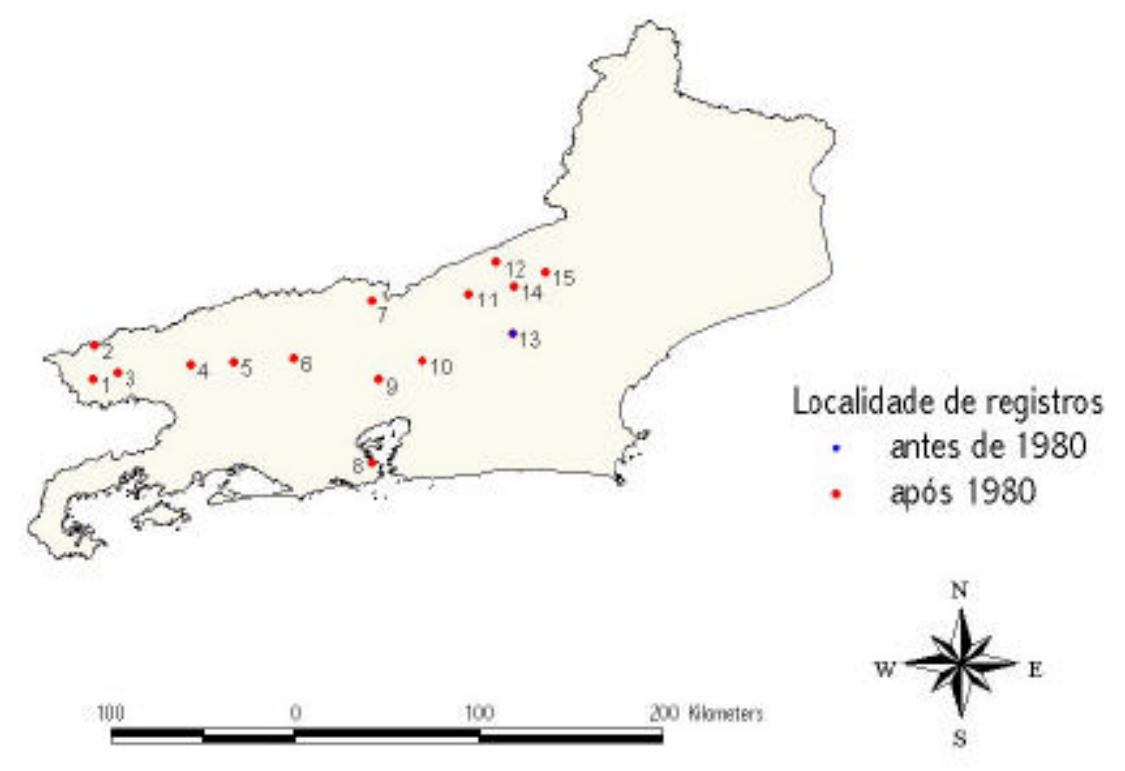

Figura 9 - 1. Itatiaia; 2. Visconde de Mauá; 3. Resende; 4. Mata da Cicuta, Volta Redonda; 5. Barra do Piraí; 6. Vassouras; 7. Três Rios; 8. Rio de Janeiro; 9. Petrópolis; 10. Teresópolis; 11. Pião; 12. Carmo; 13. Nova Friburgo; 14. Duas Barras; 15. Canta Galo 


\section{Espírito Santo}

Os registros históricos encontrados de Primolius maracana no Estado do Espírito Santo são de espécimes provindos da região central do Estado. Exemplares foram coletados no ano de 1939 no Córrego Juparana (Linhares) e no Córrego do Cupido (Sooretama) e, em 1940, nas proximidades do município de Colatina (APÊNDICE 2). Atualmente há registros realizados em toda a extensão do Estado. São também conhecidos registros atuais de maracanã realizados nas regiões central e norte do Estado, como em Santa Maria do Jetibá, em Itarana (Venturini \& Rehen, 2000), em Aracruz, em Conceição da Barra, em São Mateus (APÊNDICE 1), na Reserva de Linhares e na Reserva Biológica de Sooretama (Marsden et al., 2000). Em Sooretama foi avistado um grupo de 84 indivíduos de maracanã no ano de 1998 (Marsden et al., 2000). 


\section{Espírito Santo}

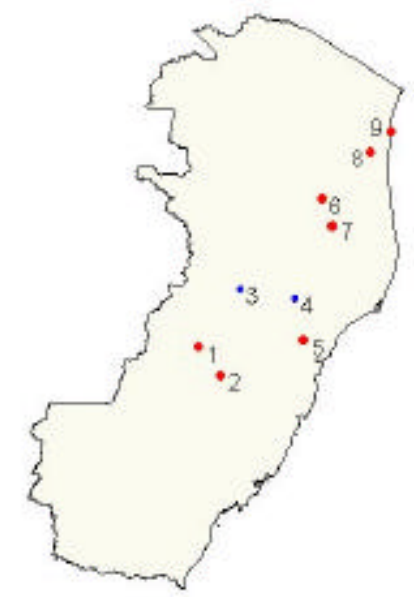

Localidade de registros

- antes de 1980

- após 1980
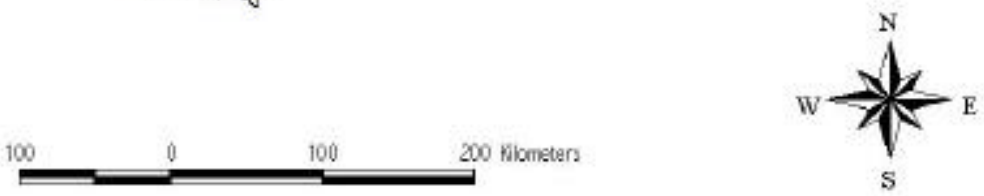

Figura 10 - 1. Itarana; 2. Santa Maria do Jetibá; 3. Colatina; 4. Córrego Juparana; 5. Aracruz; 6. Sooretama; 7. Linhares; 8. São Mateus; 9. Conceição da Barra

\section{Bahia}

Embora Primolius maracana não tenha sido incluída em "Aves da Bahia" (Pinto, 1933), existem exemplares baianos colecionados anteriormente à data dessa publicação. Pelo menos seis espécimes foram coletados por Beker no Rio do Peixe no ano de 1913, além de um exemplar coletado por Kaempfer no Morro do Chapéu em 1928 (APÊNDICE 2).

Atualmente, há registros para diferentes regiões da Bahia, principalmente na Caatinga do noroeste do Estado, onde o maracanã é considerado comum (APÊNDICE 1). Nos últimos anos o maracanã foi observado em Canudos, em Curaçá, em Caraíbas, em Jeremoabo, em Uauá (APÊNDICE 1) e no Raso da Catarina (Sick et al., 1987). A 
espécie também tem sido registrada nas matas da Chapada Diamantina (Carvalhaes, 2000; APÊNDICE 1) e alguns poucos indivíduos foram observados em áreas de Floresta Semidecídua do Sul da Bahia, nos municípios de Jussari, Itapibi, Itamari e Wenceslau Guimarães (Cordeiro, 2002). Além dessas localidades, há um exemplar coletado em 1991 nas proximidades do Rio São Francisco, em Palmas do Monte Alto (APÊNDICE 2).

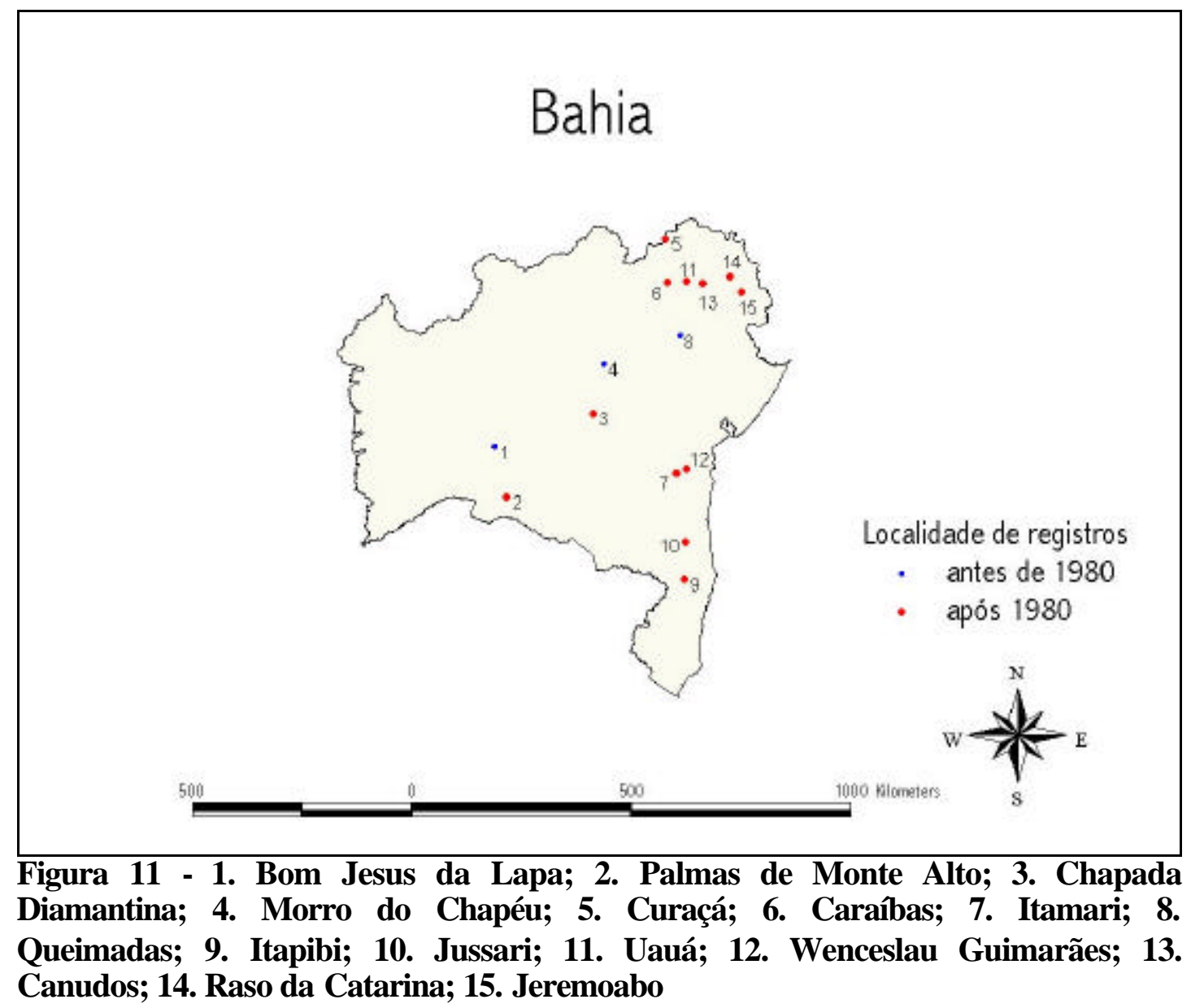




\section{Pernambuco}

Não foram reunidas informações sobre antigos registros de Primolius maracana em Pernambuco. Os registros de do maracanã para o Estado são recentes e foram realizados na Reserva Biológica de Serra Negra (Yamashita, 1985 e Coelho, 1987).

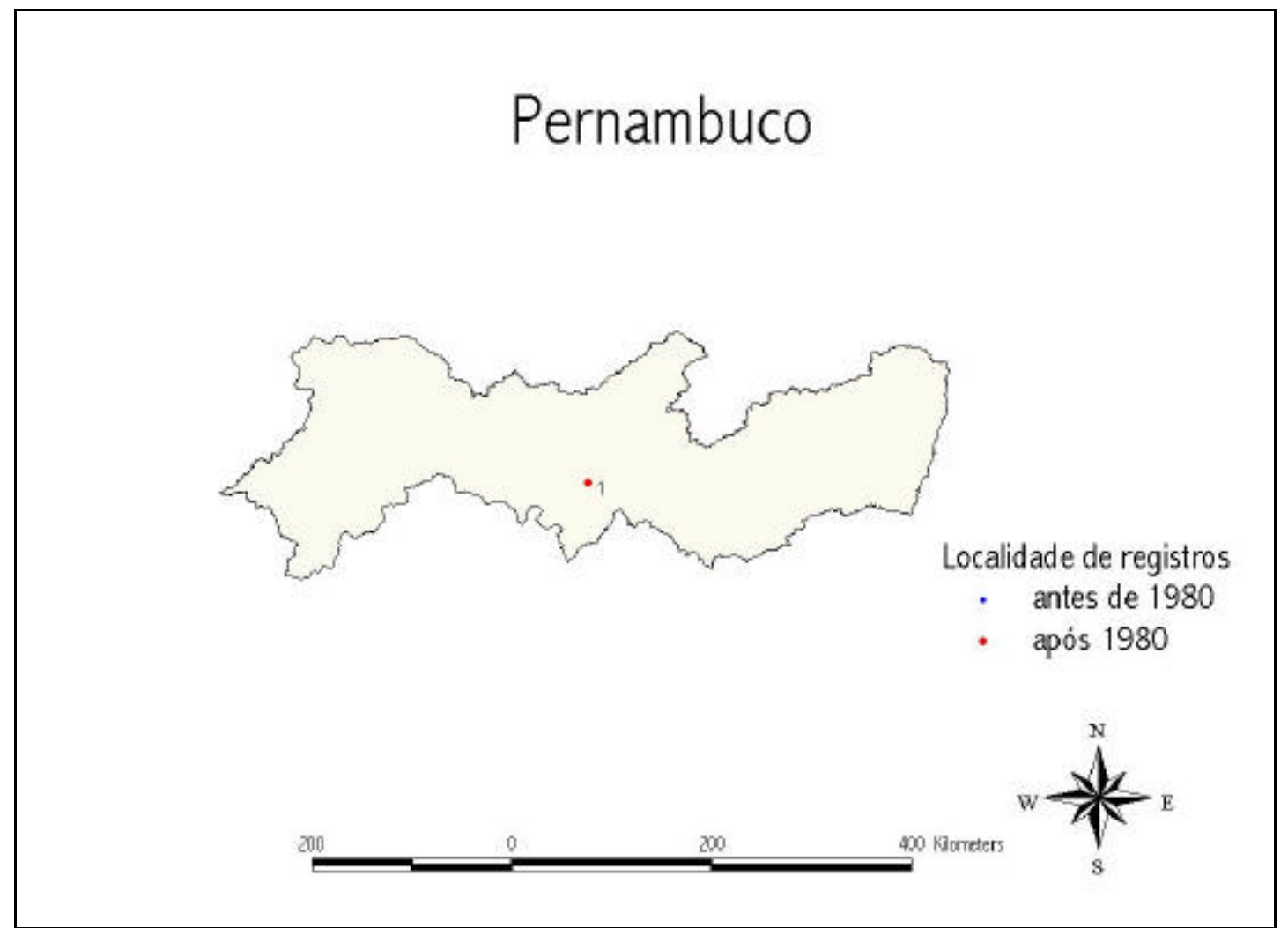

Figura 12 - 1. P.N. Serra Negra 


\section{Alagoas}

Não foram reunidas informações sobre antigos registros de Primolius maracana no Estado de Alagoas. Mas a espécie é incluída na lista de Aves de Alagoas (Pinto, 2002), ocorrendo nas cidades de Novo Lino, Barra de Santo Antônio e Pilar.

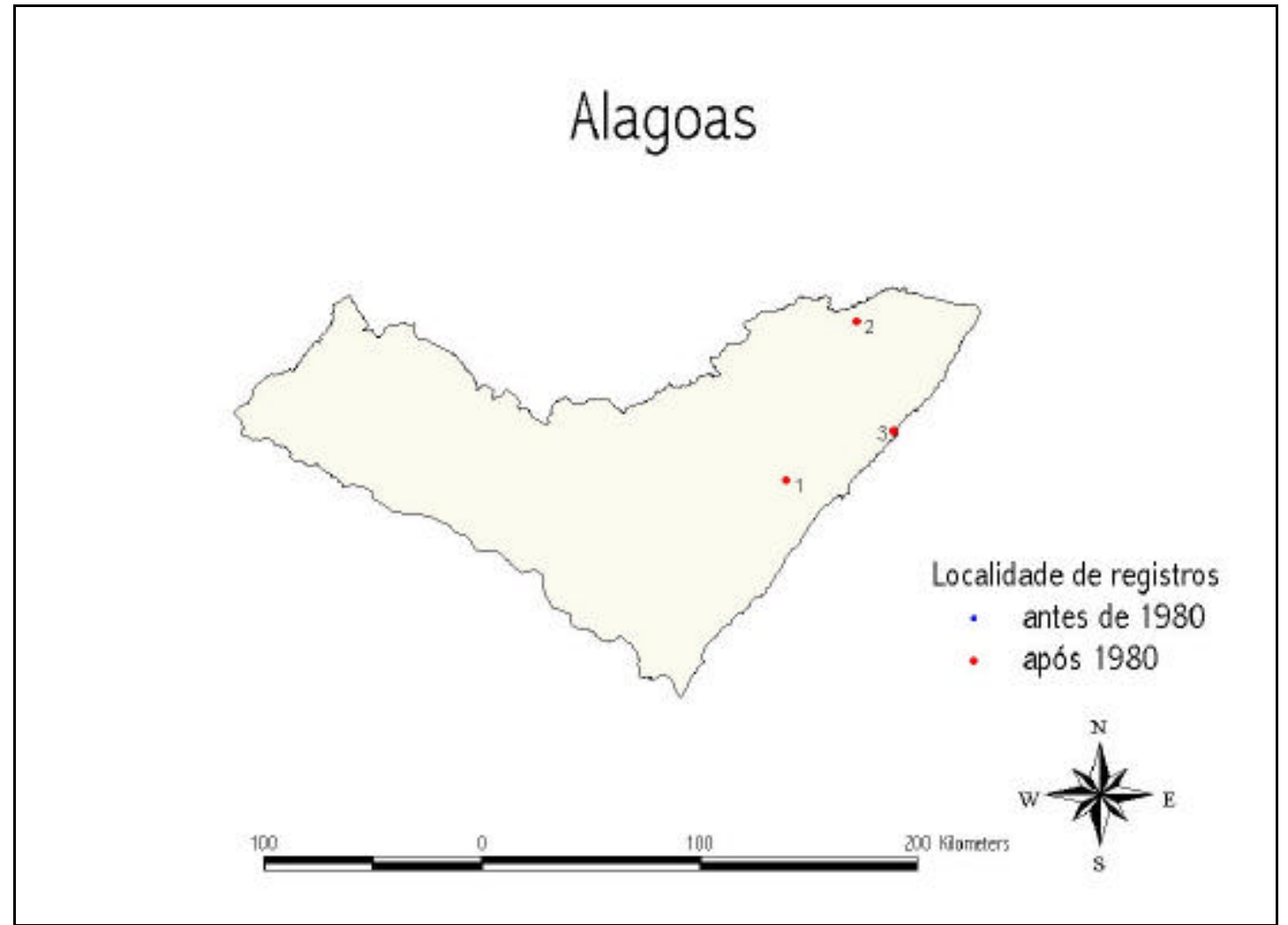

Figura 13 - 1. Pilar; 2. Novo Lino; 3. Barra de Santo Antônio 


\section{Ceará}

Não foram reunidas informações sobre antigos registros de Primolius maracana no Estado do Ceará. Mas Gonzaga Salles Jr. traz informações sobre a presença atual da espécie nos municípios de Aiuaba e Tauá (APÊNDICE 1).

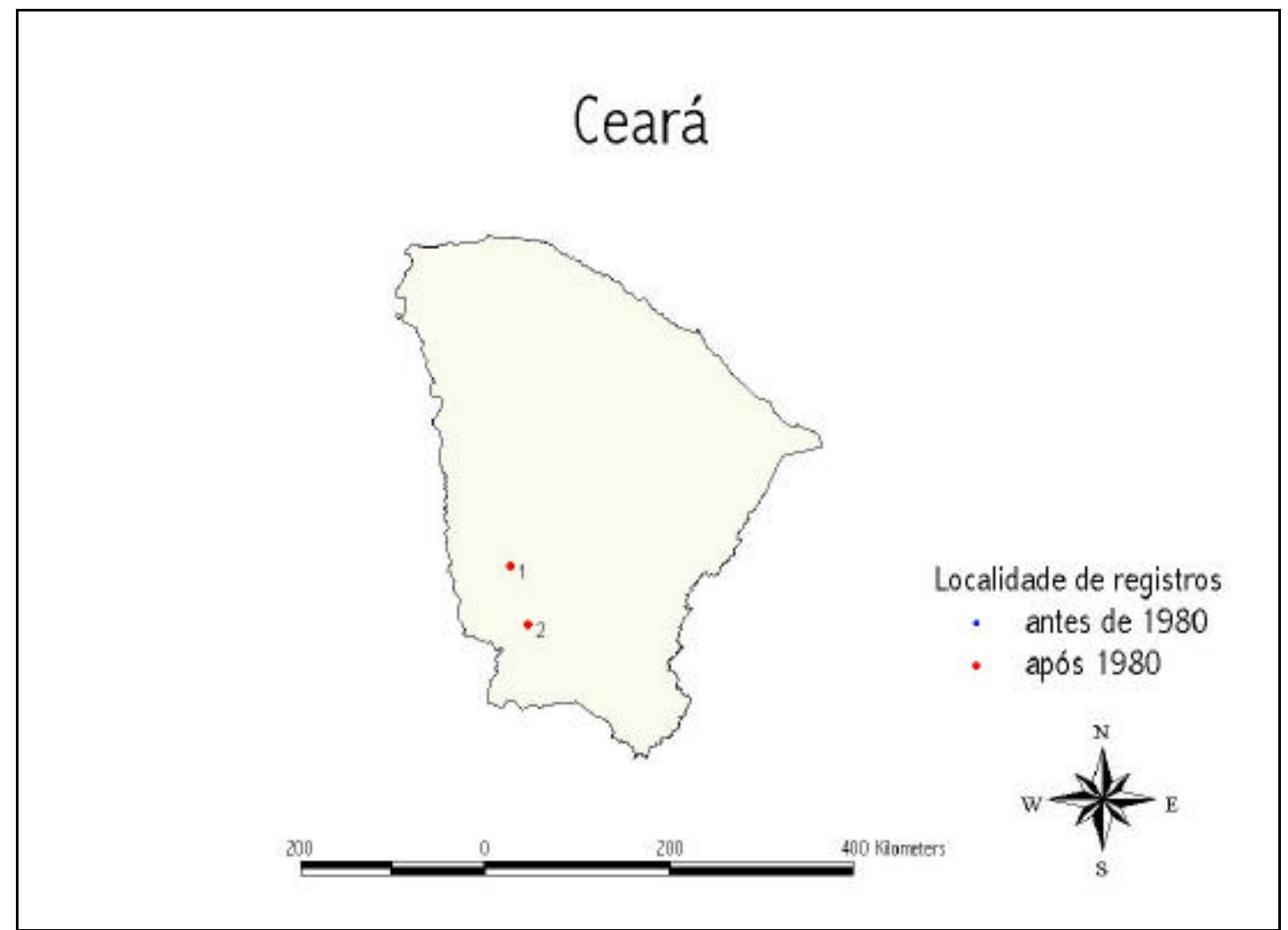

Figura 14 - 1. Tauá; 2. Aiuaba 


\section{Piauí}

Olivério Pinto cita Primolius maracana para o Estado do Piauí em seu catálogo de aves para o Brasil (1978). Em 1903 dois exemplares de maracanã foram coletados por Ottmar Reiser em Parnaguá, sul do Estado (APÊNDICE 2). Posteriormente, em 1927, E. Kaempfer coletou a espécie na mesma localidade, além de outros espécimes em Corrente, município próximo a Parnaguá (APÊNDICE 2).

Os registros atuais também têm sido realizados no sul do Estado. Olmos (1997) cita a espécie para o Parque Nacional da Serra da Capivara, atribuindo a ela o estatus de rara no local. Há também registros atuais realizados em 2000 no Parque Nacional da Serra das Confusões e na Estação Ecológica de Urucuí-Una (APÊNDICE 1).

\section{Piaú}

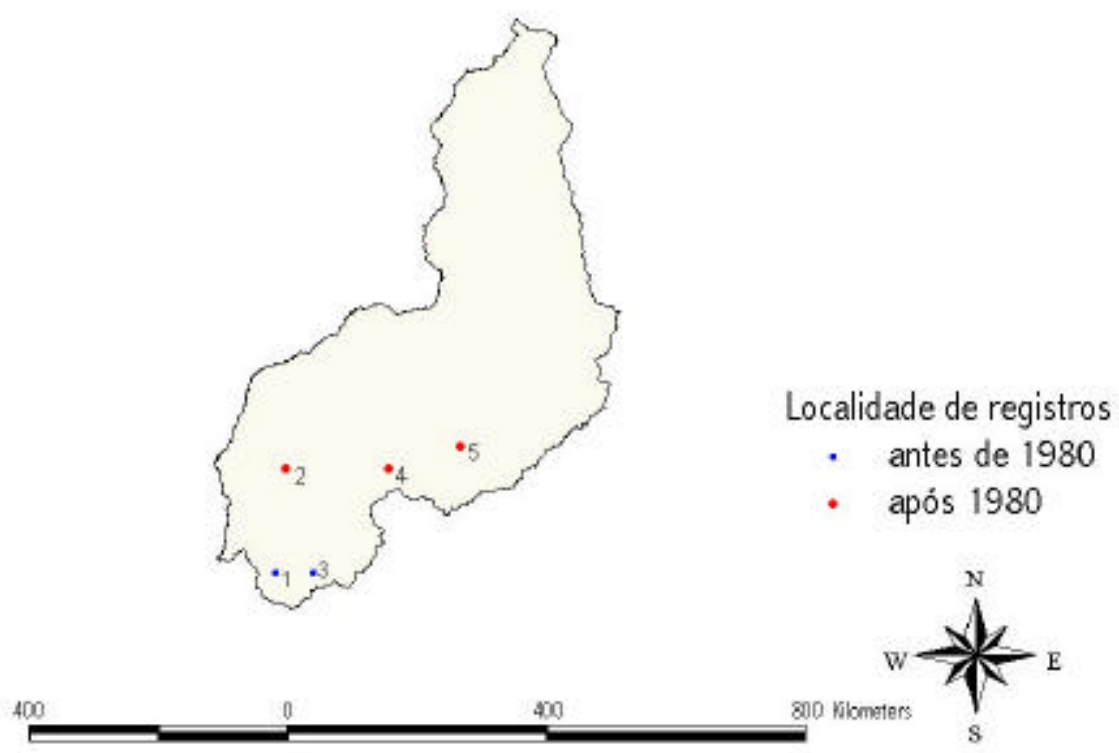

Figura 15 - 1. Corrente; 2. E.E. Urucuí-Una; 3. Parnaguá; 4. P.N. Serra das Confusões; 5. Serra da Capivara 


\section{Maranhão}

Existem 5 exemplares de Primolius maracana provindos de Miritiba, norte do Estado, coletados nos anos de 1908, 1910, 1911 e dois em 1914 (APÊNDICE 2). Foi encontrado apenas um registro sobre ocorrência atual da espécie, que vem de um exemplar coletado em 1992 no Rio Estiva, Bacabal (APÊNDICE 2).

\section{Maranhão}

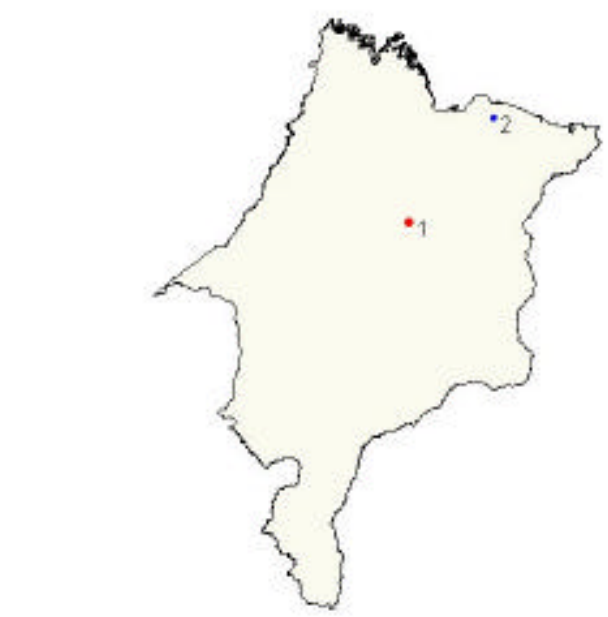

- após 1980
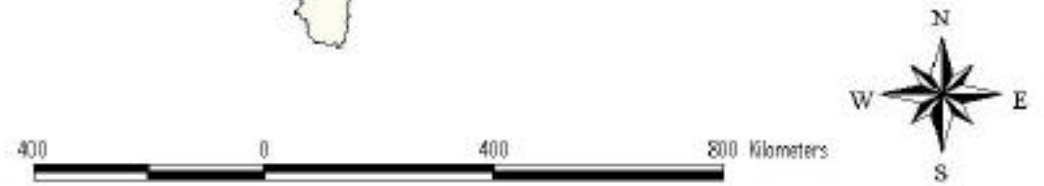

Figura 16 - 1. Bacabal; 2. Miritiba 


\section{Tocantins}

Foi encontrado apenas um registro antigo de Primolius maracana para Tocantins, que vem do Rio Palma em 1950. Entretanto foram reunidos registros atuais do maracanã realizados na região de Cerrado do Estado. Há um exemplar coletado por Alvarenga em 1989 no Rio Caiapó, próximo à Caseara (APÊNDICE 2). Posteriormente, em 2001, a espécie foi novamente registrada nos arredores de Caseara, na estrada que liga o município a Palmas (APÊNDICE 1). Há também registros atuais que foram realizados no Parque Nacional do Araguaia (Nascimento \& Flores, 2001), em Natividade, em Gurupi, em Almas e em Araguaçú (APÊNDICE 1).

\section{Tocantins}

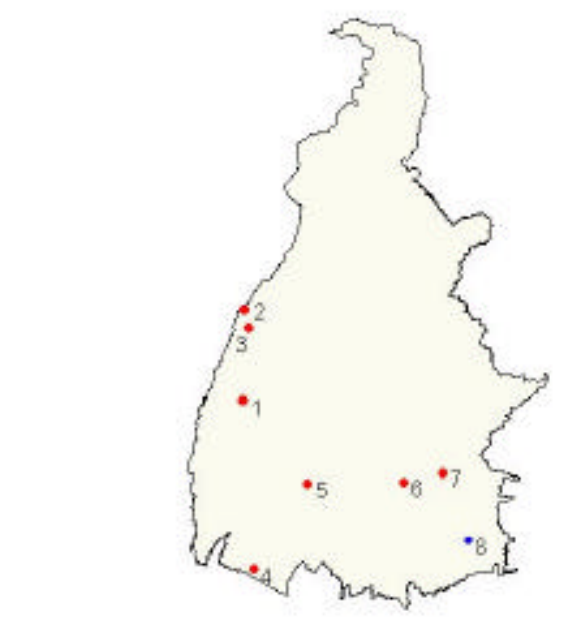

Localidade de registros

- antes de 1980

- após 1980

400

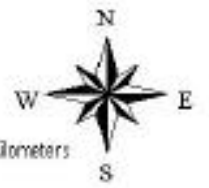

Figura 17 - 1. P.N. do Araguaia; 2. Rio Caiapó, Caseara; 3. Estrada para Palmas, Caseara; 4. Araguaçú; 5. Gurupi; 6. Natividade; 7. Almas; 8. Rio Palma 


\section{Goiás}

Os antigos registros de Primolius maracana em Goiás foram realizados em localidades que hoje correspondem ao norte do Estado, divisa com Tocantins. Blaser coletou, em 1932, cinco exemplares em Barra de São Domingos e outros cinco nos arredores de Nova Roma (APÊNDICE 2). Há outros dois exemplares coletados por Pfrimer provindos do Rio Palma (APÊNDICE 2), além de outros nove exemplares sem indicação de localidade de coleta, mas que provavelmente também vieram da mesma localidade.

A única informação encontrada sobre registros atuais da espécie é referente a observações realizadas no Parque Nacional da Chapada dos Veadeiros, no ano de 2001 (APÊNDICE 1).

\section{Goiás}

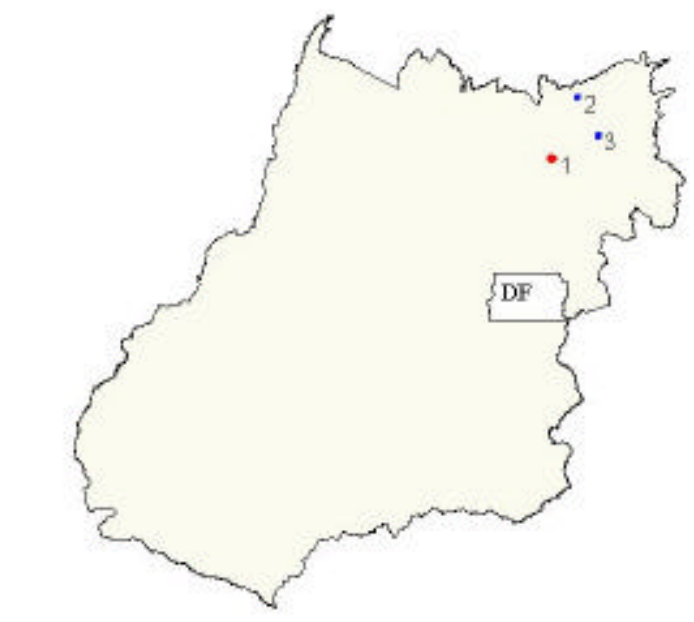

Localidade de registros

- antes de 1980

- após 1980
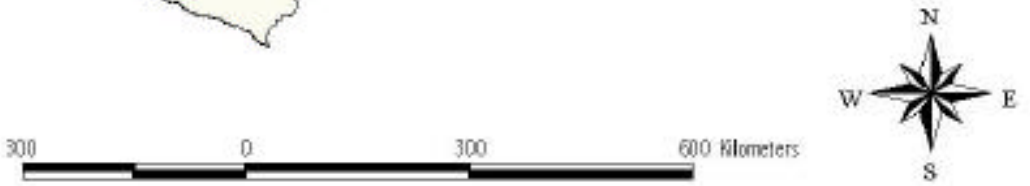

Figura 18 - 1. P.N. Chapa dos Veadeiros; 2. Barra de São Domingos; 3. Nova Roma 


\section{M ato Grosso}

Naumberg mencionou a raridade de Primolius maracana em coleções do Estado do Mato Grosso (in Pinto, 1932), sendo então conhecidos registros apenas para o Rio Roosevelt, noroeste do Estado (Naumberg, 1930), e Aquidauana, localidade hoje pertencente ao Estado de Mato Grosso do Sul (APÊNDICE 2).

Os registros atuais da espécie encontrados foram realizados principalmente ao sul do Estado. A espécie foi recentemente avistada em Barão de Melgaço, em Cangas, em Joselândia, em Pixaim, em Poconé, em Santo Antônio do Leverger, na Serra das Araras, no Parque Estadual da Serra de Santa Bárbara (APÊNDICE 1) e em Jaciara (Petermann et al., 2001). O maracanã também tem sido observado no Parque Nacional da Chapada dos Guimarães, porém os registros são de poucos indivíduos (Willis, 1990 e APÊNDICE 1). Primolius maracana foi também detectada por Bret Whitney ao norte do Estado próximo a Alta Floresta, região ecótone entre Floresta Amazônica e Cerrado, esse sendo considerado o primeiro registro atual da espécie para a região (APÊNDICE 1). 


\section{Mato Grosso}

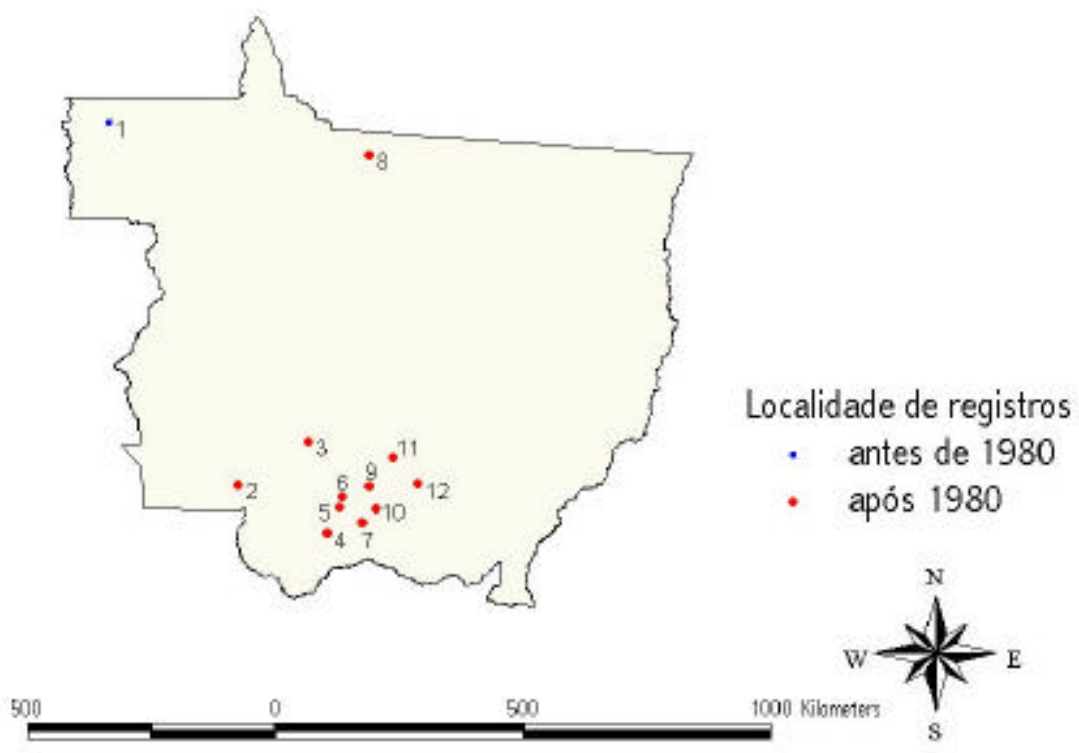

Figura 19 - 1. Rio Roosevelt; 2. P. E. Serra de Santa Bárbara; 3. Serra das Araras; 4. Pixaim; 5. Poconé; 6. Cangas; 7. Joselândia; 8. Rio Cristalino; 9. Santo Antônio do Leverger; 10. Barão de Melgaço; 11. Chapada dos Guimarães; 12. Jaciara

\section{Mato Grosso do Sul}

Os únicos registros antigos de Primolius maracana conhecidos para o Mato Grosso do Sul são de dois exemplares coletados por Lima em Aquidauana, no ano de 1931 (APÊNDICE 2). Os registros atuais reunidos para o Estado foram realizados principalmente em região de Cerrado, ao norte do Estado. A espécie foi avistada nos municípios de Coxim, Sonora e Pedro Gomes (APÊNDICE 1). Além desses, a espécie também foi registrada em Brasilândia (Nascimento et al., 2001), área de Floresta Semidecídua ao leste do Estado, e foi coletada em Bonito, município na borda da região pantaneira (APÊNDICE 2). 


\section{Mato Grosso do Sul}

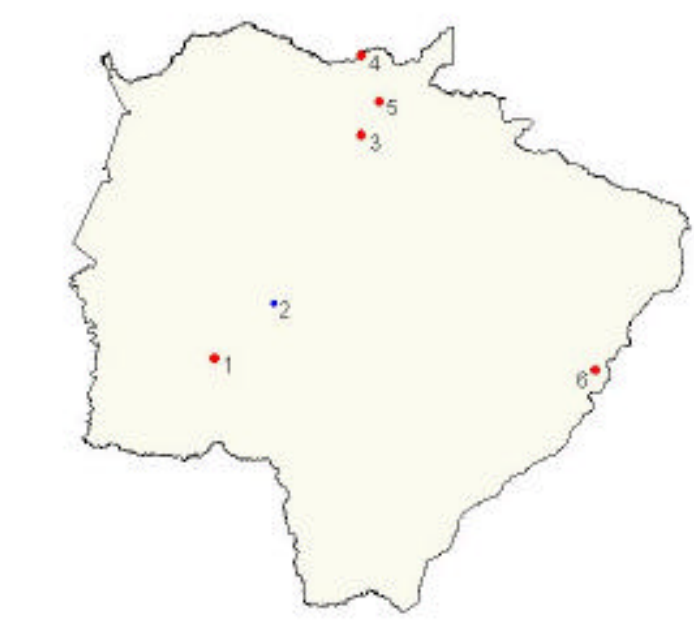

Localidade de registros

- antes de 1980

- após 1980

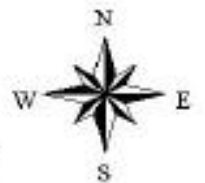

Figura 20 - 1. Bonito; 2. Aquidauana; 3. Coxim; 4. Sonora; 5. Pedro Gomes; 6. Brasilândia

\section{Pará}

Os registros de Primolius maracana no Pará foram realizados principalmente na região de vegetação aluvial do nordeste do Estado. O maracanã foi avistado por Natterer em Cajutuba, no ano de 1935 (Goeldi, 1896 e Rokitansky 1957), e espécimes foram coletados na Ilha de Marajó no anos de 1896 e 1905 (Henriques \& Oren, 1997), e em Urumanduba no ano de 1957 (APÊNDICE 2). O maracanã foi coletado na mesma região em 1974 e 1987, nos arredores de Vigia em Santa Rosa e Jussarateua do Pereira (APÊNDICE 2), onde foi considerada comum nas capoeiras junto às campinas (Novaes \& Lima, 1992). Há um exemplar de Primolius maracana com a indicação de localidade de coleta para Santarém, porém esse registro é considerado duvidoso (Forrester, 1993). 
Atualmente a espécie ainda é avistada na Ilha de Marajó (Craveiro \& Miyaki, 2000). São também conhecidas populações da espécie que habitam o sudoeste do Pará, no sul da Serra do Cachimbo e entre os Rios Cateté e Baú (APÊNDICE 1), que é uma região ecótone entre Floresta Amazônica e Cerrado.

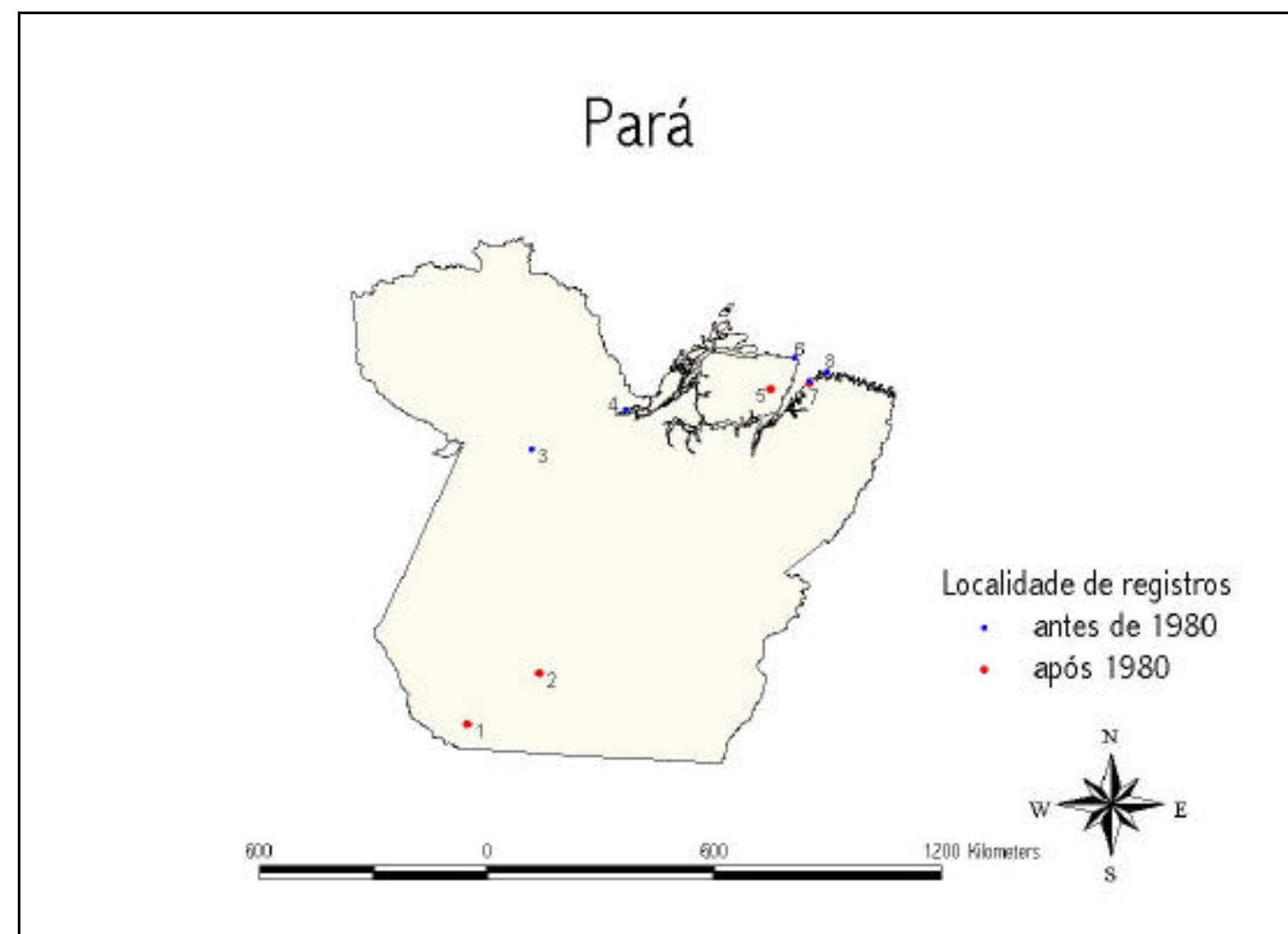

Figura 21 - 1. Serra do Cachimbo; 2. Rio Catete/Baú; 3. Santarém; 4. Urumanduba; 5. Natal, Ilha de Marajó; 6. Pascoval, Ilha de Marajó; 7. Vigia; 8. Cajutuba

\section{Rondônia}

Não foram encontradas informações sobre registros históricos de Primolius maracana no Estado de Rondônia. Foi encontrado apenas um registro da espécie para o Estado, realizado no município de Chupinguaia em 1997, e que foi considerado inédito para o Estado (Cândido Jr, 1999). 


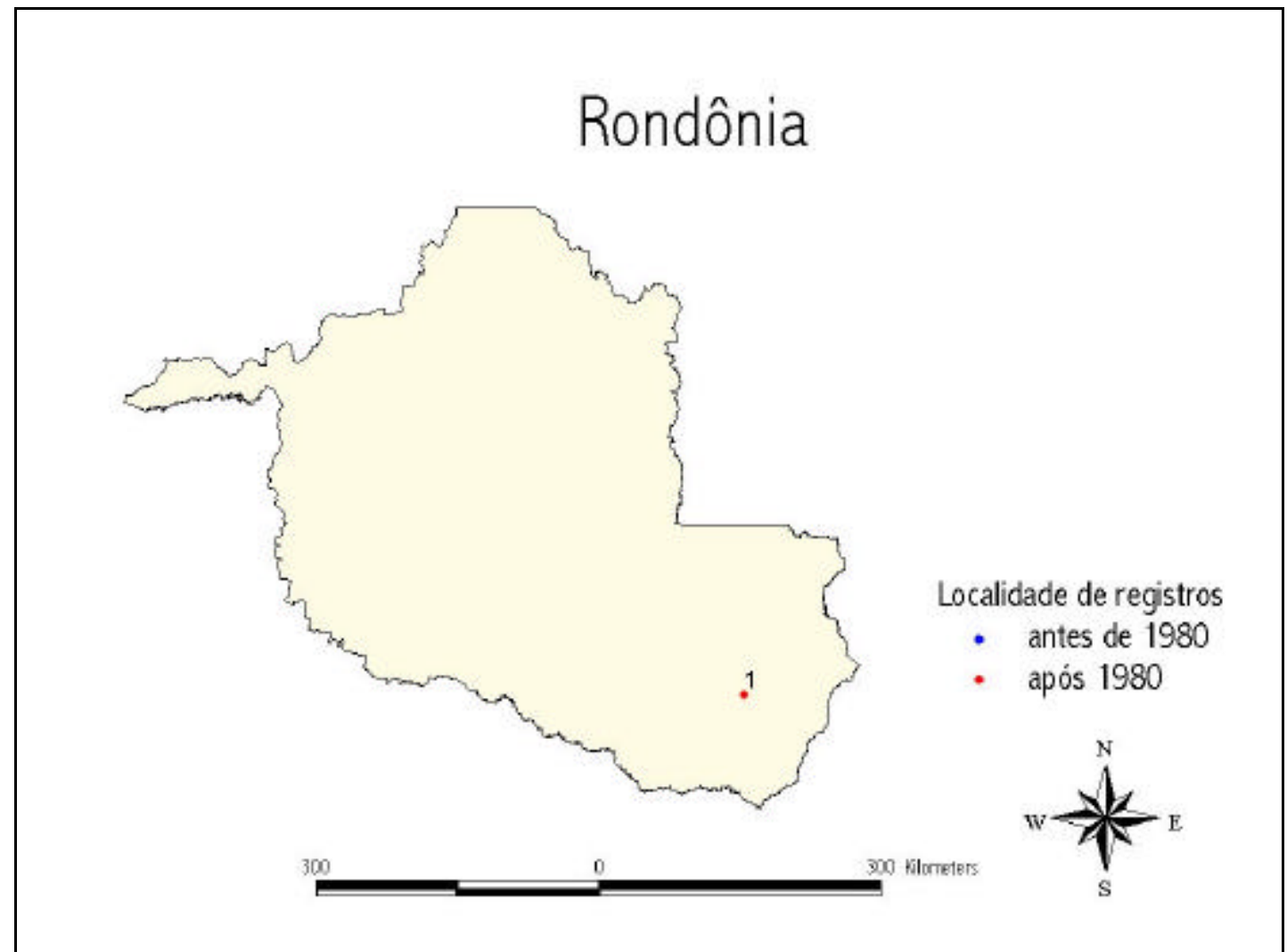

Figura 22 - 1. Chupinguaia

Sergipe, Paraíba, Rio Grande do Norte, Acre, Amazonas, Roraima e Amapá

Esses Estados não são indicados como área de ocorrência de Primolius maracana nos livros-guia sobre distribuições de aves e psitacídeos (Pinto, 1978; Forshaw, 1989; Del Hoyo et al., 1997; Sick, 1997; Juniper \& Parr, 1998 e Bird Life International, 2000). Além disso, não foram encontrados registros de Primolius maracana, tanto históricos como atuais, em diversas fontes (Chapman, 1931; Pinto, 1936; Novaes, 1957, 1965, 1974, 1978; Forrester, 1993; Parker III et al., 1996; IDEMA, 1999; Pacheco, 2000; Snethlage, 1914; Pinto, 1936, 1938, 1947, 1966; Pinto \& Camargo, 1954, 1961; Willis, 1977; Willis \& Oniki, 1988 e Schulz Neto, 1995). 


\section{DISTR IBUIÇÃO GEOGRÁFICA E ESTATUS DO MARACANÃ- VERDADEIRO primolius maracana EM SUA ÁREA DE OCORRÊNCIA HISTÓRICA.}

\section{Resumo}

O Maracanã-verdadeiro (Primolius maracana) é uma espécie de psitacídeo considerada vulnerável a extinção, porém há poucas informações disponíveis sobre a distribuição, ecologia e estatus de suas populações. Deste modo foi realizada uma revisão detalhada sobre a distribuição e o estatus da espécie, através de informações de espécimes de museus, literatura e consultas a ornitólogos com atuação no Brasil. Além disso, determinou-se as áreas de extensão de ocorrência do maracanã, histórica e atual, através dos registros compilados e da técnica do mínimo polígono convexo, e comparout as a fim de verificar possíveis mudanças na distribuição geográfica da espécie ao longo do tempo. Foram reunidos 176 registros de localização do maracanã, atuais e históricos, distribuídos amplamente em 19 Estados brasileiros, 7 Departamentos no Paraguai e 2 províncias na Argentina. Esses registros estão situados em diferentes tipos de biomas, o que sugere um amplo nicho ecológico da espécie. Também foram constatadas diferenças entre as áreas de extensão de ocorrência do maracanã, histórica e atual. Elas sugerem um aumento dos limites de ocorrência do maracanã ao nordeste da distribuição e um decréscimo dos limites a noroeste e, principalmente, ao sul de sua distribuição. Essas diferenças podem estar relacionadas a extinções ou colonizações de novas áreas de ocorrência, mas também algumas podem ser reflexos de limitações dos dados compilados ou do método empregado. Com base em todas as informações coligidas, o 
estatus atual do maracanã foi classificado como: provavelmente extinto na Argentina, no Rio Grande do Sul e em Santa Catarina; altamente ameaçado no Paraguai e no Paraná; ameaçado em São Paulo; e comum em regiões do Rio de Janeiro (centro e sul), Minas Gerais (leste) e Bahia (nordeste). O estatus da espécie em outras regiões e Estados não foi definido devido à insuficiência de dados. É necessário que regiões com carência de informação sobre avifauna sejam inventariadas e que dados já existentes sejam divulgados para a elaboração de uma revisão mais precisa do estatus referente a toda distribuição de Primolius maracana. Deve-se ainda estudar as causas que estão levando a extinções da espécie e examinar seus padrões para que sejam desenvolvidas estratégias para sua conservação em escalas local e regional.

\section{DISTRIBUTION AND STATUS OF BLUE-WINGED MACAW PRIMOLIUS MARACANÃ: ALONG ITS HISTORICAL RANGE}

\section{Summary}

The blue winged macaw (Primolius maracana) is a vulnerable species of psittacidae, however there are few available information about its geographical distribution, ecology and populations status. Thus, it was carried a detailed revision on the its status and distribution, across its entire range, using literature review/key reference texts, questionnaires and email post-out to ornithologists and ornithological institutes and checking with specimens in museums. Moreover, it was determined the historical and current range extension of blue winged macaw, by the minimum convex polygon technique, and compared them in order to verify possible changes in the geographic distributions along of the time. One hundred seventy-six sites records of blue winged macaw, current and historical, have been gathered, what were distributed across 19 Brazilian States, 7 Departments in Paraguay and 2 Provinces in Argentina. These records were placed in different types of biomas, which suggests an broad ecological niche of blue winged macaw. It was also verified differences between its historical and current range. They suggest an increase of the blue winged macaw's occurrence 
boundary in the northeast of the its original distribution and a decrease in the northwest and, mainly, in the south of its distribution. They can be related to extinctions or settlings of new sections of occurrence, but also some can be a response of the data or of the employed method limitations. According to the gathered data, the current status of blue winged macaw were classified as: probably extinct in Argentina, Rio Grande do Sul and Santa Catarina; highly threatened in Paraguay and Paraná; threatened in São Paulo; common in regions of Rio de Janeiro (center and south), Minas Gerais (east) and Bahia (northeast). Its status in other regions or States was not defined due to insufficiency of data. It is important to survey the regions with no data of blue winged macaw and to publish the already existing information, in order to turn out a complete status review for its entire distribution. Moreover, the occurrence pattern of blue winged macaw and the reasons for its extinctions must be investigated to look for the development of conservation strategies, in local and regional scales.

\subsection{Introdução}

A atual crise de extinção tem sido uma séria ameaça à diversidade biológica e um dos principais focos da ciência nas últimas décadas (Soulé, 1987; Wilson, 1988; Pimm, 1995 e Brooks, 2000). Para o grupo das aves, estimativas apontam que uma em cada oito espécies tem um alto risco de se tornar extinta nos próximos cem anos (Birdlife International, 2000). Psittacidae é a família de aves com o maior número de espécies ameaçadas, pois das 332 espécies conhecidas, 92 correm risco de extinção e 32 estão próximas a essa condição (Birdlife International, 2000), sendo que 9 foram extintas desde 1500 somente nos Neotrópicos (Galetti et al., 2002). A perda de hábitat é o principal fator para o declínio de muitas populações, além de outras causas secundárias, não menos importantes, como a introdução de espécies predadoras ou competidoras, populações naturalmente reduzidas, perseguição humana para comércio, caça e coleta de ovos, dentre outras (Collar et al., 1994 e Snyder et al., 2000). 
O Brasil é o país com maior diversidade de psitacídeos, abrigando um total de 72 espécies, motivo pelo qual foi conhecido no século XVI como "Terra dos papagaios" (Brasília sirve terra dos papagallorum) (Sick, 1997). Dentre essas espécies, 16 estão listadas no "The world list of the threatened birds" (Birdlife International, 2000), sendo que 5 estão classificadas como vulneráveis à extinção, 8 como ameaçadas, duas como criticamente ameaçadas e uma já extinta (Anodorhynchus glaucus). No final do ano de 2000, essa lista sofreu nova mudança, devido a extinção na natureza da ararinha-azul (Cyanopsita spixii), que antes era incluída entre as espécies criticamente ameaçadas (Yamashita, 2002).

Primolius maracana, o maracanã-verdadeiro, é um psitacídeo considerado vulnerável à extinção (Snyder et al., 2000 e Birdlife International, 2000), porém há poucas informações disponíveis sobre a espécie, como sua ecologia e história natural. A área de ocorrência original do maracanã é ampla e também conhece-se pouco sobre a distribuição e estatus de suas populações em diferentes regiões de sua abrangência. As informações disponíveis na literatura são pontuais, mas têm relatado sobre alterações na distribuição geográfica da espécie nas últimas décadas (Collar et al., 1994 e Juniper \& Parr, 1998), principalmente sobre extinções regionais no sul do Brasil e nordeste da Argentina (Belton, 1994, Rosário, 1996 e La Pena, 1998) e sobre recolonização no Estado do Rio de Janeiro (Pacheco, 1994). Dessa maneira foi realizada uma revisão da distribuição atual e histórica do maracanã, a fim de conhecer seu estatus em diferentes regiões geográficas e verificar possíveis alterações em sua área de ocorrência, detectando regiões temporariamente estáveis, em crescimento, ou em declínio.

\subsection{Métodos}

Foi realizada uma revisão detalhada sobre os registros de distribuição de Primolius maracana, procurando obter o maior número possível de informações sobre a ausência e presença, histórica e atual, da espécie. Utilizaram-se livros e periódicos, a fim de reunir dados de listas de espécies da avifauna de várias localidades e averiguar se 
haviam registros da espécie. Informações sobre espécimes em museus, nacionais e internacionais, foram pesquisadas por meio de cartas ou visitas à instituições e também por consultas a boletins dessas instituições. Ornitólogos com auação no Brasil também foram consultados, pessoalmente ou via correio-eletrônico, com o intuito de obter informações sobre registros da espécie e sobre listas da avifauna de certas localidades de interesse.

Utilizourse gazetteers ornitológicos para resgatar coordenadas aproximadas dos registros históricos de Primolius maracana (Paynter Jr, 1985a, b e Paynter Jr \& Taylor, 1991). Os registros encontrados foram mapeados com o auxílio do programa ArcView 3.2 para a análise da distribuição do maracanã e medição da área de extensão de sua ocorrência. Foi empregada a técnica do mínimo polígono convexo (Gaston, 1996), que é a delimitação do menor polígono que possa conter todos os pontos de ocorrência da espécie e que possua todos os vértices com ângulos internos menores ou iguais a $180^{\circ}$. Superfícies dentro do polígono que por ventura ficaram localizadas sobre o oceano foram subtraídas.

Definiu-se um polígono para registros anteriores a 1980 e outro para registros após 1980, a fim de verificar possíveis mudanças na área de distribuição geográfica do maracanã. Esses intervalos foram definidos devido à distribuição dos dados de registros compilados, onde entre os anos de 1958 e 1983 são encontrados apenas dois registros de localidade do maracanã. As razões para esse truncamento temporal dos dados disponíveis não são claras, mas ele foi usado para a distinção e representação dos cenários de distribuição antiga e atual da espécie. É também razoável considerar um período de 20 anos (1983 - 2003) como distribuição atual do maracanã, devido a conhecida longevidade das espécies dos psitacídeos.

\subsection{Resultados}

Foram reunidos 176 registros de localização de Primolius maracana distribuídos em 19 Estados brasileiros, além de 7 Departamentos no Paraguai e 2 províncias na Argentina (Figura 3.1 e APÊNDICES 1 e 2). 


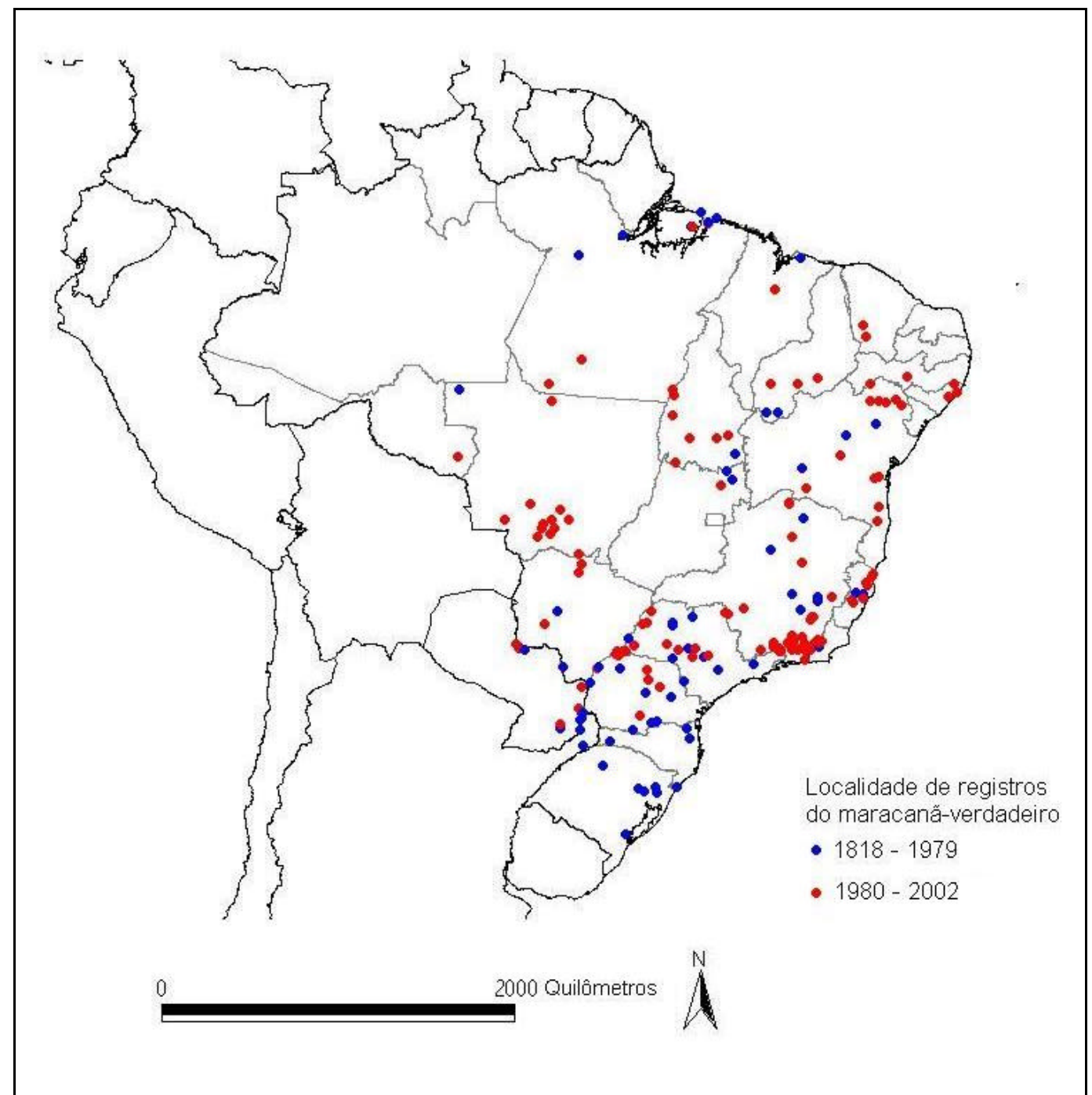

Figura 1 - Distribuição geográfica de todos os registros compilados de Primolius maracana referentes a diferentes datas

A extensão da área total de ocorrência de pontos de registro de Primolius maracana foi de $4.796 .900 \mathrm{~km}^{2}$. Foram observadas diferenças entre as áreas de extensão dos registros anteriores a 1980 e os posteriores a essa data (Figura 2.23). Essas diferenças aconteceram em distintas partes da distribuição, havendo um total de 699.500 $\mathrm{km}^{2}$ de área de decréscimo, principalmente ao sul e noroeste da distribuição, e 307.200 $\mathrm{km}^{2}$ de área de incremento, principalmente ao nordeste da distribuição. 


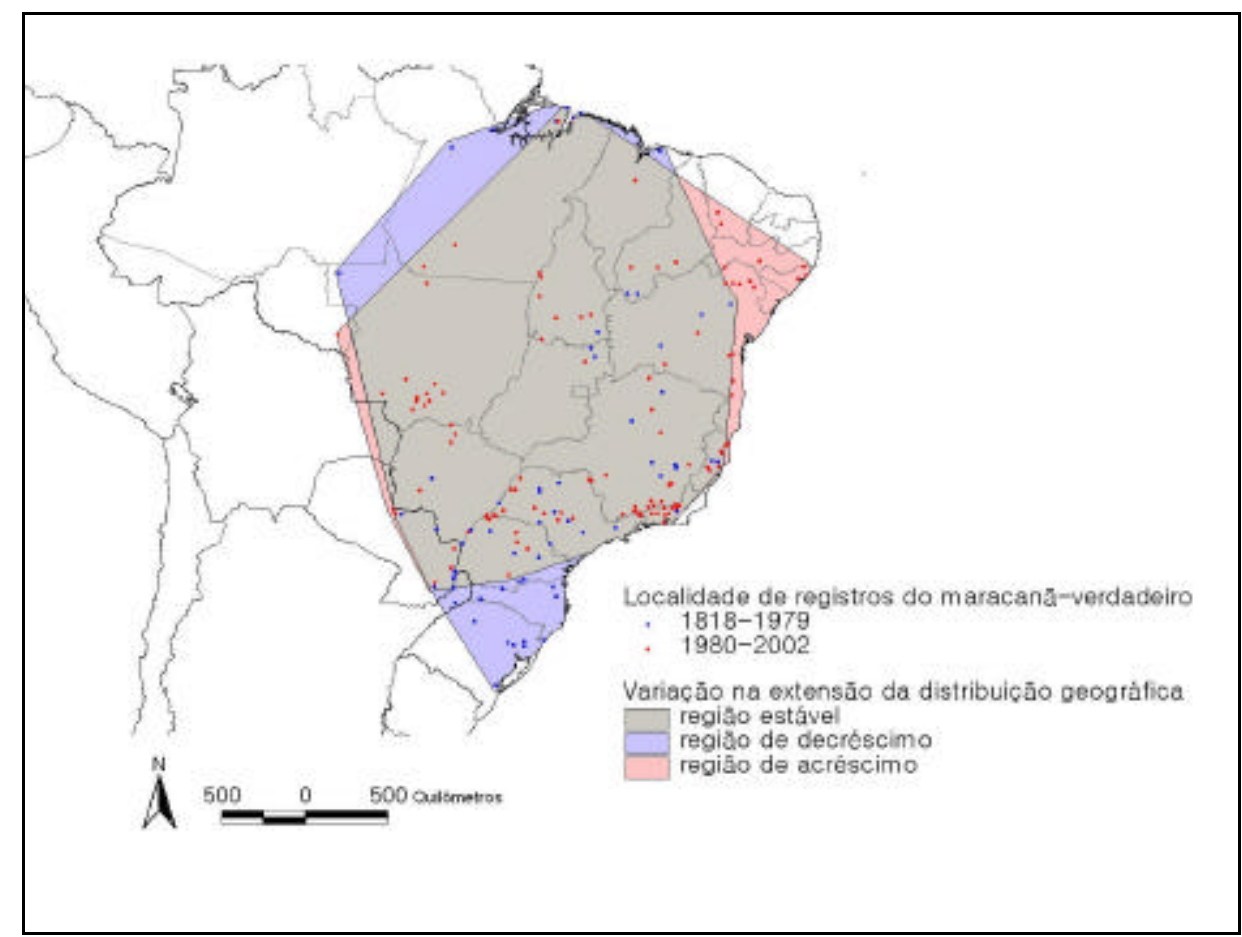

Figura 2 - Variação na extensão da distribuição de registros de Primolius maracana anteriores a 1980 e posteriores a 1980

Houve uma diferença latitudinal acentuada na quantidade de registros anteriores a 1980 em relação aos posteriores a essa data (Figura 3.3).

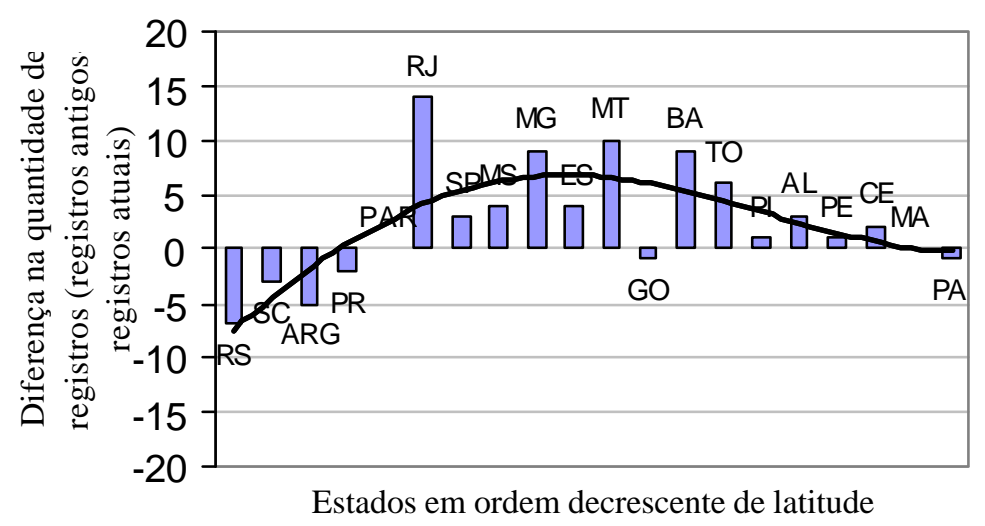

Figura 3 - Diferença entre o número de localidades de registros atuais (depois de 1980) e históricos para cada Estado, além de Argentina e Paraguai, em ordem decrescente de latitude média dos registros no Estado. 


\subsection{Discussão}

\subsubsection{Distribuição do maracanã}

As localidades de registro de Primolius maracana apresentaram ampla distribuição, ultrapassando os limites dos mapas antes apresentados nos livros-guia sobre psitacídeos (veja Pinto, 1978; Forshaw, 1989; Del Hoyo et al., 1997; Sick, 1997; Juniper \& Parr, 1998; Snyder et al., 2000 e Bird Life International, 2000). Além disso, a distribuição da espécie, indicada na literatura, até o momento não mencionava a sua ocorrência nos Estados do Ceará, Alagoas e Rondônia. Esses registros foram realizados em muitos tipos de vegetação brasileira (segundo IBGE 1993), como Florestas Estacionais Semidecíduas, Florestas Ombrófilas (Densas e Abertas), Florestas Ombrófilas Mistas (Florestas de Araucária), Florestas Estacionais Decíduas, Cerrados, Caatingas e áreas ecótones entre as diferentes vegetações.

Apesar de Primolius maracana estar distribuída em Florestas Ombrófilas do Rio de Janeiro e Espírito Santo, a espécie não ocorre nesse mesmo tipo de vegetação nos Estados da Bahia, São Paulo e Paraná, estando preferencialmente em Florestas Semidecíduas. Além disso, praticamente não há registros do maracanã em Florestas Ombrófilas da Amazônia (Snethlage, 1914; Griscon \& Greenway, 1941; Pinto, 1978; Parker III et al., 1996), apenas em suas bordas como sul de Rondônia, norte do Mato Grosso e sul e norte do Pará, além de um espécime duvidoso coletado em Santarém (APÊNDICES 1 e 2). O Pantanal Mato-grossense e Chaco Paraguaio são outras regiões onde o maracanã é encontrado apenas nas bordas (Short, 1975; Weinberg, 1984 e Tubilis \& Tomás, 1999). A ausência na região pantaneira pode ser em decorrência da presença de Primolius auricollis na área, segundo os princípios da exclusão competitiva (Hutchinson, 1959). O maracanã também não foi registrado na região dos Campos Sulinos no Rio Grande do Sul.

Espécies que possuem distribuição ampla e ocupam diferentes biomas geralmente possuem alta capacidade de dispersão e hábitos generalistas (Cowley et al., 2001), como é o caso de Primolius maracana (Nunes, 2000). Entretanto as distribuições 
internas dos táxons tendem a não ser uniformes (Rodriguez, 2002), sendo que podem ocorrer em baixas densidades e ter pequenas distribuições em qualquer lugar onde o ambiente for menos apropriado (Brown et al., 1995). No caso do maracanã, as maiores densidades de pontos de ocorrência foram observadas principalmente nas vegetações de Florestas Estacionais Semidecíduas, em Matas de Galeria do Cerrado, na Caatinga Arbórea e em Florestas Ombrófilas do sudeste, além de Florestas Mistas com Araucária do sul do país onde a espécie não vem sendo mais avistada.

\subsubsection{Alterações na distribuição da espécie ao longo do tempo}

Os limites de extensão de ocorrência de Primolius maracana estabelecidos aqui sofreram mudanças no último século, que foram mais conspícuas em sua região noroeste e sul, com decréscimo de área, e na região nordeste, com acréscimo de área. As regiões nas margens oeste e norte, por serem relativamente estreitas, foram desconsideradas.

Todas essas mudanças na extensão poderiam sugerir extinções ou colonizações de novas áreas de ocorrência, porém algumas considerações devem ser feitas em relação ao tipo de dado e metodologias utilizadas:

1. Estudos da distribuição geográfica em macro escala geralmente são dependentes da compilação de dados de ocorrência disponíveis, combinando informações de diferentes fontes integradas ao longo do tempo (Blackburn \& Gaston, 1998). A falta de sistematização na coleta de informações pode levar a vieses relacionados a erros de omissão, situação na qual a espécie é encontrada mas não foi predita, e comissão, quando a espécie foi predita mas não ocorre (Boone \& Krohn, 2000).

A comparação temporal e espacial dos dados pode ser problemática porque a quantidade e qualidade de informação não são as mesmas ao longo do tempo e do espaço. As informações sobre as comunidades de avifauna do passado foram obtidas, em sua maioria, por meio de material coletado em expedições, que nem sempre representavam todas as espécies da avifauna de uma localidade. Muitas das informações sobre a composição da avifauna recente foram obtidas em listas de espécies de 
levantamentos que contemplam toda comunidade de aves. Além disso, ao longo do tempo, houve um aumento na quantidade de ornitólogos e de informações reunidas sobre as espécies, tecnologias foram desenvolvidas para equipamentos ópticos e de bioacústica, novos sistemas de comunicação facilitaram e agilizaram a disponibilização de dados e facilitourse o acesso a muitas áreas antes remotas.

As informações sobre a composição da avifauna, tanto no passado como no presente, também foram distintas para diferentes regiões do Brasil. Em muitas regiões as informações coletadas no passado são pontuais, ou devido à falta de instituições locais que promovessem inventários intensivos de avifauna ou devido à dificuldade de acesso. Contrastam-se apenas as áreas do sul e sudeste que, em geral, foram intensivamente inventariadas no passado e foram montadas importantes coleções zoológicas (Pinto, 1945 e Straube \& Scherer-Neto, 2001), principalmente nos Museus Paraense (hoje MHNCI), Paulista (hoje MZUSP) e Nacional do Rio de Janeiro. Atualmente essas regiões ainda coletam muitos dados sobre a composição de avifauna por abrigarem um grande número de universidades e instituições, conseqüentemente de ornitólogos e pesquisas ornitológicas.

Devido à possibilidade de omissão da ocorrência prévia do maracanã na região nordeste de sua área de extensão, deve-se ter cautela em afirmar a existência de um real incremento na distribuição da espécie. No entanto, em relação ao decréscimo na região sul da área de extensão, pode-se assegurar que houve uma contração na distribuição $\left(277.100 \mathrm{Km}^{2}\right)$, pois essa região foi e ainda é relativamente bem amostrada.

2. Existem diferenças entre as medidas de área de extensão e de área de ocupação de uma espécie. A medida de área de extensão está relacionada à forma dos limites mais externos de ocorrência da espécie e a medida de área de ocupação está relacionada à superfície que a espécie realmente ocupa (Gaston, 1996).

Para a confecção do mapa de distribuição geográfica de Primolius maracana utilizourse o polígono mínimo convexo, uma técnica que mede a extensão da ocorrência e que pode ser muito influenciada por registros marginais isolados. No caso da região noroeste da extensão, as localidades de Alta Floresta - MT e Santarém - PA aumentaram significativamente a área de extensão do período anterior a 1980, em relação à área de 
extensão atual. No entanto, esses registros são isolados e ocorreram na Floresta Amazônica, um bioma onde a espécie é raramente registrada, exceto em suas bordas (ex. Chupinguaia -RO, Alta Floresta - MT, Serra do Cachimbo - PA). Dessa forma, essa área pode não corresponder a uma região significativa de contração da distribuição do maracanã, pois é uma região espacialmente e ecologicamente marginal para a espécie que possivelmente nunca ocupou efetivamente a região, ocorrendo apenas em registros esporádicos. Além disso, o registro de Santarém pode ser considerado duvidoso (Forrester, 1993), pois está localizado em região central da Floresta Amazônica, distante de outros registro da espécie, e porque o espécime encontrado no Museu Nacional do Rio de Janeiro não contém informações mais detalhadas sobre local de coleta e sobre o coletor.

\subsubsection{Implicações e recomendações para conservação}

Apesar da distribuição de Primolius maracana ser ampla e a espécie ter aparentemente um amplo nicho ecológico, ela está considerada vulnerável à extinção (Birdlife International, 2000). Todavia seu estatus é bem diverso em diferentes partes de sua distribuição. Com base nas informações coligidas o maracanã foi classificado como: provavelmente extinto na Argentina, no Rio Grande do Sul e em Santa Catarina; altamente ameaçado no Paraguai e no Paraná; ameaçado em São Paulo; e comum em regiões do Rio de Janeiro (centro e sul), Minas Gerais (leste) e Bahia (nordeste). Os dados também apontam para uma contração no limite sul de ocorrência da espécie, mas as razões para esse declínio não são claras.

Não há dados suficientes para a definição dos estatus da espécie em outras regiões e Estados, já que o nível de informação sobre a espécie também é distinto em diferentes partes de sua distribuição. $\mathrm{O}$ entendimento da distribuição geográfica de uma espécie é o aspecto da ornitologia que mais depende da compilação de dados (CAD, 1999), porém revistas de maior circulação geralmente não publicam listas de avifauna, o 
que faz com que muitos dados não sejam divulgados ou que estejam restritos a periódicos locais de difícil acesso.

Desse modo, é necessário que regiões com carência de informação sobre avifauna sejam inventariadas e que dados já existentes sejam divulgados, para a elaboração de uma revisão mais precisa do estatus referente a toda distribuição de Primolius maracana. Isso será importante para identificar as áreas que estão mantendo as prováveis populações viáveis de maracanã e regiões onde a espécie esteja sob grande ameaça, a fim de deter ou reverter os impactos que mais estão afetando sua manutenção. Deve-se ainda estudar as causas que estão levando a contração na distribuição da espécie e examinar seus padrões para que sejam desenvolvidas estratégias para sua conservação em escalas local e regional.

\subsection{Conclusões}

1. A revisão apresentada incluiu localidades de ocorrência do maracanã pouco conhecidas e que estavam dispersas na literatura, como os registros nos Estados do Ceará, Alagoas e Rondônia, o que resulta na modificação dos limites dos mapas de distribuição da espécie antes apresentados nos livros-guia sobre psitacídeos.

2. O maracanã aparentemente tem um amplo nicho ecológico, apresentando registros provindos de diversos tipos de vegetação brasileira (Florestas Estacionais Semidecíduas, Florestas Ombrófilas, Florestas Ombrófilas Mistas, Florestas Estacionais Decíduas, Cerrados, Caatingas e áreas ecótones entre as diferentes vegetações).

3. Os limites de distribuição geográfica do maracanã sofreram mudanças no último século, principalmente ao sul de sua ocorrência original, que mostrou um drástico declínio nos últimos 50 anos.

4. O estatus do maracanã foi classificado como: provavelmente extinto na Argentina, no Rio Grande do Sul e em Santa Catarina; altamente ameaçado no Paraguai e no Paraná; ameaçado em São Paulo; e comum em regiões do Rio de Janeiro (centro e sul), Minas Gerais (leste) e Bahia (nordeste). Não há dados suficientes para a definição dos estatus da espécie em outras regiões e Estados. 


\section{PREFERÊNCIA DE HÁBITAT E FATORES QUE INFLUENCIAM NA PERSISTÊNCIA DAS POPULAÇÕES REMANESCENTES DO MARACANÃ- VERDADEIRO PRIMOLIUS MARACANA EM ESCALA REGIONAL}

\section{Resumo}

O maracanã-verdadeiro (Primolius maracana) é um psitacídeo neotropical que possui uma ampla área de ocorrência histórica, contudo, está considerado vulnerável à extinção. Nas últimas décadas sua abundância e distribuição geográfica têm diminuído rapidamente, principalmente na margem sul de sua ocorrência. Essa contração tem sido generalizadamente atribuída à redução do hábitat e sua fragmentação, porém não há estudos que suportam essa hipótese. Dessa maneira, procurou-se avaliar se a probabilidade de encontro de populações de maracanãs na região sul de sua distribuição está associada a características da composição e estrutura da vegetação remanescente. Foi verificada a presença ou ausência atual do maracanã em 54 localidades nessa região, a partir da compilação de dados de levantamentos recentes de avifauna. Foram calculadas métricas de paisagem para cada uma dessas localidades que, juntamente com seus dados de coordenadas geográficas, foram relacionados com a presença ou ausência atual do maracanã através da análise de regressão logística. Entre as métricas analisadas, o "total de cobertura vegetal da paisagem" foi à única variável preditora significativa da ocorrência de Primolius maracana $(\mathrm{p}<0,01$ ), porém seu coeficiente de associação foi muito baixo no modelo ajustado $(\varnothing=0,0013)$. A variável "latitude" também foi altamente significativa $(\mathrm{p}<0,001)$, apresentando um alto coeficiente de associação $(\varnothing=$ 405835). Considerando que a latitude é apenas uma coordenada geográfica que não afeta diretamente a ocorrência de espécies, outra variável com estrutura espacial altamente 
relacionada com latitude deve estar afetando diretamente, ou afetou, as populações meridionais de Primolius maracana. Esse fator parece não estar diretamente vinculado à fragmentação do hábitat, já que a cobertura vegetal e outras características de paisagens não foram significativamente correlacionados com a latitude. Assim sendo, as razões para a contração na distribuição do naracanã permanecem pouco entendidas, sendo que outros distúrbios além da perda de hábitat podem estar relacionados a contração da distribuição geográfica do maracanã. Contudo, a significância das variáveis "latitude" e "total de cobertura vegetal da paisagem" em um modelo múltiplo indicam que elas trazem informações complementares. Um fator direcional pode levar ao declínio a distribuição e abundância da espécie até o ponto onde efeitos associados à fragmentação de hábitat contribuem significativamente para eliminá-las. Portanto, a conservação da vegetação em escalas local e regional é importante, pois a perda de cobertura vegetal pode intensificar os fatores que levam ao declínio.

\section{HABITAT PREFERENCES OF BLUE-WINGED MACAW PRIMOLIUS MARACANÃ AND FACTORS AFFECTING THE PERSISTENCE OF ITS REMAINING POPULATIONS IN REGIONAL SCALE}

\section{Summary}

The blue winged macaw (Primolius maracana) is a neotropical psittacidae that is vulnerable to the extinction, since the last decades its abundance and geographic distribution have declined, mainly in the south edge of its original range. This contraction has been commonly attributed to habitat reduction, however there is no studies supporting this hypothesis. Thus, we evaluated if the encounter probability of blue-winged macaw's populations in the south of its range is related to features of the composition and the structure of the remaining vegetation. The current presence or absence of blue-winged macaw was verified in 54 localities in this region, from the compilation of data of recent avifauna surveys. Metrics of landscape were calculated for 
each one of these localities and related to the current presence or absence of blue-winged macaw through the logistic regression analysis, as its geographic coordinates data too. Among all analyzed metrics, the "total of vegetal cover of the landscape" was the only significant variable to predict blue-winged macaw's occurrence $(p<0,01)$, in spite of its explicatory power was very low. The "latitude" was highly significant to predict bluewinged macaw's occurrence $(\mathrm{p}<0,001)$, exhibiting a higher explicatory power. Considering that latitude is only a geographic coordinate, it can't directly affect the species occurrence. Another variable with spatial structure highly related to latitude may be affecting, or has affected, the southern populations of blue-winged macaw. This factor seems not to be directly related to habitat structure and composition, since the total of vegetal cover of the landscape and other characteristics significantly have not been correlated to latitude. Consequently, the reasons for the blue-winged macaw's range contraction remain poorly understood and other disturbances, beyond the habitat reduction, can be related to that decline. However, the significance of "latitude" and "total of vegetal cover of the landscape" in a multiple model indicate they have complementary information. A directional factor can take to abundance and distribution decline of blue-winged macaw until some effects, linked to habitat reduction, contribute significantly to eliminate their populations. Therefore, the conservation of the vegetation in local and regional scales is important, cause the loss of vegetal cover can intensify the factors that lead to decline.

\subsection{Introdução}

Os táxons não possuem padrões de distribuição espacial constantes em uma ampla escala de tempo (Gaston, 1996). As espécies sofrem mudanças na distribuição de suas populações, que podem estar estáveis, em crescimento, em declínio ou rumo à extinção (Gaston, 1996). Essa distribuição espacial das espécies é influenciada por vários fatores como disponibilidade de hábitat, habilidade para dispersão e estabelecimento, presença de competidores, predadores e parasitas, tolerância climática e/ou ambiental e considerações históricas (Gaston, 1996). 
Dentro da distribuição geográfica de uma espécie suas margens tendem a ser mais susceptíveis à extinção, pois as populações tendem a ser maiores e menos variáveis no centro de sua área de distribuição geográfica e mais fragmentadas e reduzidas em suas bordas (Brown, 1995; Brown et al.., 1995 e Gaston, 1996). No centro da distribuição geográfica, as espécies geralmente estão no ótimo de seus nichos, enquanto nas bordas, as populações são ecologicamente marginais, com os requerimentos de habitas estreitos (Brooks, 2000). Além disso, as populações da periferia tendem a receber menos migrantes devido às características de hábitat que estão longe de serem ideais (Brown et al.., 1995 e Gaston, 1996), além da maior distância e da baixa densidade de ocorrência de populações vizinhas (Wilson et al., 2002).

O maracanã-verdadeiro (Primolius maracana) é um psitacídeo neotropical que tem uma ampla extensão de ocorrência histórica que abrange quase todo o Brasil, além do norte da Argentina e leste do Paraguai. A espécie tem alta mobilidade e é aparentemente generalista em escala local, na qual utiliza diferentes tipos de hábitats, incluindo áreas mais degradadas e antropizadas (ver Capítulo 5), e em escala mais ampla, onde está distribuída por diferentes tipos de vegetação e biomas brasileiros (ver Capítulo 3). Embora o maracanã apresente essas características, ele está considerado vulnerável à extinção (Birdlife International, 2000), já que nas últimas décadas sua abundância e distribuição têm diminuído rapidamente, principalmente na margem sul de sua área de ocorrência histórica.

O maracanã atualmente é considerado provavelmente extinto na Argentina (La Penã, 1998) e muito raro no Paraguai (López, 1992 e Lowen et al., 1996). No Brasil, não há registros do maracanã no Estado do Rio Grande do Sul deste 1930 (Belton, 1994), não existem dados atuais para Santa Catarina (Rosário, 1996) e suas populações são muito raras nos Estados do Paraná e de São Paulo (Bornschein \& Staube, 1991 e Nunes, 2000).

A contração da distribuição do maracanã tem sido generalizadamente atribuída à redução do hábitat pela fragmentação (Birdlife International, 2000), porém não há estudos que suportam essa hipótese. Pouco se conhece sobre a dinâmica espacial da extensão de ocorrência das espécies e como os fatores que levam à extinção interagem 
com as populações e suas características demográficas (Channell \& Lomolino, 2000a, b).

O processo de fragmentação implica em perda de hábitat, diminuição do tamanho da área originalmente contínua, na redução da conectividade da paisagem, além do surgimento de um novo tipo de hábitat entre os fragmentos (Wiens, 1997). As espécies de aves respondem diferentemente à fragmentação do hábitat dependendo de sua habilidade em utilizar e persistir nos remanescentes e seu entorno. Essa tolerância está ligada ao grau de fragmentação da paisagem, sendo que diferentes espécies podem ter distintos limiares para sua persistência (Price et al., 1999).

No caso do maracanã, como também de outros psitacídeos, conhece-se pouco os efeitos da associados a fragmentação florestal, em um ampla escala geográfica. Dessa maneira, procurou-se avaliar se a probabilidade de encontro de populações de maracanãs na região sul de sua distribuição está associada a características da composição e estrutura atual das paisagens. Os resultados podem sugerir se características da cobertura vegetal remanescente estão relacionadas com a persistência ou extinção da espécie. Um melhor entendimento sobre possíveis fatores responsáveis pela contração na distribuição é importante para o desenvolvimento de estratégias para conservação e basear tomada de decisões relativas ao manejo e reintroduções.

\subsection{Métodos}

\subsubsection{Descrição da espécie}

O maracanã-verdadeiro, Primolius [Ara] maracana (Vieillot), é um psitacídeo de médio porte que mede entre 36 e $43 \mathrm{~cm}$ e pesa entre 243 e 266 g. Sua coloração é basicamente verde, mas tem a cauda de cor azul na parte superior e ferrugínea na base, além de sinais vermelhos no dorso e no ventre. Possui a face nua, de cor amarela pálida e ao redor dos olhos branca, que contrasta com a cabeça azulada, fronte vermelha e bico negro (Del Hoyo et al., 1997; Juniper \& Parr, 1998 e Sick, 1997) (Figura 4.1). 


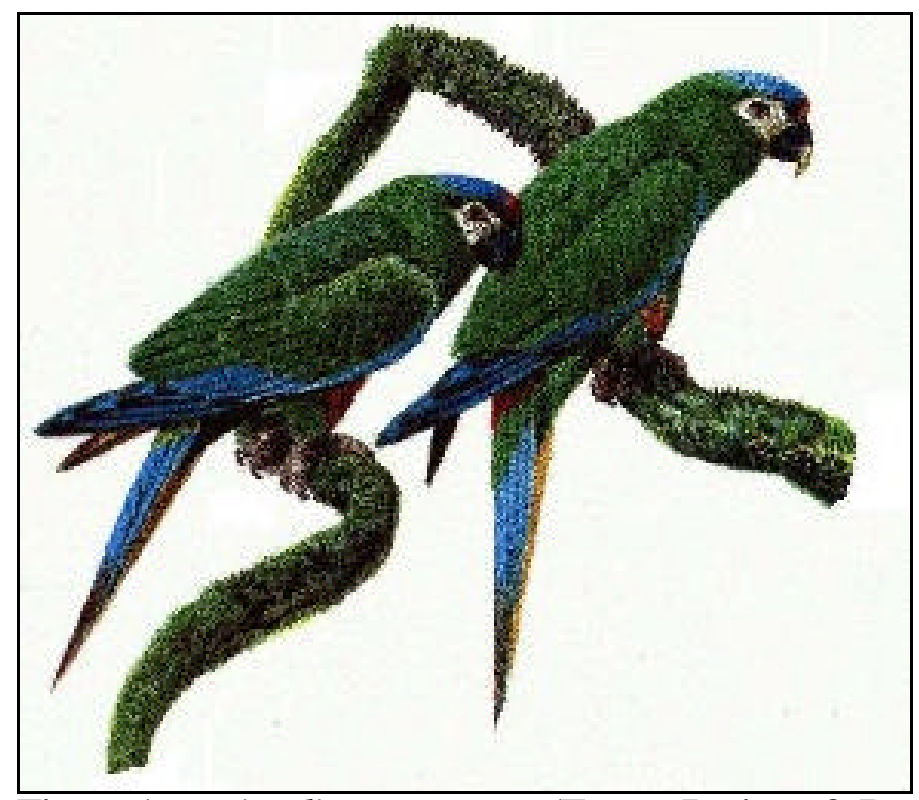

Figura 1 - Primolius maracana (Fonte: Juniper \& Parr, 1998)

A espécie está presente em diversos tipos de vegetação brasileira como Caatinga, Cerrado, Florestas Ombrófilas e Estacionais Semidecíduas e Decíduas (ver capítulo 2), habitando principalmente bordas de matas e locais próximos a rios (Juniper \& Parr, 1998). Sua ocorrência histórica abrange 19 estados brasileiros, nas regiões Sul, Sudeste, Centro-oeste, Nordeste e sudoeste da Amazônia, além do leste do Paraguai e nordeste da Argentina (ver capítulo 2). Entretanto, a espécie tem sofrido uma contração ao sul de sua distribuição geográfica, estando provavelmente extinta na Argentina (López, 1992) e extremo sul do Brasil (Belton, 1994 e Rosário, 1996) e tornando-se muito rara no Paraguai (Clay et al., 1998) e centro-sul do Brasil (Bornschein \& Straube, 1991 e Nunes, 2000).

Apesar do maracanã ser amplamente distribuído e ser considerado vulnerável à extinção pouco se conhece sobre ecologia e aspectos da biologia da espécie, salvo informações pontuais sobre sua dieta e locais de nidificação (Carvalho \& Carvalho, 1992 e Nunes, 2000). 


\subsection{2 Área de estudos, coleta de dados e análise}

Procurou-se examinar se o padrão de ocorrência atual do maracanã, ao sul de sua distribuição geográfica histórica, é afetado pela variação da composição e estrutura da vegetação remanescente. Foi verificada a presença ou ausência atual do maracanã em localidades onde a espécie já tenha sido previamente registrada, dentro do Domínio Mata Atlântica (Florestas Ombrófilas, Florestas Semidecíduas, Restingas e outros tipos de Vegetação Costeira) dos Estados do Rio Grande do Sul, Santa Catarina, Paraná, São Paulo, Rio de Janeiro, Espírito Santo e Minas Gerais. A ocorrência do maracanã em região de Cerrado, dos Estados do Paraná, São Paulo e Minas Gerais, não foi examinada, por não haver mapas disponíveis sobre sua vegetação remanescente.

Os locais onde o maracanã atualmente está ausente, mas que não há registros prévios de ocorrência da espécie, não foram incluídos nas análises, no intuito de eliminar fontes maiores de variação, como fatores históricos-biogeográficos. Além disso, as localidades com prévia ocorrência do maracanã tendem a ser áreas potenciais para a presença atual da espécie, em um contexto de nicho ecológico em macroescala (ver

Peterson, 2001). Isso porque muitas características nessa escala, como clima, relevo e outras, são pouco ou nada variáveis na escala de 100 anos. A principal mudança ambiental ocorrida nessas áreas, durante o último século, está relacionada a alterações no uso e cobertura do solo e é isso que pode ter influenciado nos padrões de ocorrência atual da espécie.

O fator responsável pela extinção de Primolius maracana não foi diretamente investigado devido a limitações dos dados utilizados. A extinção do maracanã em diferentes localidades é integrada ao longo do tempo, enquanto os dados disponíveis para a análise são referentes a informações atuais de presença ou ausência da espécie e cobertura vegetal das áreas. O ideal seria que para cada localidade fossem obtidos dados referentes à época em que a espécie tenha se extinguido e a configuração da paisagem desse período. Porém não existem dados temporais disponíveis sobre a ocorrência da espécie, bem como sobre a cobertura vegetal. 
As características de composição e estrutura das paisagens na ocasião das diferentes extinções locais possivelmente sofreram alterações, em relação às características atuais dessas áreas. Todavia, se existir algum limiar relacionado a uma característica da paisagem que condicione a extinção do maracanã no limite sul de sua ocorrência, serão encontradas muitas áreas com ausência atual da espécie que ainda apresentam esse limiar de paisagem ultrapassado. Isso porque é pouco provável que nesses locais tenham ocorrido acréscimos significantes na cobertura vegetal, mas sim decréscimos (S.O.S. Mata Atlântica \& INPE, 1998). Dessa maneira, os padrões atuais de ocorrência do maracanã, em paisagens onde a espécie já tenha sido registrada, podem sugerir se existe relação entre a fragmentação e a extinção da espécie na parte sul de sua ocorrência.

O estatus sobre a presença ou ausência do maracanã para cada localidade foi inferido a partir de dados de levantamentos de avifauna realizados entre os anos de 1984 a 2002. Essas informações foram obtidas através de literatura ou diretamente com ornitólogos de atuação no Brasil. Foram também realizadas expedições em algumas áreas de sua ocorrência histórica no Estado de São Paulo, para obter informações sobre áreas não contempladas em recentes levantamentos de avifauna. As localidades de registros históricos, para as quais não se encontraram informações sobre a composição da avifauna atual, não foram incluídas nas análises.

Os dados de ocorrência coletados entre os anos de 1984 e 1993 foram relacionados a um mapeamento da vegetação do ano de 1990 e os dados coletados entre 1994 e 2002 foram relacionados a um mapeamento da vegetação do ano de 1995 (S.O.S. Mata Atlântica \& INPE, 1998). Dessa forma pode-se trabalhar com um conjunto grande de dados, referente a um intervalo de 16 anos, diminuindo o viés relativo a mudanças na cobertura vegetal ou no estatus da espécie ao longo do anos. É razoável assumir que a informação da configuração de uma paisagem em um ponto no tempo fornece uma forte base para predições sobre relações entre espécies e paisagens em um período logo anterior ou subseqüente (Boulinier et al., 2001).

Os dados de presença ou ausência do maracanã foram relacionados com a configuração espacial da vegetação atual de Mata Atlântica das áreas de registros. As 
paisagens analisadas foram delimitadas em um raio $20 \mathrm{~km}$ de entorno do ponto central da localidade inventariada. Em casos de sobreposição de áreas de influência devido a registros vizinhos, sorteou-se uma área a fim de obter independência das amostras. $\mathrm{O}$ tamanho dessa região de influência foi baseado em estudo sobre Primolius maracana em escala local, onde se verificou que a espécie tem uma ampla área de uso, utilizando fragmentos florestais em uma superfície de pelo menos 21 quilômetros de raio (ver Capítulo 5). Além disso, já foi verificado que frugívoros com alta mobilidade podem ser influenciados por uma cobertura florestal em até 50 quilômetros de raio (Price et al., 1999).

Os mapas de cobertura vegetal na escala 1:250.000 dos anos de 1990 e 1995 (Fundação S.O.S. Mata Atlântica \& INPE, 1998) foram utilizados como base para os cálculos dos índices e métricas das paisagens, realizados nos softwares ArcView 3.2, sua extensão Spatial Analist 1.1 e Fragstats 3.2. As variáveis calculadas foram o total de cobertura vegetal (TCV), densidade de fragmentos (DF), tamanho médio dos fragmentos (TMF), porcentagem de ocupação do maior remanescente (POMR), média dos índices de forma dos fragmentos de uma paisagem (MIFF) e a média dos índices de isolamento da paisagem (MIIP) (Tabela 4.1).

Tabela 1. Índices de paisagens empregados

\begin{tabular}{|c|c|c|c|c|}
\hline Indices & Fórmula & Descrição & Unidade & Variação \\
\hline $\begin{array}{l}\text { Média dos } \\
\text { Índices de forma } \\
\text { dos fragmentos } \\
\text { em uma } \\
\text { paisagem* }{ }^{1}\end{array}$ & $\begin{array}{l}\mathrm{MIFF}=\frac{\sum(\mathrm{IFF})}{\mathrm{N}} \\
\mathrm{IFF}=\mathrm{P} / \mathrm{Pmin}\end{array}$ & $\begin{array}{l}\mathrm{IFF}=\text { índice de forma do } \\
\text { fragmento } \\
\mathrm{P}=\text { perímetro de um } \\
\text { fragmento } \\
\text { Pmin= perímetro mínimo que } \\
\mathrm{o} \text { fragmento poderia ter } \\
\text { com a mesma área de } \\
\text { cobertura }\end{array}$ & adimensional & $\begin{array}{l}1-\text { sem } \\
\text { limite }\end{array}$ \\
\hline $\begin{array}{lr}\text { Média } & \text { dos } \\
\text { índices } & \text { de } \\
\text { isolamento } & \text { da } \\
\text { paisagem* }^{2} & \end{array}$ & $\mathrm{MVPF}=\frac{\sum(\mathrm{VPF})}{\mathrm{N}}$ & $\begin{array}{l}\mathrm{VPF}=\text { distância até o } \\
\text { fragmento vizinho mais } \\
\text { próximo de cada } \\
\text { fragmento da paisagem } \\
\mathrm{N}=\text { número de fragmentos }\end{array}$ & metros & $\begin{array}{l}0-\text { sem } \\
\text { limite }\end{array}$ \\
\hline
\end{tabular}


Foram calculados os índices e métricas de paisagem para cada uma dessas localidades de presença ou ausência do maracanã. Essas variáveis foram testadas quanto à normalidade e homogeneidade de variância e, quando necessário, foram realizadas transformações. Foi utilizada a análise de Correlação de Pearson com 9999 permutações com R Package (Casgrain \& Legendre, 2001), para examinar possíveis correlações entre as variáveis explanatórias, e o Modelo de Regressão Logística, para quantificar relações entre essas variáveis e o estatus de Primolius maracana.

A Regressão logística modela a mudança na probabilidade de ocorrência de uma variável binária, como presença e ausência, em função linear de variáveis explanatórias. O odds ratio é a medida de associação da regressão logística que pode ser usada para expressar a chance de ocorrência de um fator (presença do maracanã) em função do aumento linear das variáveis explanatórias nas suas unidades de medidas (Hosmer \& Lemeshow, 1989).

\subsection{Resultados}

Foram reunidas informações de 54 localidades sobre o estatus atual (desde 1984) de Primolius maracana (Figura 4.2), através de dados da literatura, de informações sobre levantamentos de aves não publicados e obtidas diretamente com ornitólogos atuantes no Brasil (ver APÊNDICE 3) e inventários realizados no campo (ver APÊNDICE 4). 


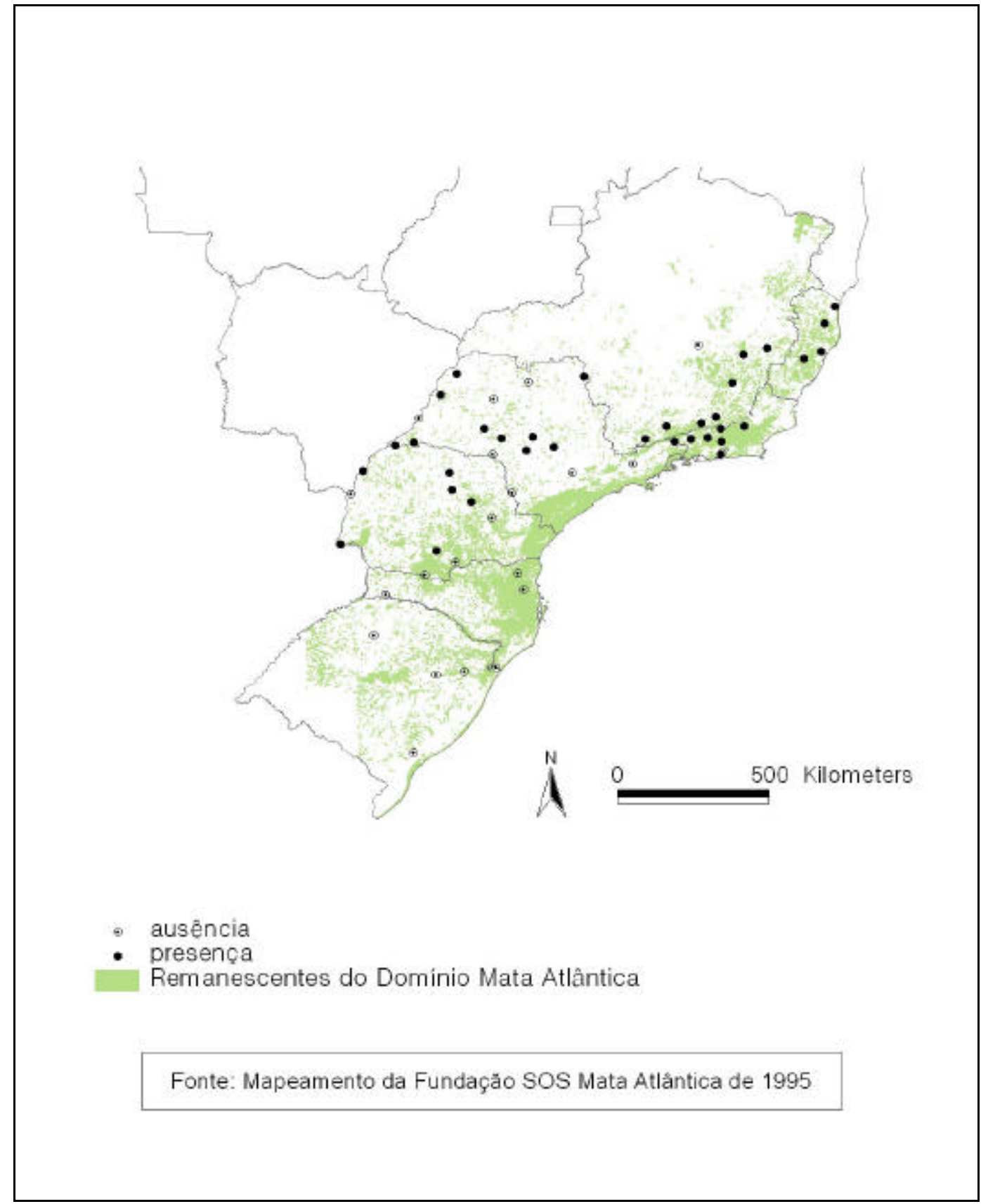

Figura 2 - Estatus atual (considerado a partir de 1980) de Primolius maracana nas localidades de Domínio Mata Atlântica no sul e sudeste do Brasil 
Os índices de paisagem foram calculados, sendo que algumas dessas variáveis explanatórias foram utilizadas em escala transformada, a fim de seguir corretamente as premissas das análises paramétricas de correlação de Pearson e Regressão Logística: logaritmo natural da área total de cobertura vegetal da paisagem, arcosseno da raiz quadrada da densidade de fragmentos, arcosseno da raiz quadrada do tamanho médio dos fragmentos da paisagem e logaritmo natural da média do isolamento dos fragmentos da paisagem As variáveis "porcentagem de ocupação do maior remanescente da paisagem" e o "índice de forma médio da paisagem" não requereram transformações.

Analisaram-se as correlações entre todas as variáveis explanatórias referentes a características das paisagens e também entre sua latitude, já que existe uma clara clina latitudinal na ocorrência do maracanã (Tabela 4.2). Apesar de cada índice e métrica calculados medirem aspectos particulares da paisagem eles foram altamente correlacionados o que pode trazer problemas de multicolinearide em modelos múltiplos. A área total de cobertura vegetal da paisagem foi a variável que mais apresentou informações redundantes com as outras variáveis explanatórias. Nenhuma das variáveis de paisagem foram significativamente correlatadas com latitude.

Tabela 2. Coeficientes e probabilidades da correlação de Pearson com 9999 permutações entre as características de paisagem e latitude dos locais de presença ou ausência de Primolius maracana.

\begin{tabular}{llllllll}
\hline & Latitude & $\ln (\mathrm{TCV})$ & $\operatorname{arq}(\mathrm{DF})$ & $\ln (\mathrm{MVPP})$ & $\operatorname{arq(TMF)}$ & POMR & MIFF \\
\hline Latitude & 1 & 0,008 & 0,109 & $-0,206$ & $-0,051$ & $-0,064$ & 0,109 \\
$\ln (\mathrm{TCV})$ & 0,008 & 1 & $0,758 * * *$ & $-0,567 * * *$ & $0,644 * * *$ & $0,622 * * *$ & $0,391 * * *$ \\
$\operatorname{arq}(\mathrm{DF})$ & 0,109 & $0,758 * * *$ & 1 & $-0,563 * * *$ & 0,028 & 0,121 & $0,339 *$ \\
$\ln (\mathrm{MVPP})$ & $-0,206$ & $-0,567 * * *$ & $-0,563 * * *$ & 1 & $-0,139$ & $-0,172$ & $-0,080$ \\
$\operatorname{arq}(\mathrm{TMF})$ & $-0,051$ & $0,644 * * *$ & 0,028 & $-0,139$ & 1 & $0,831 * * *$ & $0,351 * * *$ \\
POMR & $-0,064$ & $0,622 * * *$ & 0,121 & $-0,172$ & $0,831 * * *$ & 1 & 0,170 \\
MIF & 0,109 & $0,391 * * *$ & $0,339 *$ & $-0,080$ & $0,351 * * *$ & 0,170 & 1 \\
\hline
\end{tabular}

Notas: Abreviações: $\operatorname{Ln}(\mathrm{TCV})=$ logaritmo natural do total de cobertura vegetal da paisagem, $\operatorname{arq}(\mathrm{DF})=$ arcosseno da raiz quadrada da densidade de fragmentos, MVPP = logaritmo natural da média dos índices de isolamento da paisagem, arq(MTF) = arcosseno da raiz quadrada do tamanho médio dos fragmentos da paisagem, POMR= porcentagem de ocupação do maior fragmento da paisagem e MIFF= média dos índices de forma dos fragmentos dentro da paisagem.

$* \mathrm{p}<0,05 ; * * \mathrm{p}<0,01 ; * * * \mathrm{p}<0,001$ 
Devido à alta correlação entre a maioria das variáveis explanatórias, foram realizadas regressões logísticas simples para cada variável separadamente. A única variável que caracteriza paisagens relacionada significativamente com a ocorrência do maracanã foi o logaritmo natural da área total de cobertura vegetal da paisagem $(p<0,05)$ porém o valor de $R^{2}$ (coeficiente de correlação) da regressão foi muito baixo $\left(R^{2}=0,07\right)$. A latitude também foi significativa mente relacionada com a presença/ausência do maracanã $(p<0,001)$ e apresentou um valor $R^{2}$ de 0,27 .

Foi então ajustado um modelo múltiplo com as duas variáveis, o logaritmo natural da área total de cobertura vegetal da paisagem e a latitude. $O$ modelo foi altamente significativo ( $p<0,001$ ), seu valor de $R^{2}$ foi mais alto que os modelos simples e ambas as variáveis foram significatvas no modelo (Tabelas 4.3 e 4.4).

Tabelas 3. Teste do modelo de Regressão Logística Nominal ajustado para ocorrência do maracanã.

\begin{tabular}{llllll}
\hline Modelo (54 observações) & -LogLikelihood & gl & Chiquadrado & Prob>Chiquadrado & R2 \\
\hline diferença & 15,725864 & 2 & 31,45173 & $<, 0001$ & 0,4418 \\
completo & 19,868371 & & & & \\
reduzido & 35,594235 & & & & \\
& & & & & \\
\hline
\end{tabular}

Tabelas 4. Estimativas dos parâmetros do modelo de Regressão Logística Nominal ajustado para ocorrência do maracanã.

\begin{tabular}{llllll}
\hline Termo & Estimativa & Erro Padrão & Chiquadrado & Prob>Chiquadrado & Odds Ratio \\
\hline Intercepto & $-14,048796$ & 5,2049093 & 7,29 & 0,007 & 0,00000079 \\
$\ln (\mathrm{CV})$ & $-1,0968214$ & 0,3942969 & 7,74 & 0,0054 & 0,0013301 \\
latitude & 0,97153947 & 0,3033201 & 10,26 & 0,0014 & 405835,265 \\
\hline
\end{tabular}

\subsection{Discussão}

\subsubsection{As métricas utilizadas}

Diferentes aspectos da paisagem, como composição, estrutura espacial e configuração, podem ser representados através de métricas que variam de simples 
cálculos geométricos até índices com distintos graus de complexidade. Muitas métricas podem ser altamente correlacionadas, pois quantificam o mesmo aspecto de uma paisagem, mas de maneira distinta (Mcgarigal \& Marks, 1995). Porém, algumas métricas também podem estar representando diferentes aspectos da paisagem e serem empiricamente redundantes (Boulinier et al., 2001 e McGarigal \& Marks, 1995).

O total de cobertura vegetal da paisagem, a média do tamanhos de seus fragmentos e a porcentagem de ocupação do maior fragmento da paisagem representam características particulares das paisagens, mas que foram altamente correlacionadas entre as localidades amostradas. Isso porque locais com muita cobertura vegetal possivelmente apresentarão remanescentes de grande extensão e o tamanho do maior fragmento influenciará na média dos fragmentos da paisagem. Apesar dessas métricas serem correlacionas, se o padrão de ocorrência de uma espécie for mais fortemente relacionado à uma maior porcentagem de ocupação do maior fragmento da paisagem, sugere-se que as populações se mantêm especialmente em paisagens que mantém fragmentos dominantes com grande extensão (sistema mainland) (Wilson et al., 2002). No caso de Primolius maracana, ela foi significativamente correlacionada apenas com o total de cobertura vegetal, o que indica que a rede de fragmentos dentro da paisagem é importante para a manutenção da espécie.

As variáveis, total de cobertura vegetal, densidade de fragmentos e a média dos valores de vizinho mais próximo de cada fragmento em uma paisagem, também foram altamente correlacionadas. Isso porque mantendo constante o tamanho da paisagem analisada, se a cobertura vegetal aumentar, a distância média entre os remanescentes tende a diminuir. Essa relação geral também se repete com densidade de fragmentos, que quanto mais alta, diminui-se a distância entre remanescentes vizinhos.

No entanto, a relação entre a área total de cobertura vegetal e a densidade de fragmentos não é linear em diferentes graus de fragmentação (Tischendorf, 2001). No início do processo de fragmentação existem poucos fragmentos em uma paisagem, mas que possuem grande extensão. Conforme se intensifica o processo de perda de cobertura vegetal, as áreas começam a ser divididas e o número de fragmentos aumenta. Porém quando a diminuição da cobertura vegetal é muito intensa, o número de fragmentos volta 
a declinar. Quando se trabalha com áreas com um alto grau de fragmentação o problema da não-linearidade diminui, pois em tal intervalo a relação é aproximadamente linear e as variáveis diretamente relacionadas. Entre as 54 paisagens analisadas, aproximadamente $95 \%$ delas possuem menos de $30 \%$ de ocupação de cobertura vegetal remanescente, e apenas Sooretama, Petrópolis e Blumenau possuem entre 31\% a 45\% de ocupação.

A relação entre a média dos índices de forma dos fragmentos de uma paisagem e as métricas relativas ao tamanho dos remanescentes não é de fácil interpretação. Teoricamente o índice mede a complexidade da forma de um fragmento, comparando-o com uma forma padrão (quadrada) e, dessa maneira, não deve variar conforme o tamanho dos fragmentos (McGarigal \& Marks, 1995).

Devido aos problemas de autocorrelação das métricas e a não linearidade de alguns padrões em diferentes graus de cobertura vegetal, deve-se ter cautela no uso das métricas em análises estatísticas (McGarigal \& Marks, 1995), principalmente as multivariadas afetadas pela não-ortogonalidade dos parâmetros. A área total de cobertura vegetal, por ser altamente correlacionada com todas as outras métricas, parece ser a base dos padrões relacionados àfragmentação do hábitat.

\subsubsection{Padrões de ocorrência atual do maracanã}

Entre as métricas analisadas, a área de cobertura vegetal foi a única preditora significativa da ocorrência de Primolius maracana. Entretanto, o poder explicativo da variável foi muito baixo, mesmo levando-se em conta que estudos no campo da macroecologia geralmente apresentam correlações fracas (Blackburn \& Gaston, 1998) e que os valores de $\mathrm{R}^{2}$ da regressão logística são comparativamente mais baixos que os valores $R^{2}$ da regressão linear, com valores de 0,20 a 0,30 já considerados satisfatórios (Hensher \& Johnson, 1981). Contudo, o modelo contendo as variáveis "a área de cobertura vegetal" e "latitude" foi altamente significativo, sendo que as duas variáveis foram importantes para o modelo e seu poder explicativo foi relativamente alto. Mesmo 
assim, o valor de relação, em "odds", entre a ocorrência do maracanã e o logaritmo natural da cobertura vegetal se mantém baixo.

A forte relação entre a ocorrência atual do maracanã e a latitude pode estar vinculada a um fator responsável pela extinção da espécie através de uma correlação espúria. A latitude é apenas uma coordenada geográfica que não afeta diretamente a ocorrência de espécies, porém outra variável com estrutura espacial altamente relacionada com latitude está diretamente afetando, ou afetou, as populações meridionais de Primolius maracana. Considerando que as populações marginais tendem a ser mais reduzidas e estar no limite de seus requerimentos de hábitat (Brooks, 2000), fatores que afetam as espécie nessa áreas podem ter reflexos mais drásticos. Devido a esse fator responsável pela extinção, algumas áreas que possuem uma paisagem propícia para a ocorrência do maracanã podem estar vacantes.

Chanell \& Lamolino (2000 a b) elaboraram uma hipótese sobre a dinâmica da contração na distribuição geográfica das espécies, baseada em um estudo da trajetória da contração de 309 espécies de fauna remanescentes. Ela assume que os fatores que levam a grandes contrações na distribuição das espécies, ou até à extinção, não são uniformemente distribuídos, mas que se distribuem pela paisagem como um contágio. Esse fator direcional tende a afetar primeiramente populações de alguma borda da distribuição, devido à sua vulnerabilidade (Brooks, 2000 e Wilson et al., 2002), e as áreas mais distantes dessa região serão aquelas que manterão populações remanescentes.

A contração na distribuição do maracanã podem também ser reflexo de um fator direcional de sul para norte que afeta, ou afetou, populações da espécie. Esse fator parece não estar diretamente vinculado à fragmentação do hábitat, já que a cobertura vegetal e outros aspectos das paisagens não foram significativamente correlacionados com a latitude. Porém, a combinação desses fatores em um modelo múltiplo, aumentou o poder de explicação dos padrões atuais de ocorrência do maracanã. O fator direcional pode levar ao declínio a distribuição e abundância da espécie até o ponto onde efeitos associados à fragmentação de hábitat contribuem significativamente para eliminá-las.

Embora a latitude e a área de cobertura vegetal expliquem significativamente os padrões de abundância do maracanã, existe uma porcentagem de variabilidade não 
explicada por essas variáveis. Isso porque as localidades individuais estão sujeitas a muitas influências não mensuradas, como super exploração da espécie, introduções de espécies exóticas, estocasticidade demográfica e ambiental, depressão genética e fatores históricos (Gaston, 1996 e Wiens, 1989). Além disso, a variabilidade pode ser aumentada devido aos efeitos da imigração de indivíduos em paisagens que não apresentam características favoráveis à manutenção da espécie, porém que estão próximas a áreas que mantém populações produtivas e são fontes de migrantes (Thomson et al., 1996).

As razões para a contração na distribuição do maracanã permanecem pouco entendidas, apesar de ter sido verificado que a perda de cobertura vegetal pode intensificar os fatores que levam ao declínio. $\mathrm{O}$ fator de contágio que afeta ou afetou a ocorrência do maracanã pode estar relacionado a outros distúrbios além da perda de hábitat, como mudanças climáticas, efeitos de biocidas, introdução de espécies ou patógenos, e outros (Chanell \& Lamolino, 2000b). A razão de declínio pode também ser uma soma de fatores que afetam as populações marginais e que resulta em uma reação em cadeia, pois extinções locais aumentam a distância entre as populações vizinhas e conseqüentemente afetam a dinâmica de migração dos indivíduos.

O conceito de metapopulação é insuficiente para incluir espécies muito móveis com dinâmicas populacionais em larga escala, como alguns psitacídeos (Nally \& Horrocks, 2000). Isso porque os movimentos da espécie dentro de uma paisagem não estão relacionados com a dinâmica de migração e de recolonização de áreas onde ocorreram extinções locais (Hanski, 1994), mas sim com a utilização de diferentes hábitats dentro da área de uso da espécie (ver Capítulo 2). Entretanto, é provável que uma dinâmica similar à de metapopulação opere em uma escala mais ampla, existindo paisagens que não são capazes de sustentar populações de uma espécie, mas que são ocupadas devido a imigração de indivíduos provindos de outras populações vizinhas mais produtivas (Wilson et al., 2002). Dessa forma a persistência regional do maracanã também pode depender da ocupação contínua de populações maiores e persistentes. 


\subsubsection{Implicações e recomendações para conservação}

Muitas características da biologia e história natural das espécies podem trazer informações sobre a vulnerabilidade à extinção (Purvis et al., 2000). Uma ampla distribuição geográfica é a principal característica inversamente relacionada ao risco de extinção total de uma espécie (Purvis et al., 200). Primolius maracana possui uma distribuição muito ampla, o que faz supor que a espécie esteja imune a tal fatalidade em um futuro próximo. No entanto, é importante que a conservação da espécie não seja negligenciada, pois observações de declínios parciais na distribuição podem ser indícios de reduções muito mais severas no futuro (Chanell \& Lamolino, 2000b e Rodriguez, 2002).

Chanell \&Lamolino (2000) sugerem que as áreas finais a serem atingidas pela contração em contágio devam ser os principais alvos para estratégias de conservação, porém já foi também proposto que os esforços sejam direcionados para os locais afetados no início da contração, no intuito de prevenir o declínio (Rodriguez, 2002). No caso de Primolius maracana recomenda-se que se priorize conservar as maiores populações dos Estados de São Paulo e Paraná, que estão no limite meridional de ocupação atual da espécie, já que se essas populações núcleo forem perdidas ou entrarem em declínio, é possível que ocorra mais uma contração ampla e abrupta na distribuição da espécie.

Alguns autores também sugerem que o tamanho e a forma da área de distribuição de uma espécie oscilam durante o tempo, ocorrendo extinções locais e recolonização (Gaston, 1996). Dados históricos mostram que o maracanã já passou por processo de recolonização no Estado do Rio de Janeiro, a partir da década de 80, e atualmente a espécie é considerada muito comum nessas localidades (Pacheco et al., 1994). Dessa forma, é importante que se concentre na conservação da vegetação em macroescala, já que paisagens próximas a locais de ocorrência do maracanã, que eventualmente recebam imigrantes, são potenciais para serem efetivamente ocupadas pelo maracanã, mas isso pode depender das condições (composição e estrutura) do hábitat. 


\subsection{Conclusões}

1. O total de cobertura vegetal de uma paisagem, pode ser a melhor representação dos padrões relacionados à fragmentação do hábitat e foi a única característica de paisagem significativamente relacionada com a ausência atual do maracanã ao sul de sua ocorrência original; entretanto seu poder explicativo foi muito baixo.

2. O padrão atual de ocorrência do maracanã ao sul de sua distribuição está altamente relacionado com a variação latitudinal, que por sua vez não está relacionado com nenhuma das métricas de paisagem analisadas. Isso sugere a existência de um fator, com estrutura espacial em clina latitudinal, que está diretamente afetando, ou afetou, as populações meridionais do maracanã. Esse fator não está diretamente vinculado à fragmentação do hábitat. Dessa forma, as razões para a contração na distribuição do maracanã permanecem pouco entendidas. 


\section{PREFERÊNCIA DE HÁBITAT E FATORES QUE INFLUENCIAM NA PERSISTÊNCIA DAS POPULAÇÕES REMANESCENTES DO MARACANÃ- VERDADEIRO PRIMOLIUS MARACANA EM ESCALA LOCAL}

\section{Resumo}

O Maracanã- verdadeiro Primolius maracana é uma espécie de psitacídeo considerada vulnerável a extinção, por estar havendo redução na distribuição e abundância de suas populações em diferentes partes de sua área de ocorrência. No Estado de São Paulo o maracanã se distribuía amplamente em Florestas Estacionais Semidecíduas do interior paulista, porém atualmente está restrito a poucas localidades. A Estação Ecológica dos Caetetus (2800 ha) mantém a maior população de maracanã do Estado de São Paulo e está imersa em um mosaico de paisagem, constituído por pequenos remanescentes de vegetação nativa que também podem ter um relevante papel na manutenção da espécie. Examinou-se o uso desses remanescentes satélites pelo maracanã, no entorno de $25 \mathrm{~km}$ de raio da E.E. dos Caetetus. Foram selecionadas aleatoriamente 36 dessas áreas e amostrou-se a quantidade de visitas por maracanãs através do método de contagens em pontos estratégicos. Cada fragmento obteve um "índice de visitas de maracanãs" que foram relacionados a características espaciais dos fragmentos e sua paisagem do entorno, através do cálculo de suas métricas e da análise de regressão linear. A espécie foi registrada em $70 \% \quad(n=29)$ das áreas amostradas, porém a frequiência de visitas variou entre os fragmentos. $O$ "índice de visitas de maracanãs" foi diretamente relacionado com a "distância mínima do fragmento até a cidade mais próxima" $(p<0,05)$ e o "tamanho do remanescente" $(p<0,05)$, e inversamente relacionado a "distância mínima do fragmento até um dormitório 
conhecido de maracanã" ( $\mathrm{p}<0,01)$. A "distância mínima do fragmento até a E.E. dos Caetetus" também foi inversamente relacionada à frequiência de visitas $(p<0,05)$, mas apenas em um modelo de regressão simples. De maneira geral, as características de paisagem no entorno dos fragmentos explicaram mais a variação da freqüência de visitas pelo maracanã que as características dos fragmentos em si, o que sugerem a importância do mosaico de vegetação para a manutenção da espécie na região de E. E. dos Ceteteus. Esses remanescentes podem estar servindo como locais de forrageamento, de pernoite e/ou de nidificação do maracanã, além de funcionar como elementos de conectividade da paisagem, oferecendo abrigo e descanso para as aves durante os deslocamentos. Conseqüentemente, para a conservação da espécie, deve-se incentivar a manutenção do máximo possível de áreas remanescentes nativas em uma paisagem, dando ênfase aos fragmentos de maiores dimensões, próximos aos dormitórios do maracanã e a E. E. dos Ceteteus.

\section{HABITAT PREFERENCES OF BLUE-WINGED MACAW PRIMOLIUS MARACANÃ AND FACTORS AFFECTING THE PERSISTENCE OF ITS REMAINING POPULATIONS IN LOCAL SCALE}

\section{Summary}

The blue-winged macaw Primolius maracana is a vulnerable species of psittacidae, which since the second half part of the last century has been suffering a rapid distribution and population decline, in different parts of its historical range. The blue-winged macaw use to be widely distributed through the Semideciduous Forests of the country side of São Paulo, however nowadays it is restricted $\mathfrak{b}$ few localities. The Caetetus Ecological Station (2800 ha) holds the largest blue-winged macaw populations of São Paulo State and it is placed in a mosaic of landscape, consisting of small remnants of native vegetation that may have some value to the specie's maintenance. The use of these satellites remnants by blue-winged macaw was investigated, in around 
$25 \mathrm{~km}$ of ray from Caetetus. Tirty-six of these areas have been randomly selected to check the frequency of blue-winged macaw's visits, through the method of countings in advantage points. Each remnant got a "blue-winged macaw's visit index" that was related to spatial remnants features and its surrounding landscape, through the linear regression model. The species was recorded in $70 \%(n=29)$ of the sampled areas, however the frequency of visits varied among the remnants. The "index of visits of maracanãs" was directly related to "distance to the closest city" $(\mathrm{p}<0,05)$ and to "remnant size" $(\mathrm{p}<0,05)$, and inversely related to "distance to the closest known roost of blue winged macaw " $(\mathrm{p}<0,01)$. The "shortest distance to the Caetetus Ecological Station" was also inversely related to the frequency of visits $(\mathrm{p}<0,05)$, but only in a simple regression model. In general way, the landscape features around of the fragments explained more the variation of the blue-winged macaw's visit index than the features of the fragments itself, which suggests the importance of landscape mosaic for the bluewinged macaw's maintenance in the Ceteteus region. These remnants can be used by blue winged macaw as feeding sites, nesting or overnight areas, besides working as elements of conectivity of the landscape, offering shelter and rest for the birds during their displacements. Therefore, the maintenance of the maximum remnants of native vegetation in the landscape must be goal to conserve blue-winged macaw, focusing manly in large patches, near the roosts and the Ceteteus reserve.

\subsection{Introdução}

Psitacídeos representam a família de aves com o maior número de espécies ameaçadas de extinção e têm pelo menos $28 \%$ de suas espécies incluídas nas categorias de ameaçadas (Birdlife International, 2000 e Snyder et al., 2000). A situação agrava-se com o aumento de perturbações das áreas que abrigam essas espécies, devido à vulnerabilidade à perda de hábitat. Esse fator tem sido apontado como o principal responsável pelo declínio da maioria das espécies de psitacídeos ameaçadas (Birdlife International, 2000 e Snyder et al., 2000). 
O maracanã-verdadeiro Primolius maracana é um psitacídeo neotropical considerado vulnerável à extinção, por estar havendo redução na distribuição e abundância de suas populações em diferentes partes de sua área de ocorrência (Birdlife International, 2000 e ver capítulo 2). No Estado de São Paulo o maracanã se distribuía amplamente em Florestas Estacionais Semidecíduas do interior paulista, porém atualmente está restrito a poucas localidades (Nunes, 2000). Esse tipo de Floresta foi drasticamente reduzido a $2 \%$ de sua cobertura vegetal original e hoje se apresenta em fragmentos descontínuos de tamanhos e graus de isolamento variáveis, rodeados por campos de culturas agrícolas, pastagens ou centros de habitação humana (Viana \& Tabanez, 1996).

A Estação Ecológica dos Caetetus é um dos maiores emanescentes de Floresta Estacional Semidecídua do Estado de São Paulo (2.178 ha). Essa unidade de conservação representa um importante fragmento de floresta nativa de sua região, por funcionar como refúgio para espécies locais da fauna silvestre (Cullen et al., 2000). Nessa área também se encontra a maior população de maracanã-verdadeiro do Estado, com aproximadamente 150 indivíduos (Nunes, 2000). Apesar da área florestal estar concentrada na Estação Ecológica dos Caetetus, a configuração espacial dos hábitats vizinhos também pode ter um importante papel na manutenção de algumas espécies no local, como o maracanã-verdadeiro.

Por muitos anos a ecologia se baseou na relação espécie-área, que prevê um número maior de espécies em áreas com maiores dimensões (Macarthur \& Wilson, 1963, 1967 e Willis, 1979). Isso porque o tamanho de área geralmente está relacionado com disponibilidade de recursos, níveis de predação, competição e parasitismo, alterações microclimáticas, etc (ver Andrén, 1994). No entanto, nos últimos anos, verificourse que para algumas espécies, não só o tamanho do fragmento é importante, mas também a paisagem do entorno (Boulinier et al., 2001; Graham \& Blake, 2001; Lee et al., 2002 e Wiens, 1997).

Alguns estudos sugerem que grandes frugívoros de copa, entre eles os psitacídeos, tendem a desaparecer em pequenos fragmentos (Aleixo \& Vielliard, 1995 e Willis, 1979), provavelmente pela dependência de grandes fruteiras que ofereçam 
recursos ao longo do ano (Willis, 1979). Contudo outros estudos mostraram a importância de pequenos remanescentes de vegetação nativa e paisagens antropizadas para a manutenção de espécies de psitacídeos, já que muitas delas são capazes de atravessar áreas abertas (Fischer \& Lindenmayer, 2002; Magalhães, 2000; Nally \& Horrocks, 2000 e Nunes, 2000).

Psitacídeos geralmente se deslocam em uma área ampla, o que pode influenciar na conectividade da paisagem para as espécies (Fischer \& Lindenmayer, 2002) e criar oportunidades para seleção de hábitats em mesoescala (Gilardi \& Munn, 1998). Isso é importante, pois o declínio de táxons em hábitats isolados pode ser resultado de sua baixa mobilidade ou da sua relutância em atravessar espaços abertos (Villard \& Taylor, 1994). Todavia essa mobilidade pode variar de acordo com a configuração da paisagem e sua matriz (Fischer \& Lindenmayer, 2002 e Wiens, 1997).

O maracanã já foi muitas vezes observado deslocando-se da Estação Ecológica dos Caetetus para pequenos remanescentes florestais ou áreas agrícolas do entorno (Nunes, 2000). Dessa forma foi examinado o uso dos fragmentos florestais no entorno da Estação Ecológica dos Caetetus por Primolius maracana, a fim de identificar áreaschave para sua conservação e verificar quais as características que podem ser importantes para a escolha desses locais fora da reserva, pela espécie.

\subsection{Métodos}

\subsubsection{Descrição da espécie}

O maracanã-verdadeiro, Primolius [Ara] maracana (Vieillot), é um psitacídeo de médio porte que mede entre 36 e $43 \mathrm{~cm}$ e pesa entre 243 e 266 g. Sua coloração é basicamente verde, mas tem a cauda de cor azul na parte superior e ferrugínea na base, além de sinais vermelhos no dorso e no ventre. Possui a face nua, de cor amarela pálida e ao redor dos olhos branca, que contrasta com a cabeça azulada, fronte vermelha e bico negro (Del Hoyo et al., 1997; Juniper \& Parr, 1998 e Sick, 1997) (Figura 3.1). 


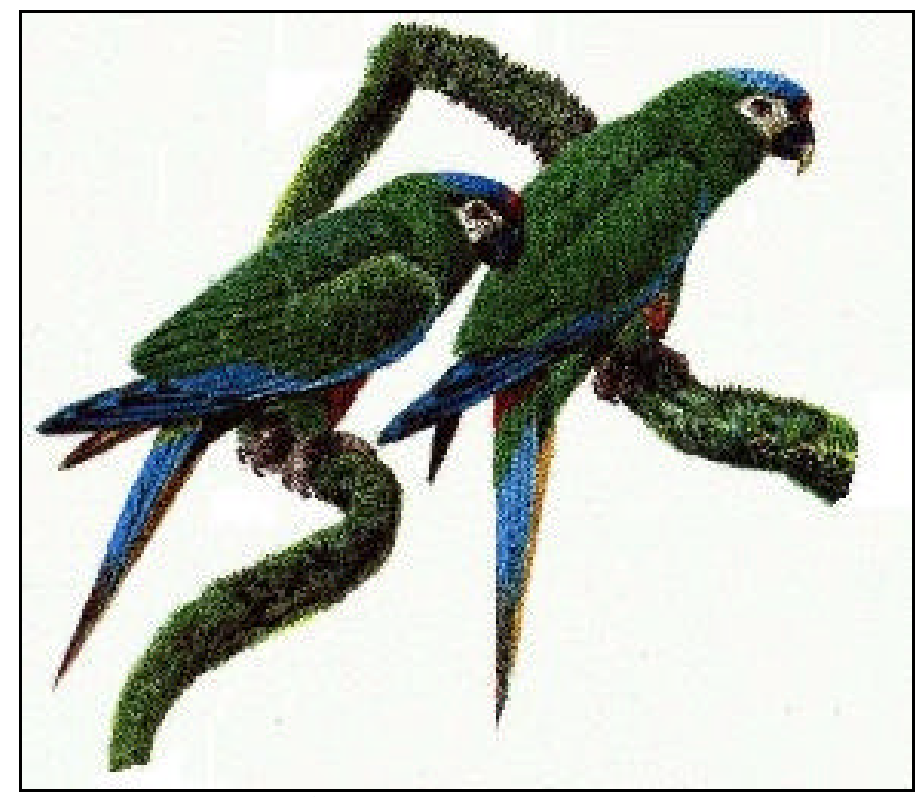

Figura 1 - Primolius maracana (Fonte: Juniper \& Parr, 1998)

A espécie está presente em diversos tipos de vegetação brasileira como Caatinga, Cerrado, Florestas Ombrófilas e Estacionais Semidecíduas e Decíduas (ver capítulo 2), habitando principalmente bordas de matas e locais próximos a rios (Juniper \& Parr, 1998). Sua ocorrência histórica abrange 19 estados brasileiros, nas regiões Sul, Sudeste, Centro-oeste, Nordeste e sudoeste da Amazônia, além do leste do Paraguai e nordeste da Argentina (ver capítulo 2). Entretanto, a espécie tem sofrido uma contração ao sul de sua distribuição geográfica, estando provavelmente extinta na Argentina (López, 1992) e extremo sul do Brasil (Belton, 1994 e Rosário, 1996) e tornando-se muito rara no Paraguai (Clay et al., 1998) e centro-sul do Brasil (Bornschein \& Straube, 1991 e Nunes, 2000).

Apesar do maracanã ser amplamente distribuído e ser considerado vulnerável à extinção pouco se conhece sobre ecologia e aspectos da biologia da espécie, salvo informações pontuais sobre sua dieta e locais de nidificação (Carvalho \& Carvalho, 1992 e Nunes, 2000). 


\subsection{2 Área de estudo}

O estudo foi desenvolvido em fragmentos de vegetação nativa no entorno de 25 km de raio da Estação Ecológica dos Caetetus (Figura 5.2 e 5.3). Essa área está situada na região centro-oeste do Estado de São Paulo e abrange parte dos municípios de Marília, Vera Cruz, Garça, Gália, Alvinlândia, Lupércio, Lucianópolis e Duartina.

Os remanescentes de vegetação nativa da região são constituídos principalmente por florestas do tipo Mesófila Semidecídua, além de áreas de transição para o Cerrado e vegetações secundárias. As florestas Mesófilas Semidecíduas pertencem ao Domínio Mata Atlântica, que é um dos ecossistemas mais ameaçados do mundo (SOS Mata Atlântica \& INPE, 1992) e que abriga nove espécies de psitacídeos em risco de extinção (Galetti et al., 2002).

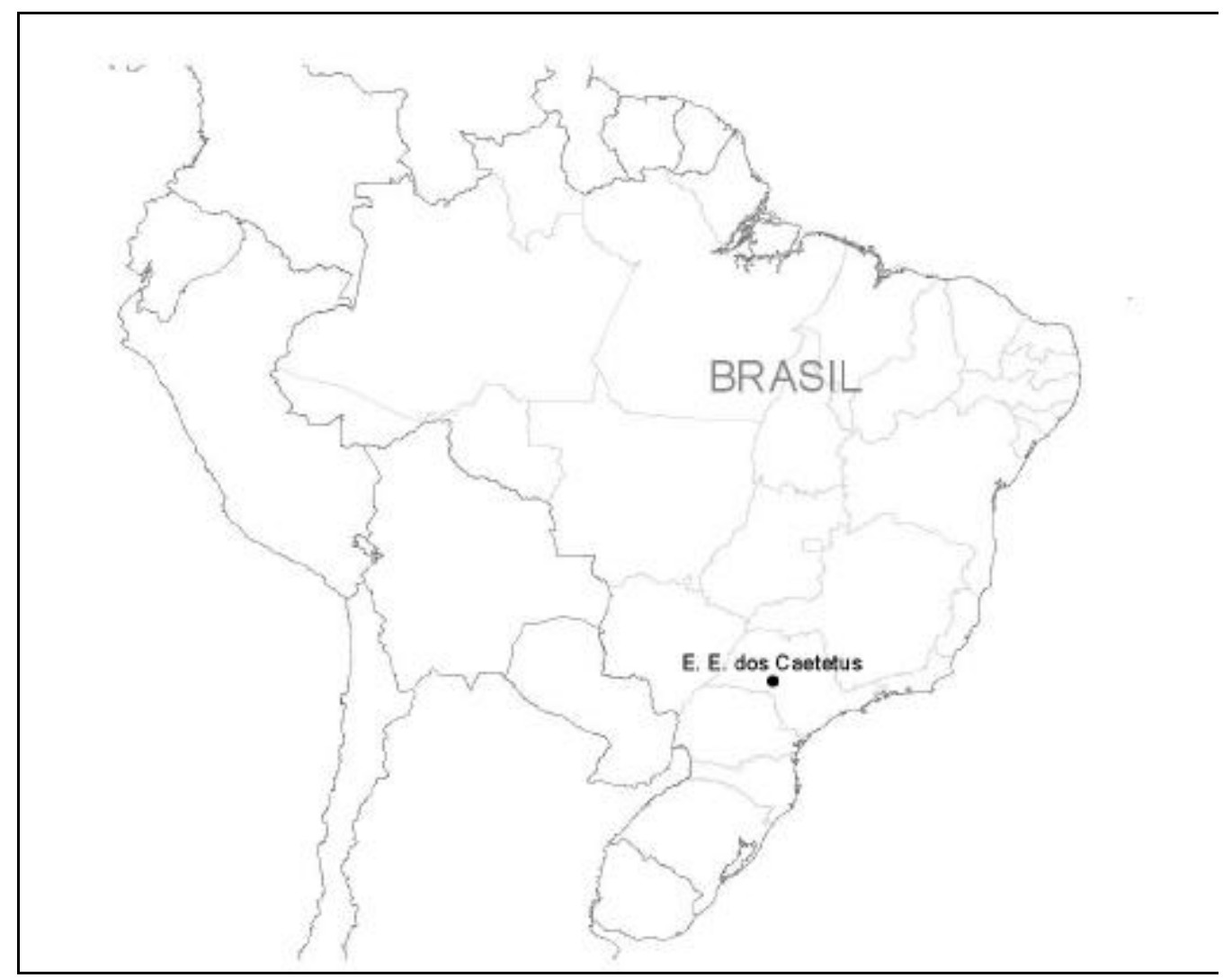

Figura 2- Localização da Estação Ecológica dos Caetetus 
A Estação Ecológica dos Caetetus possui aproximadamente 2.178 ha de cobertura vegetal, correspondendo a maior área de floresta contínua de sua região. O seu entorno é composto, principalmente, por pequenos remanescentes florestais, culturas de café, seringueira e pastagens (Viana \& Tabanez, 1996).

De maneira geral, Estação Ecológica dos Caetetus é constituída por vegetação primária, com algumas manchas de vegetação secundária com excesso de bambus e lianas, e áreas alagadas com predominância do palmito Euterpe edulis (A. Keuroghlian \& D. Eaton, dados não publicados). A floresta apresenta sazonalidade acentuada, com a queda parcial das folhas de algumas árvores durante a estação seca. 


\section{Área de estudos}

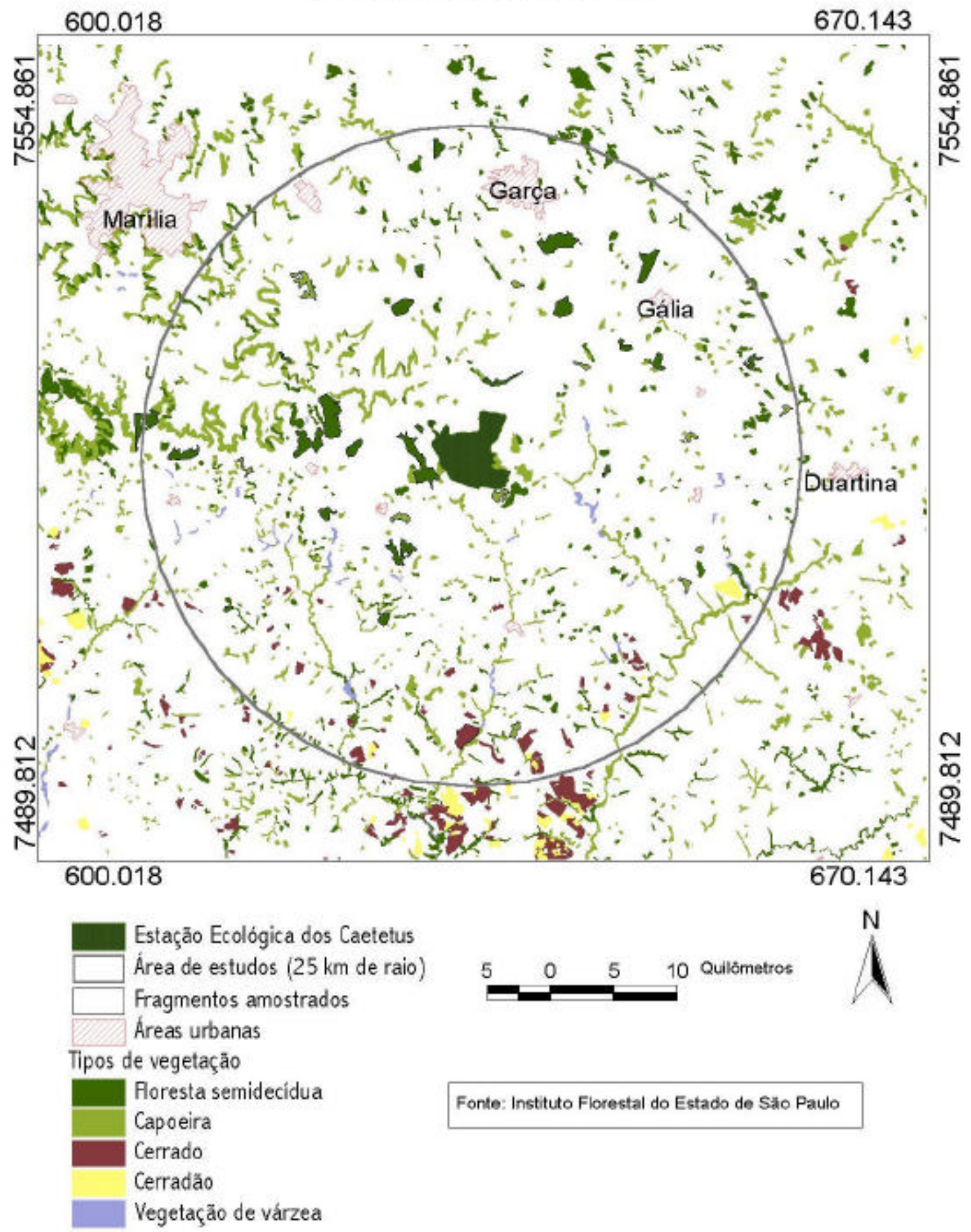

Figura 3 - Mapa de vegetação da Região da Estação Ecológica dos Caetetus 
O clima da Estação Ecológica dos Caetetus é do tipo Cwa (segundo a classificação de Koppen), com temperatura média em torno de $20^{\circ}$. A precipitação anual no local é de aproximadamente de $1480 \mathrm{~mm}$, mas com sazonalidade marcante: possui verão chuvoso, com precipitações concentradas nos meses de dezembro a fevereiro, e inverno seco, nos meses de abril a setembro.

Por ser um dos principais fragmentos de floresta nativa da região, E.E. de Caetetus representa um importante refúgio para espécies da fauna silvestre. Dentre as espécies da fauna encontrada destacam-se, além do maracanã, o mico-leão-preto (Leontopithecus chrysopygus), a anta (Tapirus terrestris), o cateto (Tayassu tajacu), a araponga (Procnias nudicollis), o jacú (Penelope obscura), o araçari (Pteroglossus aracari), nambu-guassu (Crypturellus obsoletus) e outras. Outros psitacídeos já registrados no local são a maritaca (Pious maximiliani), o periquitão (Aratinga leucophtalmus), o periquito-verde (Brotogeris versicolurus), a tiriva (Pyrrhura frontalis) e o tuim (Forpus xanthopterygius).

\subsubsection{Coleta de dados e análise}

Utilizourse o mapeamento da cobertura vegetal de escala 1:250.000, realizado pelo Instituto Florestal do Estado de São Paulo (1994), para seleção dos fragmentos amostrados, em um raio de $25 \mathrm{~km}$ no entorno da Estação Ecológica dos Caetetus (Figura 5.3). Esse mapa também serviu como base para os cálculos dos padrões de paisagem, através das métricas dos fragmentos e seu entorno. Foram realizadas pequenas edições nesse mapa, com o uso do software Spring 3.5 e da imagem de satélite LandsatTM 7 de abril de 2001, a fim de promover correções e atualizações.

Foram selecionadas aleatoriamente 36 destas áreas de vegetação natural remanescente para serem amostradas (ver APÊNDICE 5). A amostragem foi estratificada por tamanho, com classes entre 10 e 30 ha, 30 e 50 ha, 50 e 70 ha, 70 e 100ha, 100 e 200 ha e maiores que 200 ha, a diferentes distâncias do centro da E.E. dos Caetetus. 
Para avaliar o uso desses fragmentos por Primolius maracana foi utilizado o método de contagens em pontos estratégicos (Nunes \& Betini, 2002), no qual dois observadores, georreferenciados e localizados em dois diferentes pontos da borda do fragmento, registravam todos os indivíduos que voavam para dentro do fragmento florestal. Essa contagem foi realizada em um total de 7 horas e meia por cada observador em cada fragmento durante dois períodos, de manhã (6h às $10 \mathrm{~h} 30 \mathrm{~min})$ e à tarde (15h às 18h), na maioria das vezes em dias distintos. Em cada ponto de observação foi delimitado um comprimento de visão de borda para contagem das aves, a partir da visibilidade do observador, que variava nos diferentes pontos de contagem. Esse trecho era estimado in loco ou georreferenciado para posteriormente ser calculado no SIG. A cada contato com o maracanã foram registrados o número de indivíduos, o horário, a direção do vôo, rota dos bandos (dentro ou fora do fragmento) e possíveis observações relevantes (registros de alimentação, comportamento, etc.).

Cada fragmento obteve um índice de visitas de maracanãs, calculado pelo número total de indivíduos que entraram no fragmento dividido pela soma do comprimento de borda amostrado pelos 2 observadores (indivíduos $/ \mathrm{km}$ ). Esses índices foram relacionados às características dos fragmentos, como sua classe (floresta ou capoeira ou cerrado) (C), seu tamanho (T) e sua forma (índice de forma - IF). Também foram relacionados às características das paisagens do entorno dos fragmentos, como seu isolamento em relação aos fragmentos vizinhos (índice de proximidade de outro fragmento -IPF), o tipo predominante de uso da terra no entorno (café, pasto, cítricos ou eucalipto) (E), a distância mínima até a Estação Ecológica dos Caetetus (DEEC), a distância mínima até a cidade mais próxima (DC) e a distância mínima até um dormitório conhecido de maracanãs (DD). As métricas e índices de paisagem foram calculados utilizando o software de SIG ArcView 3.2, sua extensão Saptial Analist $1.1 \mathrm{e}$ o programa Fragstats 3.2 (Tabela 5.1 e ver APÊNDICE 6). 
Tabela 1. Índices de paisagem empregados

\begin{tabular}{|c|c|c|c|c|}
\hline Índices & Fórmula & Descrição & Unidade & Variação \\
\hline \multirow{2}{*}{$\begin{array}{l}\text { Índice de forma } \\
\text { do fragmento } \\
\text { (IFF)*1 }\end{array}$} & \multirow[t]{2}{*}{$\mathrm{IFF}=\mathrm{P} / \mathrm{Pmin}$} & $\mathrm{P}=$ perímetro de um fragmento & admensional & \multirow{2}{*}{$\begin{array}{l}1 \text { - sem } \\
\text { limite }\end{array}$} \\
\hline & & $\begin{array}{l}\text { Pmin=perímetro mínimo que o } \\
\text { fragmento poderia ter com a } \\
\text { mesma área de cobertura }\end{array}$ & & \\
\hline \multirow[t]{2}{*}{$\begin{array}{l}\text { Índice de } \\
\text { proximidade do } \\
\text { fragmento (IPF) } \\
*^{2}\end{array}$} & \multirow[t]{2}{*}{$\mathrm{IPF}=\sum\left[\mathrm{AV} /(\mathrm{DV})^{2}\right]$} & $\begin{array}{l}\mathrm{AV}=\text { área de um fragmento vizinho a } \\
3 \mathrm{~km} \text { de raio do fragmento em } \\
\text { questão }\end{array}$ & admensional & \multirow[t]{2}{*}{$\begin{array}{l}0 \text { - sem } \\
\text { limite }\end{array}$} \\
\hline & & $\begin{array}{l}\text { DV = distância desse fragmento } \\
\text { vizinho até o fragmento em } \\
\text { questão }\end{array}$ & & \\
\hline
\end{tabular}

Todas as variáveis foram testadas para normalidade e homogeneidade de variância e, quando necessário, foram realizadas transformações. Foi utilizada a análise de Correlação de Pearson com 9999 permutações no pacote estatístico R (Casgrain \& Legendre, 2001), para examinar possíveis correlações entre variáveis explanatórias, e o Modelo de Regressão Linear, para quantificar relações entre essas variáveis e a frequiência de visitas de Primolius maracana.

Utilizoutse um método interativo de construção do modelo de regressão múltipla (Henderson \& Velleman, 1981), o qual propõe que a seleção de variáveis deva ser feita por aquele que tenha familiaridade com os dados e tema, com o uso de gráficos e procedimentos estatísticos para diagnósticos. Os modelos são comparados, sendo avaliadas suas premissas, suas significâncias, seus coeficientes de correlação, problemas de multicolinearidade e casos influentes, para a escolha daquele que melhor estivesse ajustado.

\subsection{Resultados}

A vegetação nativa da região da Estação Ecológica dos Caetetus encontra-se atualmente fragmentada e representada por áreas de Floresta Estacional Semidecídua, Capoeira, Cerrado, Cerradão e Várzea, de diferentes dimensões, que ocupam 20,55 \% da paisagem estudada (Tabela 5.2). 
Tabela 2. Áreas de vegetação nativa remanescente da região da Estação Ecológica dos Caetetus em 25 km de raio no entorno da Estação Ecológica de Caeteus (196.343,75 ha).

\begin{tabular}{ccccc}
\hline $\begin{array}{c}\text { Tipo de } \\
\text { vegetação }\end{array}$ & $\begin{array}{c}\text { Total de cobertura } \\
\text { (ha) }\end{array}$ & $\begin{array}{c}\text { Número de } \\
\text { fragmentos }\end{array}$ & Área média (ha) & $\begin{array}{c}\text { Desvio Padrão da } \\
\text { Área média (ha) }\end{array}$ \\
\hline Floresta & $16.915,59$ & 821 & 20,60 & 86,87 \\
Capoeira & $16.326,9$ & 974 & 16,76 & 37,88 \\
Cerrado & $4.510,71$ & 125 & 36,08 & 62,10 \\
Cerradão & 798,21 & 51 & 15,65 & 15,90 \\
Várzea & $1.810,71$ & 53 & 34,16 & 44,13 \\
TOTAL & $\mathbf{4 0 . 3 6 2 , 1 2}$ & $\mathbf{2 . 0 2 4}$ & $\mathbf{1 2 3 , 2 5}$ & $\mathbf{2 4 6 , 8 8}$ \\
\hline
\end{tabular}

Foram amostrados 36 fragmentos de vegetação nativa nas proximidades da reserva, entre os dias 07 de agosto a 07 de outubro de 2001, para contagem de maracanãs. Indivíduos de Primolius maracana foram registrados voando para dentro de 25 dessas áreas. Contudo, somando contatos auditivos e visuais, foi constatada a presença da espécie em 29 desses remanescentes, mas os dados referentes a contatos auditivos ou de indivíduos saindo das áreas não foram registrados e contabilizados nos índices de visita. Entre os fragmentos em que o maracanã foi detectado, o primeiro contato com a espécie ocorreu relativamente rápido, principalmente no período das três primeiras horas de amostragem das áreas (Figura 5.4).

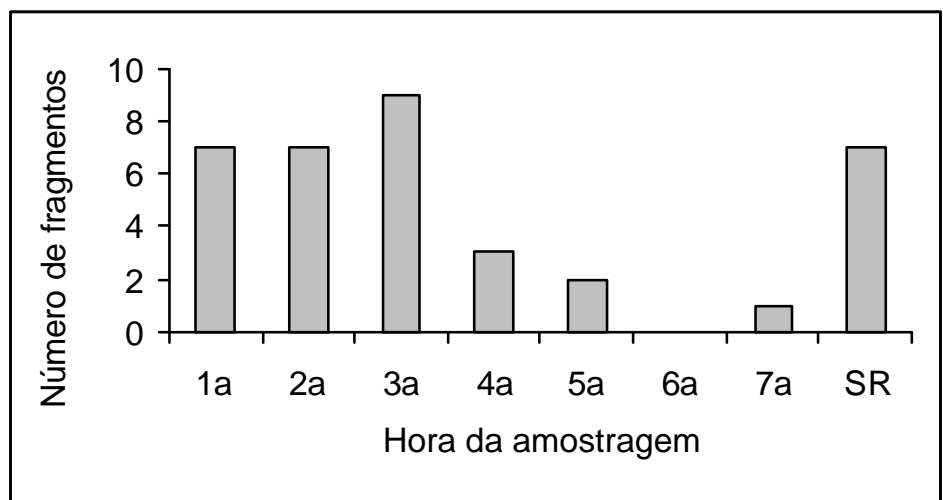

Figura 4 - Período da amostragem em que ocorreu o primeiro contato com o maracanã em certo fragmento. SR (sem registro) correspondem às áreas onde a espécie não foi detectada 
A fim de seguir corretamente as premissas das Análises de Regressão linear e Correlação de Pearson, utilizou-se algumas das variáveis explanatórias em escala transformada: arco-seno da raiz quadrada do tamanho do fragmento, arco-seno da raiz quadrada da forma do fragmento, logaritmo natural do isolamento do fragmento e raiz quadrada da distância mínima até um dormitório de maracanã conhecido. As variáveis "distância mínima até a Estação Ecológica dos Caetetus" e "distância mínima até a cidade mais próxima" não requereram transformações.

Embora a espécie tenha sido registrada entrando em $70 \%$ das áreas amostradas, a frequiência de visitas variou entre os fragmentos. Analisando a relação dessas visitas com cada variável explanatória separadamente (Figuras 5.5, 5.6, 5.7 e 5.8), verificou-se que a variação no índice de visitas foi explicada significantemente pela distância mínima até a Estação Ecológica dos Caetetus (DEEC) $(\mathrm{p}<0,05)$ e também pela distância mínima até um dormitório conhecido de maracanã (DD) ( $\mathrm{p}<0,001)$.

Em um contexto multidimensional de análise de regressão multivariada, o modelo melhor ajustado incluiu, além de DD, novas variáveis não significativas em regressões simples, como a distância da cidade mais próxima (DC) e o tamanho do fragmento. $\mathrm{O}$ modelo foi altamente significativo $(\mathrm{R}=0,56, \mathrm{p}<0,01)$ e explicou aproximadamente $57 \%$ da variância das visitas do maracanãs.

Tabelas 3. Teste do modelo de Regressão Linear Múltiplo ajustado para o índice de visitas de maracanãs em fragmentos no entorno da Estação Ecológica dos Caetetus.

\begin{tabular}{ll}
\hline R2 & Teste do modelo (Prob $>$ F) \\
\hline 0.569058 & $<.0001$
\end{tabular}


Tabelas 4. Estimativas dos parâmetros do modelo de Regressão Linear Múltiplo ajustado para o índice de visitas de maracanãs em fragmentos no entorno da Estação Ecológica dos Caetetus.

\begin{tabular}{ccccc}
\hline Termos & Estimativa & Erro padrão & t Ratio & Prob>|t| \\
\hline Intercepto & $-0,025942$ & 0,103617 & $-0,25$ & 0,8039 \\
arc[1+rq(área) & 0,0615892 & 0,029174 & 2,11 & 0,0427 \\
dist-cidade & 0,000011 & 0,000004 & 2,71 & 0,0108 \\
rq(dist-dorm) & $-0,001512$ & 0,000277 & $-5,46$ & $<, 0001$ \\
\hline
\end{tabular}

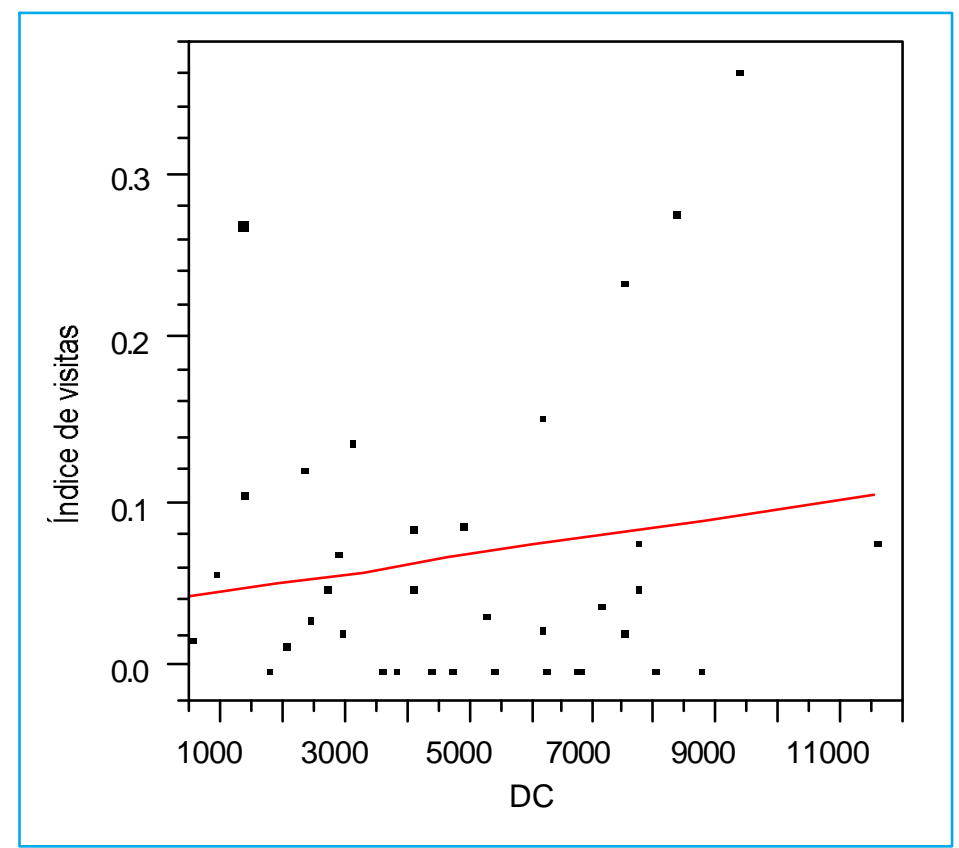

Figura 5 - Gráfico de dispersão do Índice de visitas do maracanã em relação a distância da cidade mais próxima 


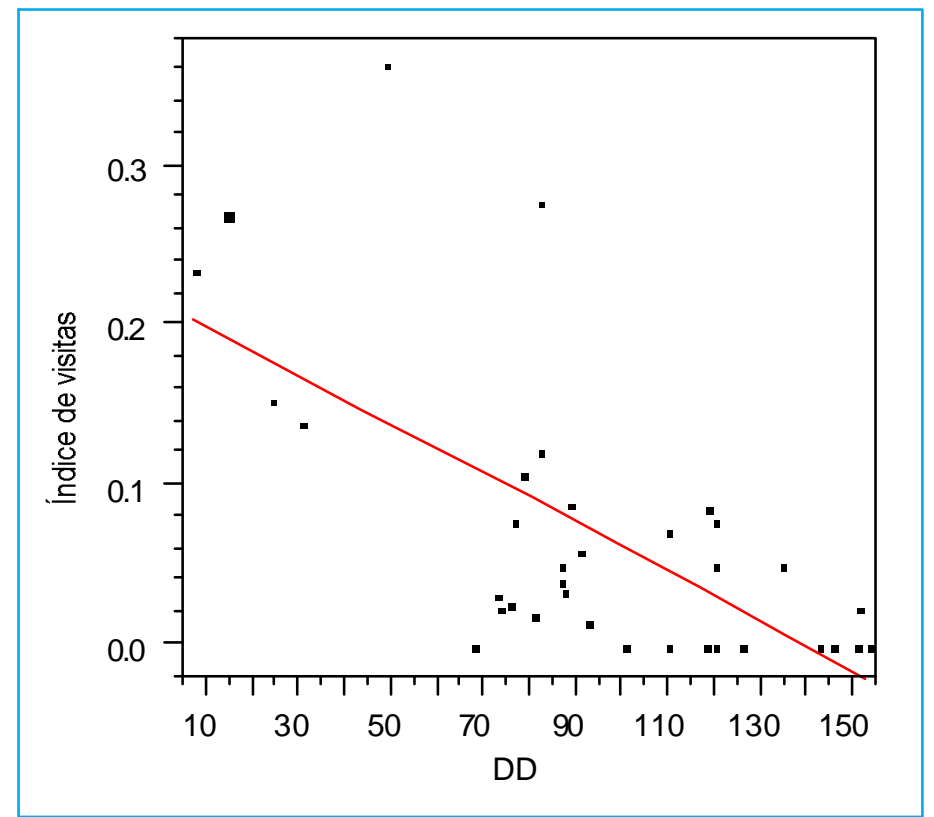

Figura 6- Gráfico de dispersão do Índice de visitas do maracanã em relação a distância mínima até um dormitório conhecido de maracanã.

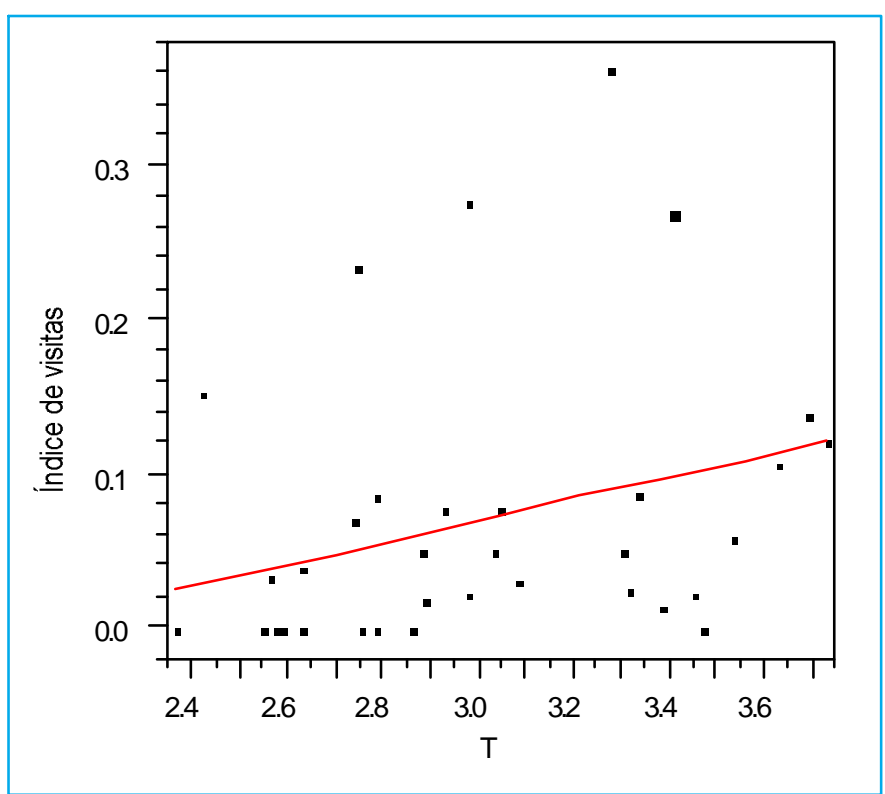

Figura 7 - Gráfico de dispersão do Índice de visitas do maracanã em relação ao tamanho do remanescente. 


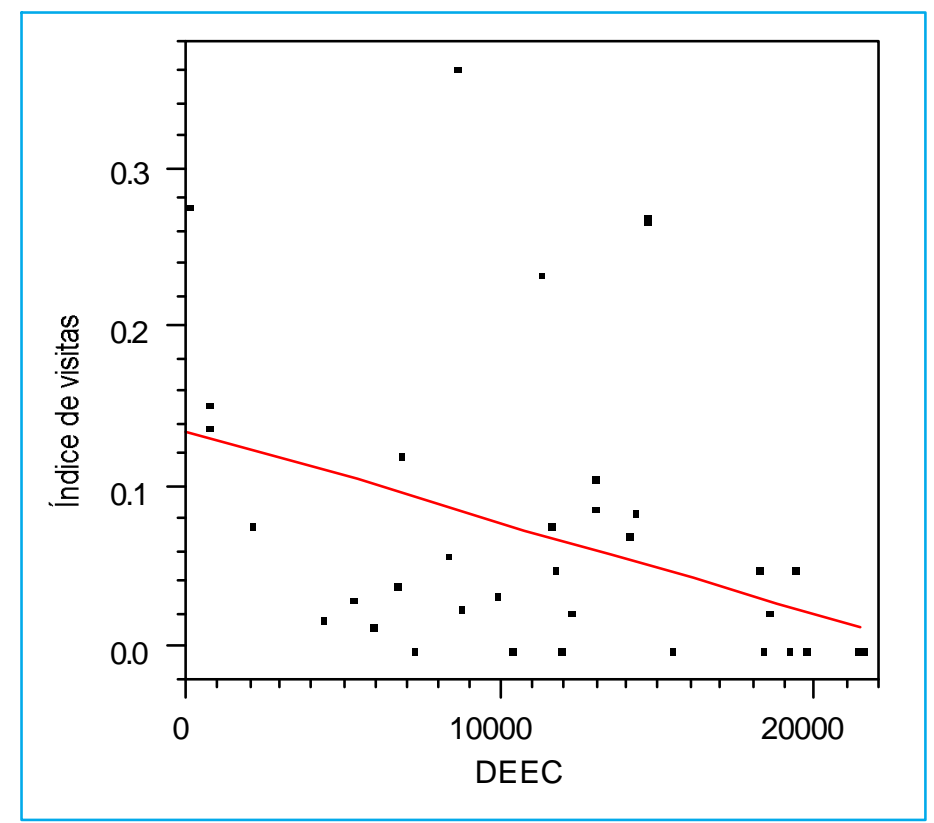

Figura 8 - Gráfico de dispersão do Índice de visitas do maracanã em relação a distância mínima até distância mínima até a Estação Ecológica dos Caetetus.

A variável "distância mínima até a Estação Ecológica dos Caetetus", que foi significativa na regressão simples, não entrou no modelo múltiplo devido à redundância nas informações (multicolinearidade) em relação à "distância mínima até um dormitório conhecido de maracanã". Essas variáveis são altamente correlacionadas $(\mathrm{R}=0,59$, p<0,001) devido à posição de um dormitório que está localizado a menos de $1 \mathrm{~km}$ da borda da reserva. Apesar dessa correlação, a troca da variável DD por DEEC no modelo múltiplo, pois diminui seu poder explicativo, bem como sua significância e a significância das outras variáveis, a "distância da cidade mais próxima" e o "tamanho do fragmento".

Durante o período de amostragem avistou-se maracanãs pousando em muitos remanescentes pequenos de vegetação nativa, em árvores isoladas na matriz e em campos de culturas agrícolas. Observou-se Primolius maracana alimentando-se de fruto do cafeeiro (Coffea arabica), que é uma das principais culturas da região, além de outros frutos exóticos como Melia azedarach. Também foram encontrados três dormitórios de maracanã com aproximadamente 20 a 30 indivíduos, nas coordenadas UTM (x1) 
630.811 (y1) 7523.454 - dormitório 1; (x2) 629.677, (y2), 7536.404 - dormitório 2; e (x3) 647.685, (y3)7535.145 - dormitório 3 (ver Figura 5.4 no apêndice). Dois deles estavam situados em guapuruvus (Schizolobium parahyba),espécie arbórea exótica para Florestas Semidecíduas, que sofriam freqüentes quedas de galhos, formando ocos usados para pernoite ou nidificação da espécie. O outro se situava em árvores nativas, isoladas na borda de um fragmento. Essas áreas normalmente se localizam em áreas abertas, próximas à borda de fragmentos.

\subsection{Discussão}

Com esse estudo pôde-se constatar que o maracanã utiliza freqüentemente as paisagens antropizadas e os fragmentos florestais de diferentes tamanhos e distâncias da maior área de floresta da região, a Estação Ecológica de Caetetus, além de estar consumindo itens exóticos em sua dieta. Um padrão similar também foi observado por Marsden et al. (2001) na Reserva Biológica de Sooretama, onde maracanãs deixavam a reserva no período da manhã, em direção a plantações de laranja e pequenos fragmentos satélites, retornando ao final da tarde.

Apesar do maracanã ter sido registrado na maioria dos fragmentos amostrados, a frequiência de visitas foi relacionada a atributos do hábitat. As características de paisagem no entorno dos fragmentos (DEEC, DC, DD), no geral, explicaram mais a variação da frequiência de visitas pelo maracanã que as características dos fragmentos em si (T). Esse padrão já foi observado em diferentes estudos e está principalmente relacionado com espécies mais móveis e generalistas (Graham \& Blake, 2001; Naugle et al., 1999 e Price et al., 1999). Isso porque muitas espécies com alta mobilidade podem atravessar áreas abertas e usar fragmentos pequenos e menos qualificados (Andrén, 1994). 


\subsubsection{Seleção de hábitat}

As variáveis de paisagem significativamente relacionadas com a frequiência de visitas de maracanãs no modelo múltiplo foram à distância mínima até a cidade mais próxima e a distância mínima até um dormitório conhecido de maracanã. A distância até a E. E. dos Caetetus também foi significativa, mas apenas em regressão simples devido à alta correlação com a distância mínima até um dormitório conhecido de maracanã. Essa correlação dificulta a interpretação dos efeitos relativos de cada variável, pois ela pode levar a correlações espúrias com a frequiência de visitas do maracanã. Também pode ocorrer das duas variáveis, DEEC e DD, serem simultaneamente importantes para a presença do maracanã, mas que refletem a dispersão de diferentes grupos: dos indivíduos que vivem em dormitórios e dos indivíduos que vivem na reserva.

Os dormitórios são comuns entre espécies de psitacídeos (Chapman et al., 1989), principalmente em ambientes fragmentados (Gilardi \& Munn, 1998). Esses últimos sugerem que, quando árvores isoladas estão disponíveis em ambientes fragmentados, psitacídeos percebem que esses locais são bons e seguros, e tendem a se congregar em áreas de dormitórios. Essas áreas aparentemente servem como centro de informação (Chapman et al., 1989) para os maracanãs e outros psitacídeos, que se agregam nesses locais no final da tarde para pernoitar, deixando-as ao amanhecer para forragear (Chapman et al., 1989). Uma reduzida distância entre o dormitório de maracanãs e um fragmento qualquer parece ser uma razão óbvia para uma alta frequiência de visitas desses psitacídeos, pois deslocamentos envolvem altas taxas metabólicas (Eckert \& Randall, 1988) e dessa maneira os indivíduos podem investir menos energia ao forragear.

A correlação entre a frequiência de visitas do maracanã e a distância até a E. E. Caetetus pode ser explicada pelo sistema "mainland" (Hanski, 1998 e Wilson et al., 2002) em que a reserva, que é a maior área florestal da região, funcionaria como uma área núcleo que serve como fonte dos indivíduos que se dispersam para outras áreas. Dessa forma, remanescentes mais próximos da reserva receberiam mais maracanãs. 
Já a correlação entre a frequiência de visitas do maracanã e a distância até a cidade mais próxima pode ser devida à quantidade de fatores impactantes que operam em áreas próximas às cidades. Uma correlação positiva entre distância a centros urbanos e ocorrência de espécies de aves já foi observada anteriormente em comunidades de aves amazônicas (Cândido Jr., 1999). Essa variável é importante, pois geralmente ela está negativamente correlacionada com o nível de fragmentação do local ( Cândido Jr., 1999).

A única variável representativa de uma característica do fragmento que contribuiu para explicar a variação na frequiência de visitas de maracanãs nos fragmentos foi o tamanho do remanescente. O tamanho de um fragmento geralmente é um fator preponderante para explicar o número de espécies que ocupam uma área (Graham \& Blake, 2001; Miller \& Cale, 2000 e Price et al., 1999), principalmente no caso de táxons mais sedentários e restritos (Lee et al., 2002). Até mesmo a ocorrência de espécies mais móveis, como muitos frugívoros, geralmente é influenciada pelo tamanho do remanescente, pois ele está relacionado com a abundância e diversidade de recursos (Price et al.., 1999). Entretanto, essas espécies mais móveis são fortemente influenciadas pela combinação de características do fragmento e da paisagem.

No caso do maracanã, o tamanho do remanescente foi importante apenas quando, a distância até um dormitório conhecido estava incluída no modelo. As duas variáveis são importantes simultaneamente em um modelo multivariado, talvez porque se áreas próximas aos dormitórios tiverem baixa quantidade ou qualidade de recursos, elas não serão capazes de suprir todas as exigências necessárias para a manutenção dos indivíduos da espécie. Dessa forma a combinação dessas duas variáveis funcionaria como uma relação custo-benefício entre o menor deslocamento para o forrageamento e o encontro de uma maior disponibilidade de recursos.

Além dos fatores de escala de paisagem e fragmento, a presença do maracanã pode ter sido influenciado por características que operam em escala local, como qualidade e disponibilidade de recursos, estrutura da vegetação, presença de predadores e outras (Wiens, 1989). Essas variáveis não mensuradas podem aumentar a variabilidade da frequiência de visitas do maracanã, enfraquecendo as relações com características dos 
fragmentos e paisagens. Contudo, algumas dessas variáveis, como estrutura da vegetação e qualidade do fragmento, são comumente correlacionadas com o tamanho do fragmento que está incluído no modelo, diminuindo assim a variação não explicada pelo modelo. Porém outras, como a disponibilidade de itens alimentares preferidos pela espécie, são espacialmente e temporalmente variadas (Loiselle \& Blake, 1988 e 1992) e podem ser responsáveis por parte da variabilidade não explicada pelo modelo. Isso porque muitos psitacídeos voam entre fragmentos em resposta à flutuação de recursos (Galetti, 1997; Nally \& Horrocks, 2000; Pizo et al., 1995; Price et al., 1999 e Sandercock et al., 2000).

Devido ao estudo ter sido conduzido em apenas uma estação climática, deve-se ter cautela na generalização dos resultados, pois eles podem sofrer mudanças em períodos sazonais diferentes, devido a variações na disponibilidade de itens alimentares e nos processos de dinâmica populacional, como mudança no padrão de dispersão dependendo do estatus reprodutivos (Sandercock et al., 2000). Porém, mesmo com essas variações, algumas características devem ser significantes para atração de indivíduos em períodos subseqüentes. Além disso, mesmo que certas características sejam importantes em apenas um período do ano para a espécie, elas são relevantes para a manutenção da espécie como um todo.

\subsubsection{Implicações e recomendações para conservação}

Espécies muito móveis, que utilizam ambientes perturbados (Villard \& Taylor, 1994) e que são capazes de modificar seu comportamento de forrageio quando muda a constituição da paisagem (Miller \& Cale, 2000), são mais tolerantes a fragmentação de hábitat e conseguem viver em paisagens com poucos remanescentes de vegetação nativa. O uso de diferentes tipos de hábitats e o consumo de espécies exóticas por Primolius maracana sugerem um comportamento generalista da espécie e a importância do mosaico de hábitats para sua manutenção em uma região fragmentada. 
Apesar do uso freqüente dos pequenos fragmentos pelo maracanã, não se sabe se uma rede com apenas fragmentos de pequeno porte teria a capacidade de manter populações da espécie. Grandes fragmentos podem representar áreas núcleo que, juntamente com as pequenas áreas, propiciam a sobrevivência das populações. Esses pequenos fragmentos podem estar servindo como locais de forrageamento, de pernoite e/ou de nidificação do maracanã, além de funcionar como elementos de conectividade da paisagem, oferecendo abrigo e descanso para as aves durante os deslocamentos (Fischer \& Lindenmayer, 2002). Price e et al. (1999) sugerem que uma rede de fragmentos pode manter frugívoros mais móveis, mas que essas espécies podem ser perdidas abaixo de um certo limiar.

O maracanã também pode apresentar outras mudanças comportamentais em áreas fragmentadas, como começar a estabelecer-se em dormitórios coletivos. Essas áreas são geralmente utilizadas por vários indivíduos e tornam-se importantes para a conservação da espécie no local.

Este estudo sugere que áreas de dormitório sejam identificadas e protegidas, pois sua conservação pode ser crucial para a manutenção do maracanã na região. Recomenda-se que esses locais sejam transformados em unidades de conservação do tipo Refúgio de Vida Silvestre, que pode ser constituída de áreas privadas e tem como objetivo proteger ambientes naturais que asseguram condições para a existência ou reprodução de espécies relevantes da fauna (BRASIL, 2000).

Como a maior parte dos fragmentos da região de estudo está em áreas privadas, exceto a Estação Ecológica dos Caetetus, a sobrevivência do maracanã não depende apenas de se detectar em áreas-chave para conservação, mas também da cooperação dos proprietários das terras. Deve ser incentivada a conservação do máximo possível de áreas remanescentes nativas, dando ênfase aos fragmentos próximos aos dormitórios e à reserva, e àqueles com maiores dimensões. Deve-se também valorizar os remanescentes de pequenas dimensões, bem como árvores isoladas na matriz, pois eles aumentam a conectividade da paisagem e a disponibilidade de recursos (Fischer \& Lindenmayer, 2002 e Price et al., 1999) para o maracanã que tem uma ampla área de vida. 
Seria importante saber quais são os requerimentos de hábitat para a escolha das áreas de dormitório, entretanto o número reduzido de dormitórios conhecidos $(n=3)$ é limitante para a realização de uma análise precisa. Porém, observando as características dos dormitórios conhecidos, supõe-se que o incentivo à manutenção e ao plantio de Guapuruvus Schizolobium parahyba pode ser importante por, aparentemente, serem áreas potenciais para o estabelecimento de novos dormitórios. Além disso, existe a vantagem dessa espécie ser pioneira de crescimento rápido, que atinge facilmente 8 a 10 metros de altura em dois anos (Lorenzi, 1992).

Deve-se concentrar esforços para manter a população de Primolius maracana na região da Estação Ecológica dos Caetetus, pois ela é a maior população remanescente da espécie na porção sul de sua área de distribuição, podendo funcionar como área fonte de migrantes para colonização de outras regiões onde o maracanã foi extinto (ver capítulos 2 e 4). Em áreas geográficas marginais da distribuição da espécie, a conservação das "populações-fonte" é vital para a persistência da distribuição regional e como um todo (Wilson et al., 2002). A extinção dessas populações poderia causar efeitos negativos em toda região, podendo aumentar rapidamente a área de contração sul da distribuição do maracanã. 


\subsection{Conclusões}

1. O maracanã é uma espécie altamente móvel, que visita freqüentemente as paisagens antropizadas e os fragmentos florestais de diferentes tamanhos e distâncias da maior área de floresta da região, a Estação Ecológica de Caetetus, e que consome itens exóticos em sua dieta. Esse comportamento sugere a plasticidade da espécie em escala local.

2. As características das paisagens no entorno dos remanescentes estudados explicaram mais a variação da frequiência de visitas pelo maracanã que as características referentes aos próprios fragmentos. Isso sugere a importância do mosaico de vegetação para a manutenção da espécie na região de E. E. dos Ceteteus.

3. A proximidade de um remanescente de vegetação a um dormitório de maracanãs ou a Estação Ecológica dos Caetetus resulta em uma alta frequiência de visitas desses psitacídeos. O tamanho dos remanescentes também é importante, principalmente para aqueles próximos aos dormitórios. Já os remanescentes próximos ao perímetro urbano das cidades são pouco visitados. Todos esses parâmetros devem ser usados para apontar quais os remanescentes prioritários para a conservação da espécie. 


\section{CONCLUSÕES GERAIS}

1. O maracanã apresentou características generalistas nas diferentes escalas espaciais analisadas, ocorrendo em muitos biomas (Cerrado, Caatinga, Mata Atlântica, Amazônia e Campos do Norte do país), em diferentes tipos de vegetação (Florestas Ombrófilas, Ombrófilas Mistas (Araucária), Decíduas, Semidescíuas, Cerrado, Caatinga arbórea e outras) e, em escala local, foi registrado visitando áreas antropizadas, como plantações de café, ilhas de vegetação, de diferentes tamanhos, situadas em paisagens degradadas, etc. Além disso, na região da Estação Ecológica de Caetetus, observoutse o consumo pelo maracanã de frutos de espécies exóticas (Melia azedarach e Coffea arabica ) e o uso de cavidades em árvores não nativas no local (Schizolobium parahyba), o que demonstra uma certa flexibilidade da espécie quanto ao aproveitamento de novos recursos que surgem com as alterações da paisagem original.

2. Tanto em escala local como regional, o maracanã foi influenciado pela composição da paisagem como um todo, sendo a manutenção do total de vegetação remanescente altamente importante, do que apenas a conservação de grandes blocos isolados.

3. Para a conservação local do maracanã, os dormitórios são alvos importantes, juntamente com a vegetação ao seu redor, priorizando os grandes fragmentos. Para a conservação regional do maracanã, a quantidade total de cobertura vegetal remanescente da paisagem é importante, devendo-se priorizar esforços para a conservação de populações-chave, que são aquelas nucleares, as mais constantes e com as maiores densidades em sua região. Na região sul de ocorrência do maracanã, aparentemente essas populações-chaves são em: Itabó (PAR), Londrina (PR), Diamante do Norte (PR), Gália (SP), Guaraçaí (SP) e Patrocínio Paulista (SP) (ver ANEXO 1). 
4. Os limites de distribuição geográfica do maracanã sofreram mudanças no último século, principalmente ao sul de sua ocorrência original, que mostrou um drástico declínio nos últimos 50 anos, porém as razões para essa contração permanecem pouco entendidas. Apesar da grande extensão de ocorrência da espécie e de seus hábitos que sugerem características comportamentais generalistas, é importante não negligenciar a conservação do maracanã-veradeiro, pois reduções parciais podem ser presságios para reduções mais severas no futuro. 
ANEXO 


\section{ANEXOA}

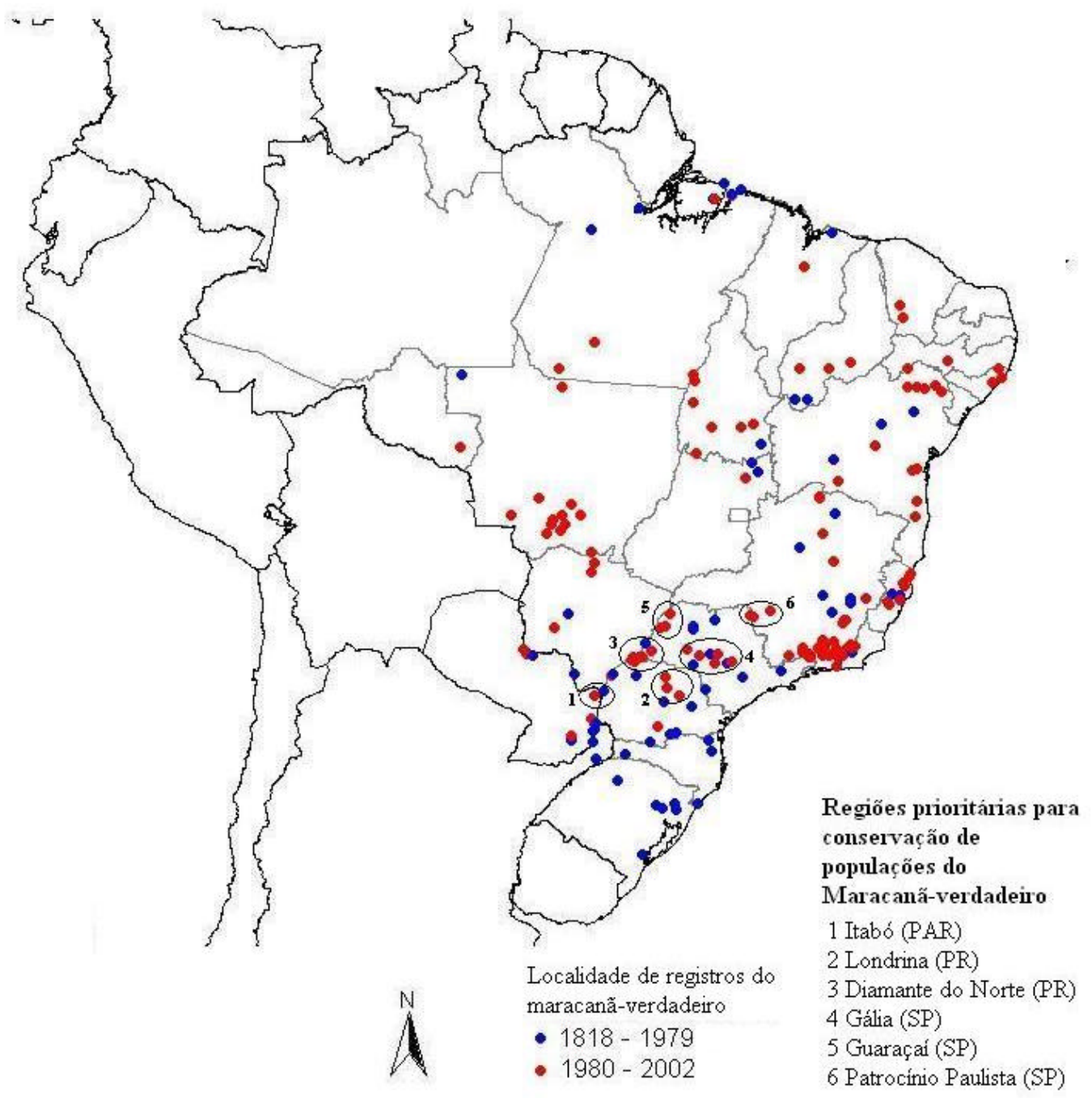

Figura 1 - Localidades prioritárias para a conservação do maracanã-veradeiro 


\section{REFERÊNCIAS BIBLIOGRÁFICAS}

ALBUQUERQUE, J.L.; BRÜGGEMANN, F.M. A avifauna do Parque Estadual da Serra do Tabuleiro, Santa Catarina, Brasil e as implicações para sua conservação. Acta Biológica Leopoldense, v.18, n.1, p.47-68, 1996.

ALEIXO, A.; VIELLIARD, J. M. E. Composição e dinâmica da avifauna da mata Santa Genebra, Campinas, São Paulo, Brasil. Revista brasileira de Zoologia, v.12, p.493$511,1995$.

ANDRÉN, H. Effects of habitat fragmentation on birds and mammals in landscapes with different proportions of suitable habitat - a Review. Oikos, v.71, n.3, p.355366, 1994.

ANJOS, L.A.; SHUCHMANN, K.L. Biogeographical afinities of the avifauna of the Tibagi river basin, Parana drainage system, southern Brazil. Ecotropica, v.3, n.1, p.43-66, 1997.

ANJOS, L.; SCHUCHMANN, K.L.; BERNDT, R.A. Avifaunal composition, species richness, and status in the Tabagi River Basin, Paraná State, southern Brazil. Ornitologia Neotro pical, v.8, p.145-173, 1997.

BAUER, C.; PACHECO, J.F. Lista das aves da Região de Visconde de Mauá, Serra da Mantiqueira, no limite dos Estados do Rio de Janeiro e Minas Gerais. Atualidades Ornitológicas, v.97, p.7, 2000.

BEGE, L.A.R.; MARTERER, B.T.P. Conservação da avifauna na região sul do Estado de Santa Catarina. Florianópolis: FATMA, 1991. 56p 
BELTON, W. Aves do Rio Grande do Sul, distribuição e biologia. São Leopoldo: Universidade do Vale do Rio dos Sinos, 1994. 584p.

BERLEPSH, H.V.; IHERING, H.V. Die vögel der Umgegend von Taquara do Mundo Novo, Prov. Rio Grande do Sul. Zeitschrift für die Gesammte Ornithologie, v. 1, p.1-85, 1885.

BIRDLIFE INTERNATIONAL. Threatened birds of the world. Cambridge: Lynx Editions and Bird Life International, 2000. 852 p.

BLACKBURN, T.M.; GASTON, K.J. Some methodological issues in macroecology. American Naturalist, v.151, n.1, p.68-83, 1998.

BOONE, R.B.; KROHN, W.B. Predicting broad-scale occurrences of vertebrates in patchy landscapes. Landscape Ecology, v.15, n.1, p.63-74, Jan, 2000.

BORNSCHEIN, M.; STAUBE, F. Sobre o status de três espécies de aves no Estado do Paraná: Crax faciolata, Ara maracana e Psarocolis decumanos. In: CONGRESSO BRASILEIRO DE ORNITOLOGIA, 1. , Belém, 1991. Resumos. Belém: Ed. Super Cores, 1991.p. 33

BOULINIER, T.; NICHOLS, J.D.; HINES, J.E.; SAUER, J.R.; FLATHER, C.H.; POLLOCK, K.H. Forest fragmentation and bird community dynamics: Inference at regional scales. Ecology, v.82, n.4, p.1159-1169, 2001.

BRASIL. Leis, decretos, etc. Lei número 9.985, de 18 de junho de 2000. Artigo 13. Diário Oficia, 2000. Institui o Sistema Nacional de Unidades de Conservação.

BROOKS, T. Conservation biology - Living on the edge. Nature, v.403, n.6765, p.26, Jan 6, 2000.

BROOKS, T.M.; BARNES, R.; BARTRINA, L.; BUTCHART, S.H.M; CLAY, R.P.; ESQUIVEL, E.Z.; ETCHEVERRY, N.I.; LOWEN, J.C.; VINCENT, J. Bird surveys and conservation in the Paraguayan Atlantic Forest. Project Canopy'92: Final Report. Cambridge: BirdLife International , 1993. 
BROWN, J.H. . Macroecology. Chicago: University of Chicago Press, 1995. 269p.

BROWN, J.H.; MEHLMAN, D.W.; STEVENS, G.C. Spatial variation in bundance. Ecology, v.76, n.7, p.2028-2043, 1995.

CAD. Comitê para atualização da distribuição geográfica de aves brasileiras. Circular n.1/1999. set. 1999. 3p.

CÂNDIDO JR, J.F. Efeito das alterações ambientais sobre a avifauna do Fstado de Rondônia, Brasil. Rio Claro, 1999. Tese (Doutorado) - Instituto de Ciências Biológicas, Universidade Estadual Paulista "Júlio de Mesquita Filho".

CARVAlHO, C.T.E.; CARVALHO, J. A nidificação de Pionus maximiliani (KUHL) e Ara maracana (VIEILLOT) em Gália, São Paulo, Brasil (AVES, PSITTACIDAE). Revista Brasileira de Zoologia, v.9, p.363-365, 1992

CASGRAIN, P. LEGENDRE, P. The $\mathbf{R}$ Package for multivariate and spatial analysis version 4.0 (development release 6) user's manual. Montreal: Université de Montréal, Département de Sciences Biologiques, 2001.

CHANNELL, R.; LOMOLINO, M.V. Dynamic biogeography and conservation of endangered species. Nature, v.403, n.6765, p.84-86, 2000 a.

CHANNELL, R.; LOMOLINO, M.V. Trajectories to extinction: spatial dynamics of the contraction of geographical ranges. Journal of Biogeography, v.27, p.169-179, 2000 b.

CHAPMAN, C.A.; CHAPMAN, L.J.; LEFEBVRE, L. Variability in Parrot Flock Size Possible Functions of Communal Roosts. Condor, v.91, n.4, p.842-847. 1989.

CHAPMAN, F.M. The upper zonal bird life of MTS Roraima and Duida. Bulletin of American Museum of Natural History, v.63, p. 1-135, 1931.

CHEBEZ, J.C. Fauna Misionera. Buenos Aires: L.O.L.A. Press, 1996. 318 p.

CHRISTIANSEN, M.B.; PITTER, E.. Species loss in a forest bird community near Lagoa Santa in Southeastern Brazil. Biological Conservation, n.80, p.23-32, 1997. 
CHROSTOWSKI, T. Kolekcja ornitologiczna ptaków paranskich. Sprawozdania Tow. Nauk. Warszawa, v.5, p.452-500, 1912.

CLAY, R.P.; CAPPER, D.R.; BARNETT, J.M.; BURFIELD, I.J.; ESQUIVEL, E.Z.; FARINÃ, R.; KENNEDY, C.P.; PERRENS, M.; POPLE, R.G. White-winged nightjars and cerrado conservation: the key findings of Project Aguará Nu 1997:1. Cotinga, v.9, p. 52, 1998.

COELHO, AGM. Aves da reserva biologica de Serra Negra, lista preliminar. Universidade Federal de Pernambuco, Publicação avulsa, n.2, p.1, 1987.

COLLAR, N.J.; CROSBY, M.J.; STATTERSFIELD, A.J. Birds to watch 2: the world list of threatened birds. Cambridge: BirdLife International, 1994. 407 p.

CORDEIRO, P.H.C. A fragmentação da Mata Atlântica no sul da Bahia e suas implicações na conservação dos psitacídeos. In: GALETTI, M.; PIZO, M.A. (Ed.). Ecologia e Conservação de psitacídeos no Brasil. Belo Horizonte: Melopsittacus Publicações Científicas, 2002. cap.11, p.215-228.

COWLEY, M.J.R.; THOMAS, C.D.; ROY, D.B.; WILSON, R.J.; LÉON-CORTÉS, J.L.; GUTIÉRREZ, D.; BULMAN, C.R.; QUINNN, R.M.; MOSS, D.; GASTON, K.J. Density-distribution relationships in British butterflies. I. The effect of mobility and spatial scale. Journal of Animal Ecology, v.70, p.410-425. 2001.

CRAVEIRO, R.B.; MIYAKI, C.Y. Analyses of the genetic variability of Propyrrhura maracana (Psittaciformes, Aves), using DNA fingerprint. Ararajuba, v.8, n.2, 2000 .

CULLEN, L. BODMER, R. E.; PADUA, C. V. Effects of hunting in habitat fragments of Atlantic Forests, Brazil. Biological Conservation, v.95, p.49-56. 2000.

DEL HOYO, J.; ELLIOTT, A.; SARGATAL, J. Handbook of the birds of the vorld: Sandgrouse to Cuckoos. Barcelona: Lynx Edicions, 1997. v.4. 679 p. 
EVANS, P.G.H. Status and conservation of Imperial and Red-necked Parrots Amazona imperalis and A. arausiaca on Dominica. Bird Conservation International, v.1, p.11-32, 1991.

FISCHER, J.; LINDENMAYER, D.B. The conservation value of paddock trees for birds in a variegated landscape in southern New South Wales. 2. Paddock trees as stepping stones. Biodiversity and conservation, v.11, p.833-849, 2002.

FORRESTER, B.C. Birding Brazil: a check-list and site guide. Irvine: John Geddes, 1993.

FORSHAW, J. M. Parrots of the wrld. 3.ed. Melbourne: Lansdowne Editions, 1989. $672 \mathrm{p}$.

GALETTI, M. Seasonal abundance and feeding ecology of parrots and parakeets in lowland Atlantic forest of Brazil. Ararajuba, n.5, p.115-126, 1997

GALETTI, M.; GUIMARÃES, P; MARSDEN, S.T. Padrões de riqueza de espécies e conservação dos psitacídeos neotropicais. In: GALETTI, M.; PIZO, M.A. (Ed.). Ecologia e conservação de psitacídeos no Brasil. Belo Horizonte: Melopsittacus Publicações Científicas, 2002. cap.1, p.17-27.

GARSKE, C.E.S.; BERNHARDT, E.D.A.; ANDRADE, V.A.; FERREIRA, I. Avifauna da Vila das Três Cruzes, Santa Bárbara do Monte Verde, Minas Gerais. In: CONGRESSO BRASILEIRO DE ORNITOLOGIA, 9., Curitiba, 2001. Ornitologia sem fronteiras; resumos. Curitiba: Fundação O Boticário de Proteção à Natureza, 2001. p. 218.

GASTON K. J. Species-range-size distributions: Patterns, mechanisms and implications. Trends in Ecology \& Evolution, v.11, p.197-201, 1996.

GILARDI, J.D.; MUNN, C.A. Patterns of activity, flocking, and habitat use in parrots of the peruvian amazon. The Condor, v.100, p.641-653, 1998.

GLIESCH, R. Lista das aves coligidas e observadas no Estado do Rio Grande do Sul. Egatea, v.15, p.276-292, 1930. 
GNAN, R.; BURCHSTED, A. Population estimates for the bahama parrot on Abaco Island, Bahamas. Journal of Field Ornithology, v.62, p.139-146, 1991.

GOELDI, E. Contornos para a fauna do Pará e da Amazônia interior. Boletim do Museu Paraense, v.1, p.336-356, 1896.

GRAHAM, C.H.; BLAKE, J.G. Influence of patch- and landscape-level factors on bird assemblages in a fragmented tropical landscape. Ecological Applications, n.11, p.1709-1721, 2001.

GRISCOM, L; GREENWAY, J.C. Birds of lower Amazonia. Bulletin of Museum of Comparative Zoology, v. 81, p.417-437.

HANSKI, I.A. Patch-occupancy dynamics in fragmented landscapes. Tree, n.9, p.131$135,1994$.

HANSKI, I.A. Metapopulation dynamics: effects of the habitat quality and landscape structure. Ecology, v.79, p.2503-2515, 1998.

HAY, G.J.; MARCEAU, D.J.; DUBE, P.; BOUCHARD, A. A multiscale framework for landscape analysis: Object-specific analysis and upscaling. Landscape Ecology, v.16, n.6, p.471-490, 2001.

HAYES, F.E. Status, distribution and biogeography of the birds of Paraguay: monographs in field ornithology 1. Colorado: American Birding Association, Springs, 1995. 230p.

HENDERSON, H.V.; VELLEMAN, P.F. Building multiple regression models interactivly. Biometrics, v.37, p.391-411, 1981.

HENRIQUES, L.M.P.; OREN, D.C. The avifauna of Marajó, Caviana e Mexicana Islands, Amazon River estuary, Brazil. Revista Brasileira de Zoologia, v.57, n.3, p.357-382, 1997.

HENSHER, D. A; JOHNSON, L. W. Applied discrete choice modeling. London: Croom-Helm, 1981. 468 p. 
HOLT, E. An ornithological survey of the Serra do Itatiaia, Brazil. Bulletin of American Museum of Natural History, v.57, p.251-326, 1928.

HOSMER, D.W.; LEMESHOW, S. Applied logistic regression: textbook and solutions manual, New York: John Wiley, Inc., 1989. 307p.

HUTCHINSON, G.E. Homage to Santa Rosalia, or why are there so many kind of animals? American Naturalist, v.93, p.145-159, 1959.

IBGE. Instituito Brasileiro de Geografia e Estatística. Mapa de vegetação do Brasil. Rio de Janeiro, 1993. Escala 1:5.000.000.

IDEMA. Lista atualizada das aves do Estado do Rio Grande do Norte. Natal: IDEMA publicações, 1999. 20p.

IHERING, H.V. As aves do Estado do Rio Grande do Sul. In: (Ed.). Anuário do Estado do Rio Grande do Sul para o ano de 1900. Porto Alegre: Editora Krahe, 1899. p.113-154.

JUNIPER, T.; PARR, M. Parrots: a guide to the parrots of the world. London: Pica Press, 1998. 583 p.

KARL, J.W.; HEGLUND, P.J.; GARTON, E.O.; SCOTT, J.M.; WRIGHT, N.M.; HUTTO, R.L. Sensitivity of species habitat-relationship model performance to factors of scale. Ecological Applications, v.10, n.6, p.1690-1705, 2000.

KIRWAN, G.M.; BARNETT, J.M.; MINNS, J. Significat ornithological observations from the Rio São Francisco valley, Minas Gerais, Brazil, with notes on conservation and biogeography. Ararajuba, v.9, p.145-161, 2000.

KOCH, Z; BÓÇON, R. Guia ilustrado das aves comuns [do] Parque nacional do Iguaçu. Curitiba: Zig Fotografias e Produções Culturais, 1994. 38p.

LA PENÃ, M.R. Aves Argentinas: lista y distribución. Buenos Aires: L.O.L.A. Press, 1998. 244p. 
LAMBERT, F.R. Trade, status and management of three parrots in the North Moluccas, Indonesia: White Cocakatoo Cacatua alba, Chattering Lory Lorius garrulus and Violet-eared Lory Eos squamata. Bird Conservation International, v.3, p.145$168,1993$.

LEE, M.; FAHRIG, L.; FREEMARK, K.; CURRIE, D.J. Importance of patch scale vs landscape scale on selected forest birds. Oikos, v.96, n.1, p.110-118, 2002.

LOISELLE, B. A.; BLAKE, J. G. Bird abundance and seasonality in a Costa Rican Lowland Forest canopy. Condor, v.9, p.761-772, 1988.

LOISELlE, B. A.; BLAKE, J. G. Population variation in a Tropical Bird Comunity. BioScience, v11, p.838-845, 1992.

LÓPEZ, N.E. Proyectos de investigación: Distribuición, ecologia y estado de psitacídeos del Departamento de Concepción, Paraguay. Flora, Fauna y Areas Silvestres, v.11, p.37, 1989.

LÓPEZ, N.E. Observaciones sobre la distribucion de psitacidos em el Departamento de Concepción, Paraguay. Boletin del Museo Nacional de Historia Natural del Paraguay, n.11, p2-25. Dec, 1992

LORENZI, H. Árvores brasileiras: manual de identificação e cultivo de plantas arbóreas nativas do Brasil. Nova Odessa: Plantarum, 1992. 382p.

LOWEN, J.C.; BARTRINA, L.; CLAY, R.P.; TOBIAS, J.A. Biological surveys and conservation priorities in eastern Paraguay: the final reports of projects CANOPY'92 and YACUTINGA'95. Cambridge: CBS Conservation Publications, 1996. 180p.

MACARTHUR, R.H.; WILSON, E.O. An equilibrium theory of insular zoogeography. Evolution, v.17, p.373-387, 1963.

MACARTHUR, R.H.; WILSON, E.O. The theory of island bogeography. Princeton: Princeton University Press, 1967. 203p.

MAGALHÃES, J.C. Aves na Fazenda Barreiro Rico. São Paulo: Ed. Plêiade, 2000. 
MARSDEN, S.J.; WHIFFIN, M.; SADGROVE, L.; GUIMARAES, P. Parrot populations and habitat use in and around two lowland Atlantic forest reserves, Brazil. Biological Conservation, v.96, n.2, p.209-217, Dec. 2000.

MCGARIGAL, K.; MARKS, B.J. FRAGSTATS: spatial pattern analysis program for quantifying landscape structure. Pacific Northwest: United States Department of Agriculture Forest Service, General Technical Report PNW-GTR-351, 1995. 122p.

MILLER, J.R.; CALE, P. Behavioral mechanisms and habitat use by birds in a fragmented agricultural landscape. Ecological Applications, v.10, n.6, p.1732$1748,2000$.

NALLY, R.M.; HORROCKS, G. Landscape-scale conservation of an endangered migrant: the Swift Parrot (Lathamus discolor) in its winter range. Biological Conservation, v.92, p.335-343, 2000.

NASCIMENTO, J.L.X.; FLORES, J.M. Levantamento avifaunístico do Parque Nacional do Araguaia, Tocantins. In: CONGRESSO BRASILEIRO DE ORNITOLOGIA, 9., Curitiba, 2001. Ornitologia sem fronteiras: resumos. Curitiba: Fundação O Boticário de Proteção à Natureza, 2001. p.293.

NASCIMENTO, J.L.X.; FLORES, J.M.; LINARES, S.F.T.P.; DONOLA, E. Estudos dos impactos decorrentes da implantação da Usina Hidrelétrica de Porto Primavera (Sérgio Motta) sobre a avifauna da região. In: IX CONGRESSO BRASILEIRO DE ORNITOLOGIA, Curitiba, 2001. Ornitologia sem fronteiras; resumos. Curitiba: Fundação O Boticário de Proteção à Natureza, 2001. p.294.

NAUGLE, D.E.; HIGGINS, K.F.; NUSSER, S.M.; JOHNSON, W.C. Scale-dependent habitat use in three species of prairie wetland birds. Landscape Ecology, v.14, n.3, p.267-276, 1999.

NAUMBERG, E.M.B. Remarks on Kaempfer's collection in Eastern Brazil. Auk, v.44, p.60-65, 1928.

NAUMBERG, E.M.B. The birds of Mattogrosso, Brazil. Bulletin of American Museum of Natural History, v.60, p.1-32, 1930. 
NAVAS, J.; BÓ, N.A. Aves nuevas o poco conocidas de Missiones, Argentina. II Comunicaciones Zoológicas del Museo de História Natural de Montevideo, v.166, n. 12, p.1-9, 1998.

NOVAES, F.C. Contribuição ornitológica do nordeste do Acre. Boletim do Museu Paraense Emílio Goeldi, Zoologia, v.9, p.1-30, 1957.

NOVAES, F.C. Notas sobre algumas aves da serra de Parima, território de Roraima (Brazil). Boletim do Museu Paraense Emílio Goeldi, Zoologia, v.54, p.1-10, 1965.

NOVAES, F.C. Ornitologia do território do Amapá I. Publicações Avulsas do Museu Paraense Emílio Goeldi, Zoologia, v.25, p.1-121, 1974.

NOVAES, F.C. Ornitologia do território do Amapá II. Publicações Avulsas do Museu Paraense Emílio Goeldi, Zoologia, v.29, p.1-75, 1978.

NOVAES, F.C.; LIMA, M.F.C. As aves das campinas, capoeiras e manguezais do leste do Pará. Boletim do Museu Paraense Emílio Goeldi, Zoologia, v.8, p.272-303, 1992.

NUNES, M.F. Ecologia e Conservação do Maracanã-verdadeiro Primolius maracana (PSITTACIDAE) em um fragmento florestal do Sudeste do Brasil. Rio Claro, 2000. Monografia (Graduação) - Instituto de Ciências Biológicas, Universidade Estadual Paulista "Júlio de Mesquita Filho".

NUNES, M.F.; BETINI, G.S. Estimativas de tamanhos populacionais de psitacídeos. In: GALETTI, M.; PIZO, E M. A. (Ed.). Ecologia e Conservação de psitacídeos no Brasil. Belo Horizonte: Melopsittacus Publicações Científicas, 2002. cap.7, p.123-140.

OLMOS, F. Birds of the Sierra da Capivara National Parkin the "caatinga" on northeastern Brasil. Bird Conservation International, v.3, p.21-36, 1997.

PACHECO, J.F. Alguns registros históricos para ornitologia do Amapá. Atualidades Ornitológicas, v.96, p.5, 2000. 
PACHECO, J.F.; FONSECA, P.S.M.; MATTOS, G.T.; SIMON, E.J.E. O status de Ara maracana (Vieillot) no Rio de Janeiro e na Zona da Mata de Minas Gerais. In: CONGRESSO BRASILEIRO DE ORNITOLOGIA, 4., Recife, 1994. Resumos. Recife: Universidade Federal Rural de Pernambuco, 1994. p.142.

PARKER, T.A.; GOERCK, J.M. The importance of National Parks and Biological Conservation in the Atlantic forest region of Brazil. Ornithological monographs, v.48, p.527-541, 1997

PARKER III, T.A.; STOTZ, D.F.; FITZPATRICK, J.W. Ecological and distributional databases. In: STOTZ, D. F.; FITZPATRICK, J. W. (Ed.). Neotropical birds, ecology and conservation. Chicago: University of Chicago Press, 1996. p.113-436.

PAYNTER JUNIOR. Ornithological Gazetter of Argentina. Cambridge: Harward University Bird Department of Museum of Comparative Zoology, 1985a. 509p.

PAYNTER JUNIOR. Ornithological Gazetter of Paraguay. Cambridge: Harward University Bird Department of Museum of Comparative Zoology, 1985b. 61p.

PAYNTER JR, R.A.; TAYLOR, M.A. Ornithological Gazetter of Brazil. Cambridge: Harward University Bird Department of Museum of Comparative Zoology, 1991. 2v. 789p.

PETERMANN, P.; OLIVEIRA, C.R.A.; BERNARDON, B.; OLIVEIRA, F.F.; NABUCO, H.C.G. Aves de uma área do cerrado no divisor continental entre as bacias de La Plata e do Amazonas, sul do Mato Grosso. In: IX CONGRESSO BRASILEIRO DE ORNITOLOGIA, 9., Curitiba, 2001. Ornitologia sem fronteiras; resumos. Curitiba: Fundação O Boticário de Proteção à Natureza, 2001. p.308.

PETERSON, A.T. Predicting species' geographic distributions based on ecological niche modeling. The Condor, v.103, p.599-605, 2001. 
PICHORIM, M.; BÓÇON, R. Estudo da composição avifaunística dos municípios de Rio Azul e Mallet, Paraná, Brasil.Acta Biológica Leopoldense, v.18, p.129-144, 1996.

PIMM, S.L. The future of biodiversity. Science, v.269, p.347-350, 1995.

PINTO, F. Aves de Alagoas.: http://ww.ao.com.br/checlis.htm. (20 out. 2002)

PINTO, O.M. Resultados ornitológicos de uma excursão pelo oeste de São Paulo e Mato Grosso. Revista do Museu Paulista, v.17, p.689-826, 1932.

PINTO, O.M. Aves da Bahia. Boletim Biológico de São Paulo, v.1, p.5-11. 1933.

PINTO, O.M. Notas de ornitologia Amazônica. Revista do Museu Paulista, v.20, p.29-244. 1936.

PINTO, O.M. Catálogo das aves do Brasil e lista dos exemplares que representam no Museu Paulista. Revista do Museu Paulista, v.22, p.1-566, 1938.

PINTO, O.M. Cinqüenta anos de investigação ornitológica. Arquivos de Zoologia de São Paulo, v.4, p.261-340, 1945.

PINTO, O.M. Contribuições ornitológicas a ornitologia do baixo Amazonas. Arquivos de Zoologia de São Paulo, v.5, p.311-482, 1947.

PINTO, O.M. Aves do Itatiaia. Papéis Avulsos de Zoologia, v.10, p.155-208, 1951.

PINTO, O.M. Súmula histórica e sistemática da ornitologia de Minas Gerais. Arquivos de Zoologia de São Paulo, v.8, p.1-51, 1952.

PINTO, O.M. Estudo crítico e catálogo remissivo das aves do território federal de Roraima. Caderno da Amazônia, n.8, p.1-176, 1966.

PINTO, O.M. Novo catálogo das aves do Brasil: Aves não Passeriformes e Passeriformes não Oscines, com exclusão da família Tyrannidae. São Paulo: Emp. Gráfica Revistas dos Tribunais, 1978. 446p. 
PINTO, O.M.; CAMARGO, E.A. Resultados ornitológicos de uma expedição ao território do Acre pelo departamento de Zoologia. Papéis Avulsos de Zoologia, v.11, p.371-417, 1954.

PINTO, O.M.; CAMARGO, E.A. Resultados ornitológicos de 4 recentes expedições do Depto Zool ao nordeste do Brasil, com a descrição de 6 novas espécies. Arquivos de Zoologia de São Paulo, v.11, p.193-284, 1961.

PIZO, M.A.; SIMÃO, I.; GALETTI, M. Diet and flock size of sympatric parrots in the Atlantic forest of Brazil. Ornitologia Tropical, v..6, p.87-95, 1995.

PODITIAGUIN, D.B. Materiales al estudio de las aves de la boca del Rio Apa. Revista de la Sociedade del Ciencias del Paraguay, v.6, p.97-114, 1994.

PRICE, O.F.; WOINARSKI, J.C.Z.; ROBINSON, D. Very large area requirements for frugivorous birds in monsoon rainforests of the Northern Territory, Australia. Biological Conservation, v.91, n.2/3, p.169-180, 1999.

PURVIS, A.; GITTLEMAN, J.L.; COWLISHAW, G.; MACE, G.M. Predicting extinction risk in declining species. Proceedings of Royal Society of London, v.267, p.1947-1952, 2000.

RAUH, T.; ROSÁRIO, L.A. Lista preliminar das aves existentes nos parques e reservas de Santa Catarina. Florianópolis: Fundação Amparo \& Tecnologia \& Meio Ambiente, 1979. 26p.

REGALADO, L. B.; DA SILVA, C.; BARRELA, E W. Levantamento da comunidade de aves do Morro de Araçoiaba - Floresta Nacional de Ipanema/ IBAMA, Iperó, SP. In: CONGRESSO BRASILEIRO DE ORNITOLOGIA, Campinas, 1996. Resumos. Campinas: Unicamp, 1996. p.98.

RODRIGUEZ, J.P. Range contraction in declining North American bird populations. Ecological Applications, v.12, n.1, p.238-248, Feb, 2002.

ROKITANSKY, G. Johann Natterer, Erster Ornitologe Oesterreichs. Journal Ornithology, v..98, n.2, p.133-144, 1957. 
ROSÁRIO, L.A. As aves em Santa Catarina: distribuição geográfica e meio ambiente. Florianópolis: Fundação Amparo \& Tecnologia \& Meio Ambiente, 1996. 326p.

S.O.S. MATA ALÂNTICA:. Atlas da evolução dos remanescentes florestais e ecossistemas associados do domínio da Mata Atlântica no período de 1991 -1995. São Paulo: Fundação S.O.S. Mata Atlântica, 1998. 87p.

SANDERCOCK, B.K.; BEISSINGER, S.R.; STOLESON, S.H.; MELLAND, R.R.; HUGHES, C.R. Survival rates of a neotropical parrot: Implications for latitudinal comparisons of avian demography. Ecology, v.81, n.5, p.1351-1370, 2000.

SCHERER-NETO, P.; ANJOS, L.; STRAUBE, F. Avifauna do Parque estadual de Vila-Velha, Estado de Paraná. Arquivos de Biologia e Tecnologia, v.37, p.223229, 1994.

SCHERER-NETO, P.; STRAUBE, F.C.; ANJOS, L. Aves. In: (Ed.). Relatório do inventário faunístico do parque florestal de Caxambú, Castro-SP. Curitiba: Divisão de Zoologia e Geologia/ Prefeitura de Curitiba, 1984.

SCHUlZ NETO, A. Lista de aves da Paraíba, João Pessoa. Paraíba: Superintendência do IBAMA, 1995. 10p.

SHORT, L.L. A zoographic analyses of the South American Chaco avifauna. Bulletin of American Museum of Natural History, v.154, p.163-352, 1975.

SICK, H. Ornitologia brasileira. Rio de Janeiro: Nova Fronteira, 1997. 912p.

SICK, H.; GONZAGA, L.P.; TEIXEIRA, D.M. A arara-azul-de-Lear, Anodorhynchus leari Bonaparte 1856. Revista Brasileira de Zoologia, v.3, n.7, p.441-463, 1987.

SILVEIRA, F.L. The birds of Serra da Canastra National Park and adjacent areas, Minas Gerais, Brazil. Cotinga, v.10, p.55-63, 1998.

SNETHLAGE, E. Catálogo das aves amazônicas. Boletim do Museu Paraense Emilio Goeldi, v.8, p.1-153, 1914. 
SNYDER, N.F.R.; WILEY, J.W.E.; KEPLER, C.B. . The parrots of Luquillo: natural history and conservation of the Puerto Rican Parrot: The Western Foundation, 1987. $384 p$.

SNYDER, N.F.R.; MCGOWAN, P.; GRAJAL, A. Parrots survey and conservation Action Plan 2000. Cambridge: IUCN Grand, 2000. 180 p.

SOULÉ, M.E. Viable populations for Conservation. Cambridge: Cambridge University Press, 1987. 206 p.

STRAUBE, F.C. Contribuições ao conhecimento da avifauna da região sudeste do estado do Paraná. Biotemas, v.1, p.63-75, 1988.

STRAUBE, F.C.; BONSCHEIN, R. A contribuição de André Mayer à história natural do Paraná (Brasil): Sobre a coleção de aves do extremo noroeste do Paraná e Sul do Mato Grosso do Sul. Arquivos de Biologia e Tecnologia, v.32, p.441-471, 1989.

STRAUBE, F.C.; BONSCHEIN, R.; SCHERER-NETO, P. Coletânea da avifauna da região noroeste do Estado do Paraná e áreas limítrofes. Arquivos de Biologia e Tecnologia, v.39, p.193-214, 1996.

STRAUBE, F.C.; SCHERER-NETO, P. História da ornitologia no Paraná. In: CONGRESSO BRASILEIRO DE ORNITOLOGIA, 9., Curitiba, 2001. Ornitologia sem fronteiras; resumos. Curitiba: Fundação O Boticário de Proteção à Natureza, 2001, p.43-116.

SZTOLCMAN, J. Étude des collections ornithologiques de Paraná. Annales Zoologici Musei Polonici Historiae Naturalis, v.5, n.3, p.197-235, 1926.

THOMSON, J.D.; WEIBLEN, G.; THOMSON, B.A.; ALFARO, S.; LEGENDRE, P. Untangling multiple factors in spatial distributions: Lilies, gophers, and rocks. Ecology, v.77, n.6, p.1698-1715, 1996.

TISCHENDORF, L. Can landscape indices predict ecological processes consistently?

Landscape Ecology, v.16, n.3, p.235-254, 2001.

TRAVASSOS FILHO, L. Excursão científica a Porto Cabral, margem paulista do Rio 
Paraná. Arquivos de Zoologia de São Paulo, v.4, p.1 -32, 1944.

TRAVASSOS FILHO, L. Segunda expedição científica a Porto Cabral, margem paulista do Rio Paraná. Arquivos de Zoologia de São Paulo, v.5, p.89-134, 1946.

TUBILIS, D.P.; TOMÁS, W.M. Distribution of birds in a naturally patchy forest enviroment in the Pantanal wetland, Brazil. Ararajuba, v.7, p.81-89, 1999.

VASCONCELOS, M.F.; ROOS, A.L. Novos registros de aves para o PE do Morro do Diabo, São Paulo. Mellopsittacus, v.3, p.81-84, 2000.

VENTURINI, A.C.; REHEN, M.P. Contribição e conhecimento das aves e mamíferos dos Municípios de Santa Maria de Jequitiba e Itarana. Neotropical Atlântico, v.1, n.2. 2000. http://www.originalisnatura.com.br/informa/neot1a.htm. (20 out. 2002).

VIANA, V. M.; TABANEZ, A. A. Biology and conservation of forest fragments in the Brazilian Moist Forest. In: SCHELlAS, J.; GREENBERG, R. (Eds.). Forest patches in tropical landscapes. Washington: Island Press, 1996.

VILLARD, M.; TAYLOR, P.D. Tolerance to habitat fragmentation influences the colonization of new habit by forest birds. Oecologia, v.98, p.393-401, 1994.

WEGE, D.C.; LONG, A.J. Key areas for threatened birds in the Neotropics. Cambridge: BirdLife International, 1995. 311p. (BirdLife Conservation Series)

WEINBERG, L.F. Aves do Pantanal do Mato Grosso do Sul. Boletim FBCN, v.19, p.81-88, 1984.

WIENS, J. A. Spatial Scaling in ecology. Functional Ecology, n.3, p.385-397. 1989.

WIENS, J. A. Metapopulation dynamics and landscape ecology. In: Hanski, A.; Gilpin, M.E. (Ed.). Metapopulation biology: ecology, genetics, and evolution Cambridge: . Academic Press, 1997. cap.3, p.43-68.

WILLIS, E.O. Lista preliminar das aves da parte noroeste e áreas vizinhas à reserva Ducke. Revista Brasileira de Biologia, v.37, p.858-601, 1977. 
WILLIS, E.O. The composition of avian communities in remanescent woodlots in southern Brazil. Papeis Avulsos de Zoologia, v.33, p.1-25, 1979.

WILLIS, E.O. Aves observadas em Balbina, Amazonas e os prováveis efeitos da barragem. Ciência e Cultura, v.40, p.280-284, 1988.

WILLIS, E.O. Levantamento preliminar das aves de inverno em 10 áreas do sudoeste de Mato Grosso. Ararajuba, v.1, p.19-38, 1990.

WILLIS, E.O.; ONIKI, Y. Levantamento preliminar em treze áreas do Estado de São Paulo. Revista Brasileira de Biologia, v.41, p.121-135, 1981.

WILLIS, E.O. Avifaunal transects across the open zones of northern Minas Gerais, Brazil. Ararajuba, v.2, p.41-58, 1991.

WILSON, E.O. Biodiversity. Washington: National Academic Press, 1988 b. 538p.

WILSON, R.J.; ELLIS, S.; BAKER, J.S.; LINEHAM, M.E.; WHITEHEAD, R.W.; THOMAS, C.D. Large-scale patterns of distribution and persistence at the range margins of a butterfly. Ecology, v.83, n.12, p.3357-3368, 2002.

YAMASHITA, C. Ocorrência de Ara maracana e Pyrrhura leucotis em Serra Negra (PE). In: CONGRESSO BRASILEIRO DE ZOOLOGIA, 1985. Resumos, 1985. p.225-256.

YAMASHITA, C. Histórico comentado sobre a arara-azul-de-Spix (Cyanopsitta spixii), um especialista de hábitat da Caatinga. In: GALETTI, M.; PIZO, E M. A. (Ed.). Ecologia e conservação de psitacídeos no Brasil. Belo Horizonte: Melopsittacus Publicações Científicas, 2002. cap.13, p.229-235.

ZIMMERMANN, C.E. Nota sobre a avifauna do Parque Ecológico Spitzkopf Blumenau/ SC. Dynamis, v.1, n.3, p.7-13, 1993. 
APENDICE 


\section{APÊNDICE 1}

Tabela 1. Dados não publicados de registros de Primolius maracana, obtidos em consulta a ornitólogos. As informações entre parênteses após o nome dos observadores referem-se às datas dos registros e a letra "a" é designada para registros em que as datas não foram especificadas, porém vieram com a informação de que a espécie tem ocorrência atual no local.

Continua

\begin{tabular}{|c|c|c|}
\hline$\overline{\mathbf{U F}}$ & Localidade de registro & Fonte* \\
\hline$\overline{\mathrm{BA}}$ & Canudos & Yara Barros (2001) \\
\hline $\mathrm{BA}$ & Caraíbas & Eduardo Carrano (1999) \\
\hline BA & Curaçá & Yara Barros (2001) \\
\hline BA & Jeremoabo & Eduardo Carrano (1999) \\
\hline BA & Uauá & Eduardo Carrano (1999) \\
\hline $\mathrm{CE}$ & Aiuaba & Luiz Gonzaga Sales Jr. (a) \\
\hline $\mathrm{CE}$ & Tauá & Luiz Gonzaga Sales Jr. (a) \\
\hline ES & Conceição da Barra & Carlos Yamashita (a) \\
\hline ES & São Mateus & Edwin O' Willis** (1993) \\
\hline GO & P.N. Chapada dos Veadeiros & Eduardo Carrano (2001) \\
\hline MG & Baependi & Tadeu Mello Jr. (a) \\
\hline MG & Itajubá & Herculano Alvarenga (a) \\
\hline MG & Itamonte & Carlos Yamashita (a), Herculano Alvarenga (a) \\
\hline MG & Juiz de Fora & Luís Fábio Silveira (1999) \\
\hline MG & P.E. de Ibitipoca & Dante Burzzetti (1996), Luís Fábio Silveira (1996) \\
\hline MG & P.E. do Rio Preto & Tadeu Mello Jr (2001) \\
\hline MG & PN. Serra da Canastra & Luís Fábio Silveira (desde 1996), Tadeu Mello Jr (1997) \\
\hline MS & Coxim & Eduardo Carrano (2000) \\
\hline MS & Pedro Gomes & Eduardo Carrano (2000) \\
\hline MS & Sonora & Eduardo Carrano (2000) \\
\hline MT & Barão de Melgaço & Eduardo Carrano (2001) \\
\hline MT & Cangas & Eduardo Carrano (2001) \\
\hline \multirow[t]{2}{*}{ MT } & Joselândia & Eduardo Carrano (2001) \\
\hline & & Continua \\
\hline$\overline{\mathbf{U F}}$ & Localidade de registro & Fonte* \\
\hline MT & P.E. Serra de Santa Bárbara & Eduardo Carrano (2000) \\
\hline MT & P.N. Chapada dos Guimarães & Dante Buzzetti (1990, 1998), Eduardo Carrano (2001) \\
\hline MT & Pixaim & Eduardo Carrano (2001) \\
\hline MT & Poconé & Eduardo Carrano (2001) \\
\hline MT & Rio Cristalino & Braulio A. Carlos (a) \\
\hline
\end{tabular}




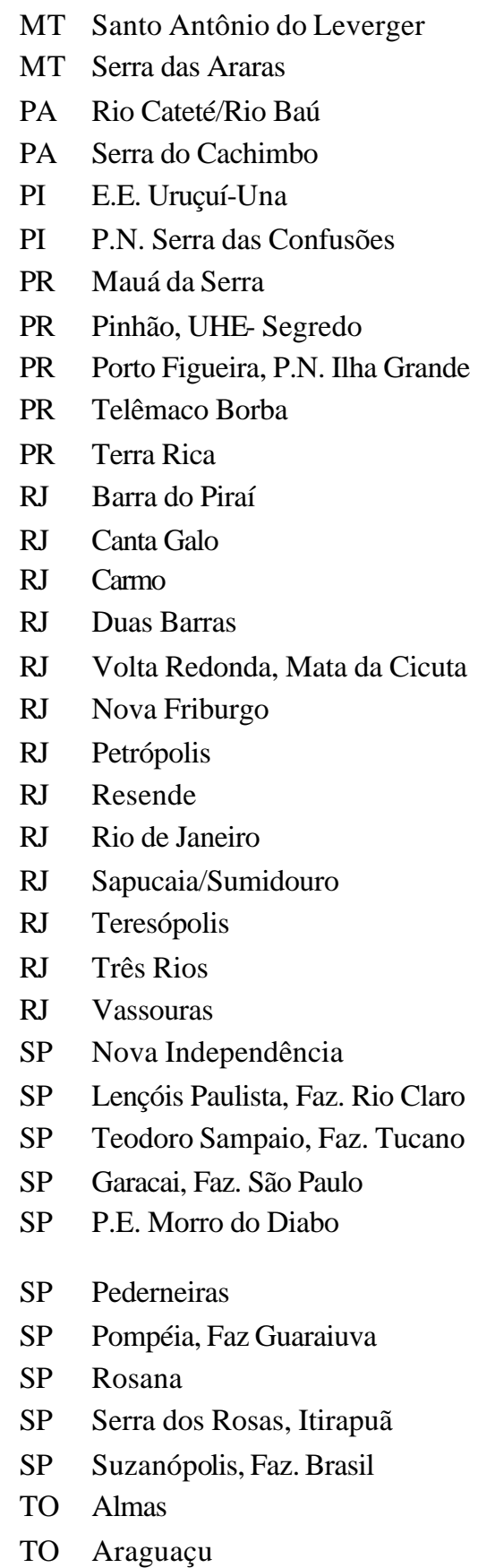

Eduardo Carrano (2001)

Eduardo Carrano (2001)

Carlos Yamashita (a)

Carlos Yamashita (a)

Luís Fábio Silveira (2000)

Luís Fábio Silveira (2000)

Eduardo Carrano (2000)

Fernando Costa Straube (1992)

Eduardo Carrano (2001)

Eduardo Carrano e Pedro Scherer-Neto (1997)

Alberto Urben-Filho (1999)

Herculano Alvarenga (a)

Ricardo Gagliardi (1992)

Ricardo Gagliardi (1992)

Ricardo Gagliardi (1992)

Carlos Yamashita (a), Herculano Alvarenga (a)

Marcos Raposo (a)

Marcos Raposo (a)

Marcos Raposo (a), Carlos Yamashita (a)

Marcos Raposo (a)

Ricardo Gagliardi (1992)

Marcos Raposo (a)

Carlos Yamashita (a)

Herculano Alvarenga (a)

Edwin O' Willis (1984)

Tadeu Mello Jr. (1997)

Tadeu Mello Jr. (2000)

Edwin O' Willis (1984)

Eduardo Carrano, Cassiano Ribas e Pedro Scherer-Neto (1999)

Fernando Costa Straube (2000)

Edwin O' Willis (1986)

Eduardo Carrano e Pedro Scherer-Neto (1997)

Edwin O' Willis (1997)

Edwin O' Willis (1996)

Eduardo Carrano (1998)

Alexandre Aleixo (a)

Conclusão

\begin{tabular}{cll}
\hline UF & Localidade de registro & Fonte* \\
\hline TO & Caseara, estrada p/ Palmas & Dante Burzzetti (1999) \\
TO & Gurupí & Eduardo Carrano (1998) \\
TO & Natividade & Eduardo Carrano (1998) \\
\hline
\end{tabular}

Notas: *ornitólogos: Alberto Urben-Filho (Sociedade Fritz Müller de Ciência Naturais), Alexandre Aleixo (colaborador do Museu Emílio Goeldi), Braulio A. Carlos (Pantanal Bird Club), Carlos Yamashita 
(IBAMA/SP), Dante Burzzetti (USP), Eduardo Carrano (colaborador do MHNCI, PR), Cassiano F. Ribas (colaborador do MHNCI, PR), Edwin O' Willis (UNESP- Rio Claro), Fernando Costa Straube (Sociedade Fritz Müller de Ciência Naturais), Herculano Alvarenga (ornitólogo- SP), Luís Fábio Silveira (USP), Luiz Gonzaga Sales Jr. (UECE), Marcos Raposo (MNRJ), Pedro Scherer-Neto (MHNCI), Ricardo Gagliardi (ornitólogo - RJ), Tadeu Mello Jr (UNIFRAN, S.P.), Yara Barros (projeto Ararinha Azul). **Dados obtidos através da Aracruz Celulose S. A., Espírito Santo. 


\section{APÊNDICE 2}

Tabela 1. Espécimes de Primolius maracana depositados em museus nacionais e internacionais.

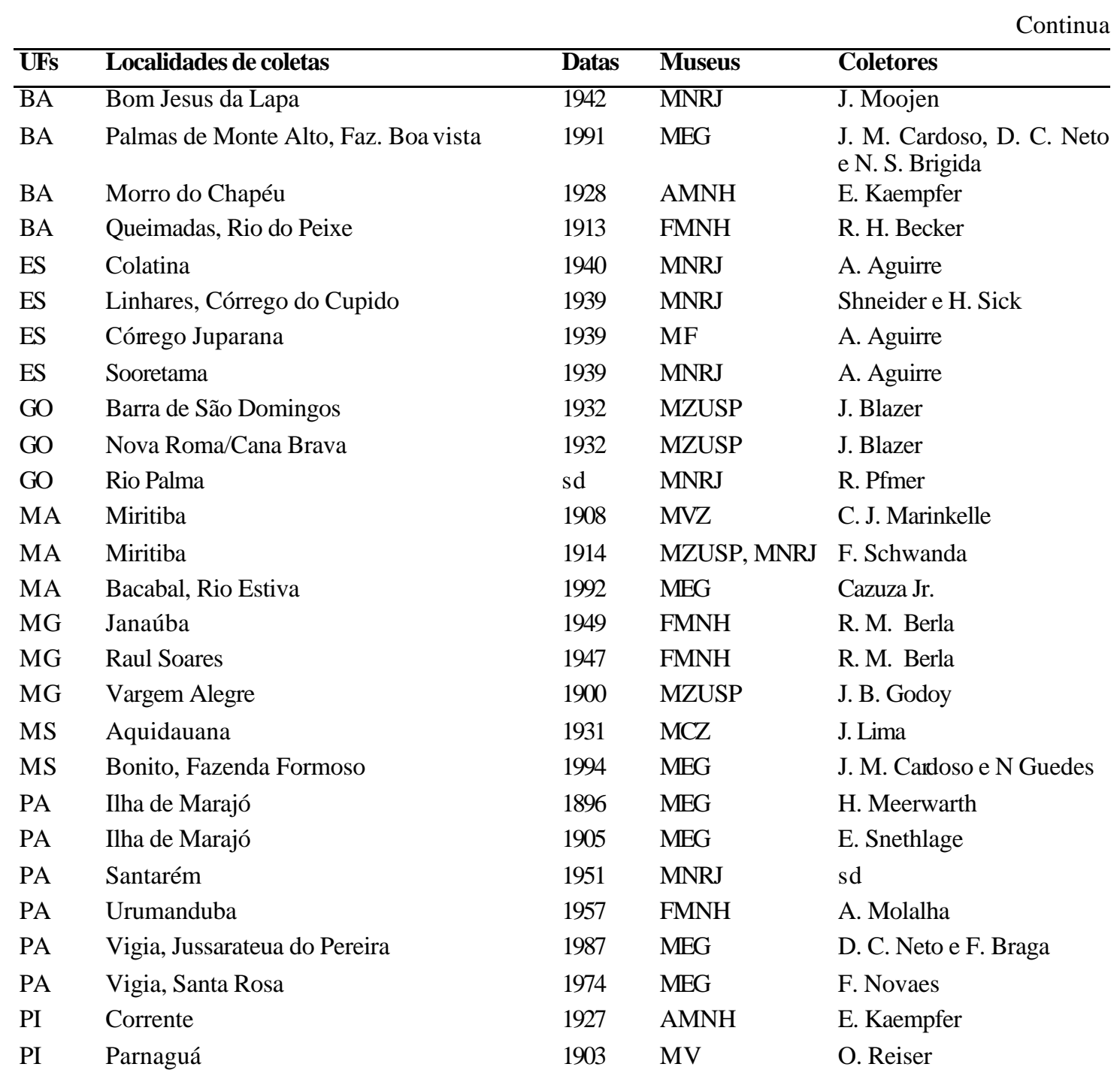




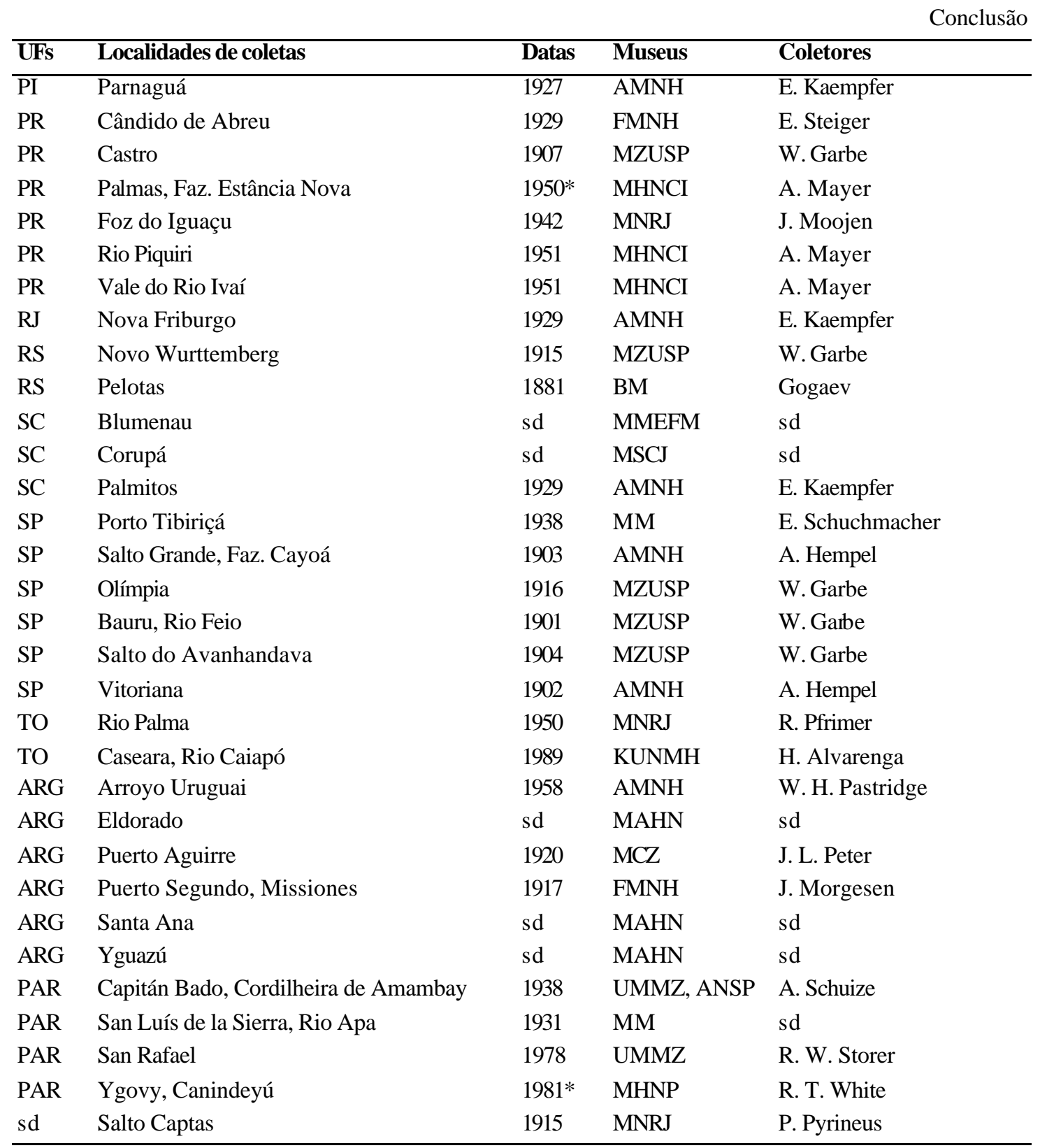

Notas: Museu de Zoologia da USP (MZUSP), Museu Paraense Emílio Goeldi (MEG), Museu Nacional do Rio de Janeiro (MNRJ), Museu de História Natural do Capão da Imbuia (MHNCI), Museu da Fauna (MF), Museu Sagrado Coração de Jesus (MSCJ), Museu Municipal Eco. Fritz Muller (MMEFM) Museo Nacional de Historia Natural del Paraguay (MNHNP), Museo Argentino de Ciencias Naturales (MACN), American Museum of Natural History (AMNH), Field Museum of Natural History (FMNH), Museum of Vertebrate Zoology (MVZ), Museum of Comparative Zoology (MCZ), University of Kansas Natural History Museum (KUNHM), University of Michigan Museum of Zoology (UMMZ), Academy of Natural Sciences of Philadelphia (ANSP), British Museum (BM), Museu de História Natural de Viena (MHNV) e Museu de Munich (MM).

O código "sd" significa "sem dados".

*datas de coletas aproximadas inferidas a partir de informações na literatura 


\section{APÊNDICE 3}

Tabela 1 - Estatus atual (considerado a partir de 1980) de Primolius maracana nas localidades de Domínio Mata Atlântica no sul e sudeste do Brasil. O número "0" significa ausente e "1" presente e o símbolo "*” indica dados não publicados, adquiridos através de comunicação pessoal.

Continua

\begin{tabular}{lccl}
\hline Local & UF & Estatus & Fonte \\
\hline Aracruz & ES & 1 & Aracruz Celulose 2000 \\
Conceição da Barra & ES & 1 & C. Yamashita* \\
Santa Maria do Jetibá & ES & 1 & Venturini, 2000 \\
Sooretama & ES & 1 & Marsden et al.,.2000 \\
Baependi & MG & 1 & T. Mello Junior* \\
Caratinga & MG & 1 & T. Mello Junior* \\
Itajubá & MG & 1 & H. Alvarenga* \\
Juiz de Fora & MG & 1 & L.F. Silveira* \\
Lagoa Santa & MG & 0 & Christiansen \& Pitter, 1997 \\
Raul Soares (Rio Doce) & MG & 1 & Willis \& Oniki, 1991 \\
Santa Bárbara do Monte Verde & MG & 1 & Garske et al. 2001 \\
Viçosa & MG & 1 & Maldonato 1998 \\
Castro & PR & 0 & Bornschein \& Straube,1991; Scherer-Neto et al., \\
Diamante do Norte, EE.dos Caiuá & PR & 1 & Straube et al., 1996 \\
Foz do Iguaçú & PR & 1 & Bornschein \& Straube 1991 \\
Mauá da Serra & PR & 1 & E. Carrano* \\
Londrina, P.E. Mata dos Godoy & PR & 1 & Anjos et al., 1997a, b \\
P.N. Ilha Comprida & PR & 1 & E. Carrano* \\
Palmas & PR & 0 & Bornschein \& Straube, 1991; Pichorin \& Boçon, \\
Pinhão & PR & 1 & F. C. Straube* \\
Rio Piquiri & PR & 0 & Straube et al., 1996 \\
São Domingos & PR & 0 & Bornschein \& Straube, 1991; Pichorin \& Boçon \\
& & & 1996 e D. Kajiwara* \\
& & & \\
\hline & & &
\end{tabular}


Conclusão

\begin{tabular}{|c|c|c|c|}
\hline Local & $\overline{\mathbf{U F}}$ & Estatus & Fonte \\
\hline Telêmaco Borba & PR & 1 & E. Carrano, P.Scherer-Neto* \\
\hline Duas Barras & $\mathrm{RJ}$ & 1 & R. Gagliardi* \\
\hline Volta Redonda, Floresta da Cicuta & $\mathrm{RJ}$ & 1 & C. Yamshita* \\
\hline Itatiaia & $\mathrm{RJ}$ & 1 & Parker \& Goerk, 1997 \\
\hline Petrópolis & $\mathrm{RJ}$ & 1 & M. Raposo* \\
\hline Rio de Janeiro & $\mathrm{RJ}$ & 1 & M. Raposo* \\
\hline Três Rios & $\mathrm{RJ}$ & 1 & C. Yamshita* \\
\hline Vassouras & $\mathrm{RJ}$ & 1 & H. Alvarenga* \\
\hline Canela & $\mathrm{RS}$ & 0 & Belton, 1994 \\
\hline Novo Wurttemberg & $\mathrm{RS}$ & 0 & Belton, 1994 \\
\hline Pelotas & $\mathrm{RS}$ & 0 & Belton, 1994 \\
\hline Poço das Antas & $\mathrm{RS}$ & 0 & Belton, 1994 \\
\hline Torres & $\mathrm{RS}$ & 0 & Belton, 1994 \\
\hline Blumenau & $\mathrm{SC}$ & 0 & Rosário, 1996 e Zimmermann, 1993 \\
\hline Corupá & $\mathrm{SC}$ & 0 & Rosário, 1996 \\
\hline Palmitos & $\mathrm{SC}$ & 0 & Rosário, 1996 \\
\hline Anhembi & SP & 1 & Observação Pessoal \\
\hline Gália, E.E. Caetetus & SP & 1 & Nunes, 2000 \\
\hline Ipanema & $\mathrm{SP}$ & 0 & Regalado et al., 1996 \\
\hline Lençóis Paulista & SP & 1 & T. Mello Ju nior* \\
\hline Taubaté, Matto Dentro & SP & 0 & Alvarenga* \\
\hline Itararé, Morungaba & SP & 0 & Observação pessoal \\
\hline Nova Independência & SP & 1 & E.O Willis* \\
\hline Olímpia & SP & 0 & Observação pessoal \\
\hline Teodoro Sampaio, P.E. Morro do Diabo & SP & 1 & E. Carrano* \\
\hline Patrocínio Paulista & SP & 1 & Observação pessoal \\
\hline Pederneiras & SP & 1 & F. C Straube* \\
\hline Pompeia & SP & 1 & E.O Willis* \\
\hline Presidente Epitácio, Porto Tibiriçá & SP & 0 & Observação pessoal \\
\hline Salto do Avanhandava & SP & 0 & Observação pessoal \\
\hline Salto Grande & SP & 0 & Observação pessoal \\
\hline Suzanópolis & SP & 1 & E.O Willis* \\
\hline
\end{tabular}

Nota: * Carlos Yamashita (IBAMA/SP), Eduardo Carrano (colaborador do MHNCI, PR), Edwin O' Willis (UNESP- Rio Claro), Fernando Costa Straube (Sociedade Fritz Müller de Ciência Naturais), Herculano 
Alvarenga (ornitólogo- SP), Luís Fábio Silveira (USP), Marcos Raposo (MNRJ), Rdro Scherer-Neto (MHNCI), Ricardo Gagliardi (ornotólogo - RJ), Tadeu Mello Jr (UNIFRAN, S.P.). 


\section{APÊNDICE 4}

\section{Áreas visitadas no Estado de São Paulo}

Foram visitadas sete localidades de antigos registros de Primolius maracana no Estado de São Paulo, a fim de verificar se a espécie ainda persiste nessas áreas. Procurou-se amostrar os maiores remanescentes de floresta dessas regiões. Se havia trilhas no interior dos fragmentos, elas eram utilizadas e, caso contrário, a borda da mata era percorrida. Foram também explorados pontos estratégicos com ampla visão, a fim de detectar vocalização da espécie e indivíduos em vôo (Nunes \& Betini, 2002). Esse método é adequado para registrar espécies de psitacídeos que têm a característica particular de voarem acima do dossel e de se deslocarem para dentro ou para fora dos fragmentos florestais nos períodos do nascer e por do sol (Evans, 1991; Gnan \& Burchsted, 1991; Lambert, 1993 e Snyder et al., 1987), como Primolius maracana (Marsden et al., 2000 e Nunes, 2000).

Os moradores locais das áreas visitadas também foram entrevistados a fim de obter informações sobre quais espécies de psitacídeos ocorrem na região de estudo. $\mathrm{O}$ método empregado foi de entrevista não-estruturada, em que o entrevistador introduz o assunto informalmente para o entrevistado e coleta informações a partir do depoimento realizado.

1. Fazenda Barreiro Rico $\left(\mathbf{2 2}^{\circ} \mathbf{4 0}{ }^{\prime} 48^{\prime}\right.$ ' s, 48 ${ }^{\circ} 09^{\prime} 00$ ' o): Propriedade particular no município de Anhembi, localizada na região do interflúvio Tietê-Piracicaba, que mantém fragmentos vizinhos de Floresta Semidecídua, totalizando 2200 ha, e que estão rodeados por áreas de pastagens e plantações de cana-de-açúcar. O local é próximo ao 
represamento do Rio Tietê em Barra Bonita, realizado no ano de 1961, que inundou áreas de a mata ciliar da região. Primolius maracana foi registrada na mata da fazenda por Willis, no final da década de 70 (Willis, 1979).

Em nosso estudo foram realizadas duas visitas na localidade, entre 8 e 10 de junho de 2000 e em 5 e 6 de junho de 2001, somando 38 horas de observação. Durante esse período foram obtidos 9 contatos com o maracanã, 7 em 2000 e 2 em 2001, indicando que a espécie é pouco abundante no local. Além do maracanã, outras espécies de psitacídeos foram registradas na área: Brotogeris versiculorus, Pyrrhura frontalis, Aratinga leucophtalmus, Pionus maximilliani e Amazona aestiva

2. Fazenda Santa Cecília $\left(2^{\circ} 34^{\prime} 48^{\prime \prime}\right.$ s, $47^{\circ} 16$ '12” o): Propriedade particular localizada no Município de Patrocínio Paulista que mantém um Fragmento de 100 ha de floresta Semidecídua, rodeado principalmente por áreas de cerrado e pastagem. Esse remanescente, apesar de reduzido, possui uma vegetação composta de muitas espécies arbóreas altas com grandes diâmetros, como figueiras, e representa um dos maiores fragmentos de mata da região. Primolius maracana foi anteriormente registrada no local por Willis em 1997 (informação pessoal).

Em nosso estudo foi realizada uma visita na localidade, de 29 de janeiro a 2 de fevereiro de 2002, somando 34 horas de observação. Durante esse período foram obtidos 18 contatos com indivíduos de Primolius maracana, porém alguns desses registros provavelmente foram de um mesmo grupo de indivíduos, registrados em dias diferentes. Aparentemente visitaram a área entre 5 a 9 indivíduos da espécie. Outros psitacídeos também foram observados como Brotogeris versiculorus, Aratinga auricapilla, Aratinga aurea, Pionus maximilliani e Aratinga leucophtalmus.

3. Região de Salto Grande (22 ${ }^{\circ} 13{ }^{\prime} 48^{\prime}{ }^{\prime}$ s, $4^{\circ} 9^{\circ} 9^{\prime} 00 ’$ ' o): Região sul do Estado de São Paulo, nas margens do Rio Paranapanema. Hempel visitou a região em 1903, quando era quase que inteiramente virgem (Pinto, 1945), e coletou Primolius maracana na Fazenda Cayoá, nas margens do Paranapanema. Atualmente ocorrem pequenos fragmentos de Floresta Semidecídua rodeados principalmente por pasto e plantações de 
soja, cana-de-açúcar e mais raramente café. Há em Salto Grande uma usina hidrelétrica construída no ano 1960, que resultou na inundação de áreas de mata ciliar.

Durante o período de 17 a 21 de fevereiro de 2002 foram visitados o remanescente de mata da Fazenda Cayoá (2255'38' s, 4959'17 o) e outros fragmentos

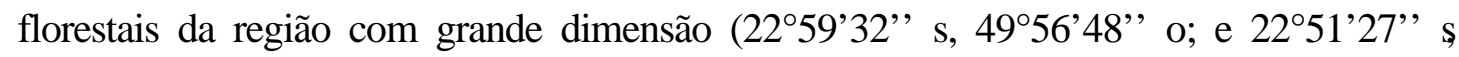
4957'56 o). Foi realizado um total de 37h27min de observação em matas da região e Primolius maracana não foi registrada. Conversas com moradores indicaram a presença de "um maracanã", que é raro, porém as descrições foram contraditórias. Outros psitacídeos foram observados como Brotogeris versiculorus, Pionus maximilliani $e$ Aratinga leucophtalmus.

4. Região de Olímpia (20 44 '00' s; 48 54 '36” o): Região norte do Estado de São Paulo, onde praticamente não restam remanescentes de Florestas Semidecíduas e predominam culturas de cana de açúcar e pastagens. Garbe visitou a região em 1916 e coletou um espécime de Primolius maracana nas proximidades da então pequena Vila Olympia.

Durante o período de 3 a 7 de abril de 2002 foram visitados os maiores remanescentes florestais da região $\left(20^{\circ} 50^{\prime} 41^{\prime \prime}\right.$ s, 49 $05^{\prime} 34^{\prime \prime}$ o; e $20^{\circ} 37^{\prime} 36^{\prime \prime}$ s, 4905'25" o). Foi realizado um total de 34h22min de observação e Primolius maracana não foi registrada. A população local também foi informalmente consultada, porém não houve descrições que indicassem a presença do maracanã na área. Outros psitacídeos foram observados como Brotogeris versiculorus, Aratinga auricapilla, Aratinga aurea, Forpus crysopterygius, Aratinga leucophtalmus e Amazona aestiva.

5. Região de Itararé $\left(\mathbf{2 4}^{\circ} 02{ }^{\prime} 24\right.$ ' s; $4^{\circ} \mathbf{2 4}^{\prime 36}{ }^{\prime \prime}$ o): Região de limite meridional do Estado, em área ecótone entre Floresta Ombrófila Mista com Araucária e regiões de Savana. Atualmente os maiores fragmentos florestais concentram-se em áreas mais íngremes e o entorno é principalmente composto por reflorestamento de Pinus sp., além da ocorrência de áreas de mineração, em sua maioria de calcário. Há dois antigos 
registros de Primolius maracana para a região, feitos por Natterer em 1918, em Itararé e Morungaba (próximo ao Rio Itararé).

Entre os dias 24 e 28 de abril de 2002, os maiores fragmentos da região foram

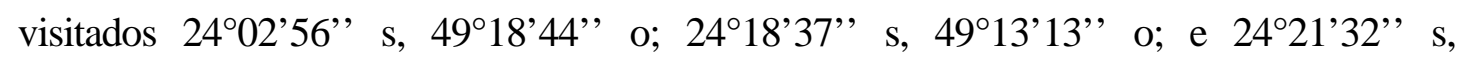
49²3'54" o), somando um total de 38h40min de observação. Durante esse período, Primolius maracana não foi avistada na localidade. Conversas com moradores indicaram a presença de "um maracanã", que é raro, chamado Araguari, porém as descrições foram contraditórias. Outros psitacídeos foram observados como Pyrrhura frontalis, Brotogeris versiculorus, Pionus maximilliani, Forpus crysopterygius $e$ Amazona aestiva.

\section{Região de Salto do Avanhandava e São Jerônimo (21 ${ }^{\circ} 1^{\prime} 48$ 's ; 1958'12'”}

o): Região noroeste do Estado, a margem esquerda do baixo Rio Tietê, na altura da cidade de Penápolis. Em 1903, o coletor do Museu Paulista, Ernesto Garbe, colecionou dois exemplares de Primolius maracana na região, um nas proximidades do Salto do Avanhandava e outro em São Jerônimo, córrego que deságua nesta altura do rio Tiête. Atualmente a paisagem se constitui principalmente de culturas de cana-de-açúcar, pastagens e pequenos remanescentes florestais. Além da mudança no uso da terra, a paisagem do Salto do Avanhandava também foi modificada em relação a 1903 devido à barragem do Rio Tietê construída em Barbosa em 1982 que resultou o alagamento de matas ciliares e também do Salto do Avanhandava.

Os maiores fragmentos florestais dessa região foram visitados de 9 a 13 de agosto de 2002, somando um total de 36h40min de observação, porém o maracanã não foi registrado. Moradores da região também foram consultados, porém não houve indicações da ocorrência da espécie no local. Outros psitacídeos avistados no local foram Forpus crassopterygius, Brotogeris versiculorus, Aratinga auricapilla, Aratinga aurea, Aratinga leucophtalmus, Amazona aestiva, Amazona amazônica, Pionus maximilliani e houve indícios e relatos da presença de Ara ararauna no local. 
7. Região de Porto Tibiriçá (21 ${ }^{\circ} 48$ '36” s; 5209’36” o): Região extremo oeste do Estado de São Paulo, às margens do Rio Paraná, divisa com Mato Grosso do Sul. A localidade que hoje é conhecida como Presidente Epitácio foi visitada por E. Schuchmacher em 1938, quando ainda havia grandes áreas florestais (Travassos Filho, 1944 e 1946) que coletou Primolius maracana no local. Atualmente a paisagem é constituída principalmente por pastagens restando fragmentos florestais ao norte do município, no Rio do Peixe, e ao sul em direção ao Pontal do Paranapanema.

A região foi visitada entre 14 a 18 de agosto de 2002, somando 34 horas de observação. Durante esse período o maracanã não foi avistado. Apenas uma entrevista nos chamou a atenção, que foi um integrante de um acampamento de sem-terra vizinho a um fragmento florestal, que indicou a presença da "arara azul e amarela e, às vezes outro tipo, menor, do bico preto". Entretanto o maracanã não foi avistado no local, apenas a arara-canindé Ara ararauna e o periquito verde (Aratinga leucophtalmus), além de outros psitacídeos menores.

Uma gerência regional do IBAMA e um escritório da CESP foram também visitados a fim de obter informações de apreensões e levantamentos de aves na localidade. No IBAMA não houve indicações da presença do maracanã no local e na CESP foi examinada uma lista de aves da região elaborada por J. Nascimento do CEMAVE, a qual não incluía Primolius maracana na lista local, porém a espécie havia sido avistada ao noroeste da região, em Brasilândia-MS no ano de 2000. O maracanã também é raramente avistado no Pontal do Paranapanema, o que não exclui a possibilidade de alguns indivíduos eventualmente cruzarem a região de Presidente Epitácio. Os psitacídeos avistados na região foram: Forpus crassopterygius, Brotogeris versiculorus, Aratinga aurea, Aratinga leucophtalmus, Amazona aestiva, Amazona amazonica, Pionus maximilliani e Ara ararauna. 


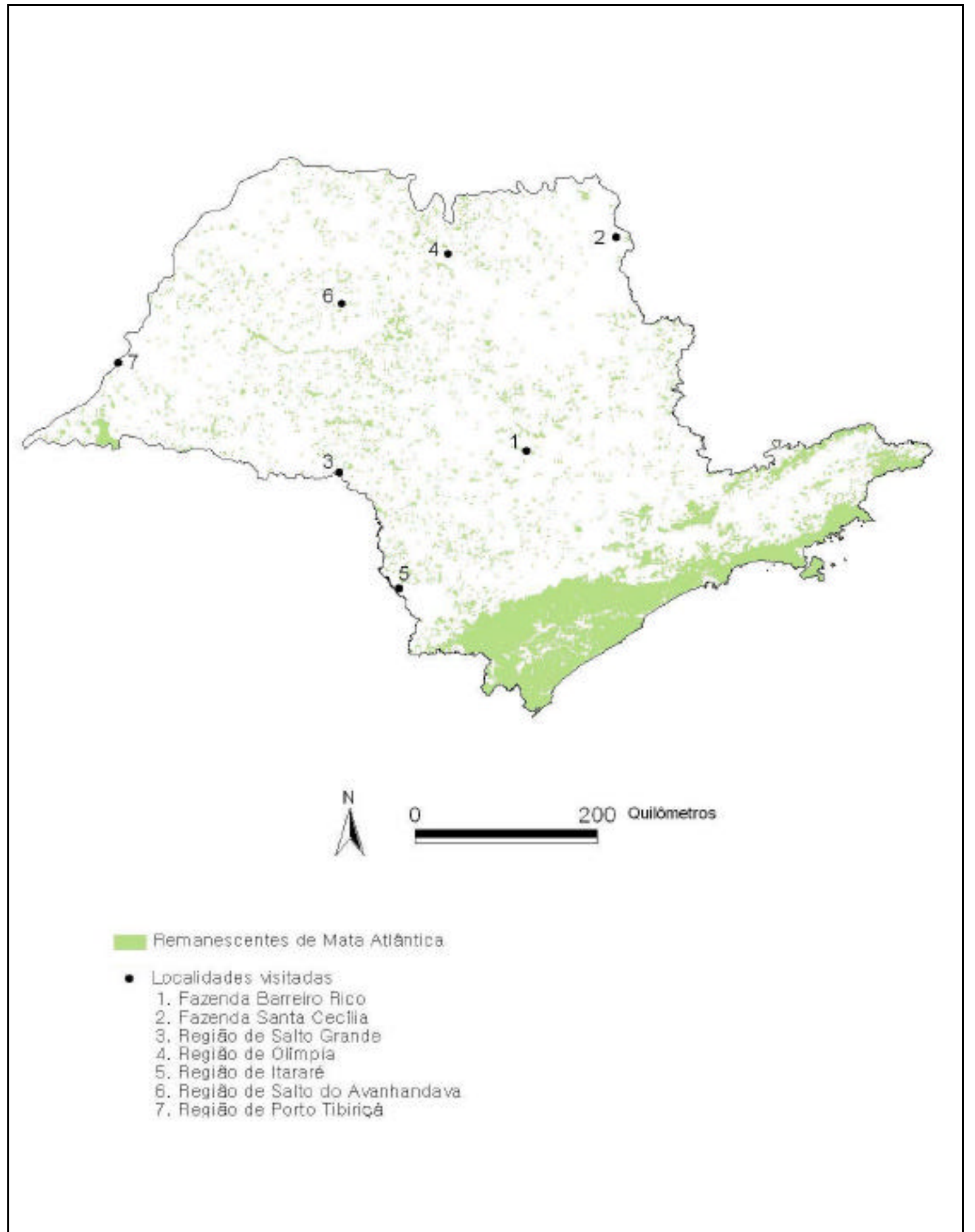

Figura 1 - Localidades visitadas no Estado de São Paulo 
APÊNDICE 5 


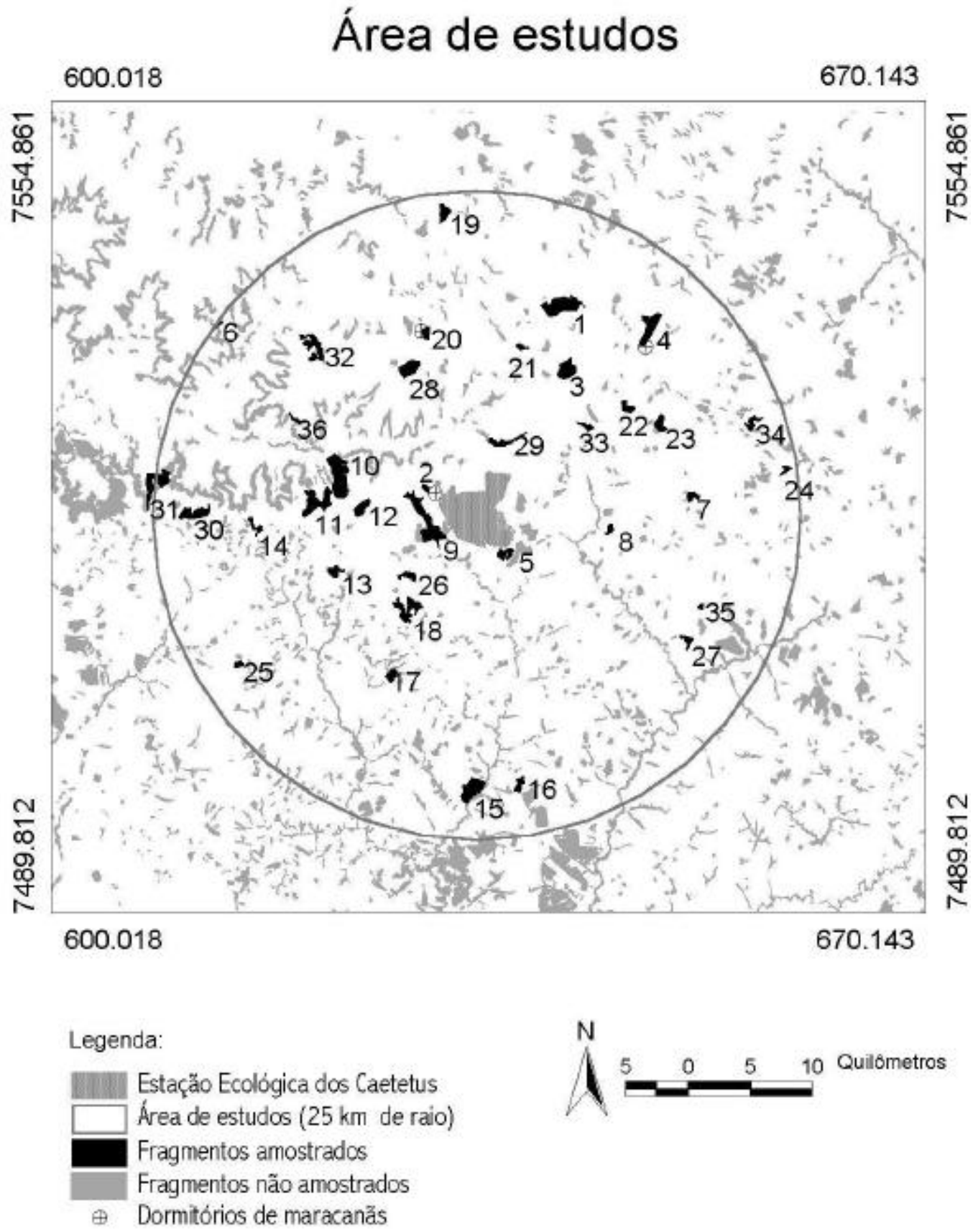

Figura 1 - Fragmentos amostrados e dormitórios encontrados no entorno da E. E. dos Caetetus 


\section{APÊNDICE 6}

Tabela 1 - Fragmentos amostrados, suas características e índices de visitas de maracanãs.

\begin{tabular}{|c|c|c|c|c|c|c|c|c|c|}
\hline & & & & & & & & & Continua \\
\hline Fragmento & $\mathrm{C}$ & $\mathrm{E}$ & $\begin{array}{c}\mathrm{T} \\
\text { (ha) }\end{array}$ & IF & IPF & $\begin{array}{c}\mathrm{DC} \\
(\mathrm{km})\end{array}$ & $\begin{array}{c}\text { DEEC } \\
(\mathrm{km})\end{array}$ & $\begin{array}{r}\text { DD } \\
(\mathrm{km})\end{array}$ & $\begin{array}{l}\text { Índice de } \\
\text { visitas de } \\
\text { maracanãs }\end{array}$ \\
\hline 1 & mata & café & 321,21 & 1,75 & 1,01 & 1,34 & 13,01 & 6,22 & 0,11 \\
\hline 2 & mata & café & 21,78 & 1,28 & 88,25 & 6,19 & 0,66 & 0,59 & 0,15 \\
\hline 3 & mata & café & 164,97 & 1,23 & 1,41 & 6,19 & 8,76 & 5,79 & 0,03 \\
\hline 4 & mata & pasto & 200,61 & 1,72 & 0,68 & 1,37 & 14,70 & 0,21 & 0,27 \\
\hline 5 & capoeira & eucalipto & 78,75 & 1,98 & $1.759,46$ & 8,32 & 0,09 & 6,84 & 0,28 \\
\hline 6 & mata & café & 19,17 & 1,40 & $1.392,96$ & 1,73 & 21,26 & 15,95 & 0,00 \\
\hline 7 & capoeira & cítricos & 45,99 & 1,41 & 4,14 & 2,90 & 14,03 & 12,17 & 0,07 \\
\hline 8 & mata & pasto & 31,41 & 1,34 & 2,05 & 6,70 & 7,20 & 13,99 & 0,00 \\
\hline 9 & mata & eucalipto & 363,96 & 2,61 & $1.274,88$ & 3,08 & 0,70 & 0,97 & 0,14 \\
\hline 10 & mata & cítricos & 394,47 & 1,71 & 418,54 & 2,29 & 6,83 & 6,87 & 0,12 \\
\hline 11 & mata & café & 260,46 & 2,21 & 543,56 & 0,92 & 8,28 & 8,28 & 0,06 \\
\hline 12 & mata & café & 99,09 & 1,36 & 5,83 & 2,41 & 5,34 & 5,37 & 0,03 \\
\hline 13 & mata & pasto & 70,38 & 1,52 & 3,73 & 7,74 & 11,61 & 14,44 & 0,08 \\
\hline 14 & capoeira & pasto & 51,03 & 2,31 & 26,61 & 4,12 & 14,25 & 14,20 & 0,09 \\
\hline 15 & cerrado & pasto & 218,88 & 1,45 & 722,60 & 7,49 & 18,58 & 23,01 & 0,02 \\
\hline 16 & capoeira & pasto & 51,57 & 1,60 & 27,68 & 6,76 & 18,35 & 23,69 & 0,00 \\
\hline 17 & mata & eucalipto & 63,00 & 1,28 & 115,10 & 7,74 & 11,65 & 14,48 & 0,05 \\
\hline 18 & mata & café & 191,79 & 2,68 & 3,04 & 2,06 & 5,98 & 8,59 & 0,01 \\
\hline 19 & mata & café & 87,93 & 1,41 & 1,15 & 4,08 & 19,42 & 7,59 & 0,05 \\
\hline 20 & mata & café & 46,62 & 1,17 & 1,74 & 7,50 & 11,27 & 0,06 & 0,24 \\
\hline 21 & capoeira & pasto & 30,69 & 1,54 & 1,41 & 5,29 & 9,87 & 7,71 & 0,03 \\
\hline 22 & mata & pasto & 60,57 & 1,37 & 0,85 & 3,63 & 10,33 & 4,58 & 0,00 \\
\hline 23 & mata & pasto & 78,84 & 1,45 & 21,48 & 2,90 & 12,18 & 5,47 & 0,02 \\
\hline 24 & capoeira & pasto & 32,40 & 1,71 & 3,33 & 5,37 & 21,57 & 14,57 & 0,00 \\
\hline 25 & mata & pasto & 29,52 & 1,22 & 11,19 & 8,75 & 19,74 & 20,53 & 0,00 \\
\hline 26 & capoeira & pasto & 64,08 & 1,80 & 2,54 & 0,53 & 4,38 & 6,63 & 0,02 \\
\hline 27 & capoeira & pasto & 47,79 & 1,77 & 4,53 & 6,21 & 15,45 & 22,73 & 0,00 \\
\hline 28 & mata & café & 151,74 & 1,27 & 3,52 & 9,32 & 8,55 & 2,38 & 0,36 \\
\hline 29 & mata & café & 90,90 & 2,56 & 121,91 & 11,58 & 2,09 & 5,92 & 0,08 \\
\hline 30 & mata & café & 159,03 & 1,86 & 24,75 & 2,70 & 18,18 & 18,17 & 0,05 \\
\hline
\end{tabular}




\begin{tabular}{cccccccccc}
\hline Fragmento & $\mathrm{C}$ & $\mathrm{E}$ & $\begin{array}{c}\mathrm{T} \\
(\mathrm{ha})\end{array}$ & IF & IPF & $\begin{array}{c}\text { DC } \\
(\mathrm{km})\end{array}$ & $\begin{array}{c}\text { DEEC } \\
(\mathrm{km})\end{array}$ & $\begin{array}{c}\text { Conclusão } \\
(\mathrm{km})\end{array}$ & $\begin{array}{c}\text { Indice de } \\
\text { visitas de } \\
\text { maracanãs }\end{array}$ \\
\hline 31 & mata & pasto & 230,76 & 2,31 & $6.688,39$ & 4,40 & 21,30 & 21,32 & 0,00 \\
32 & capoeira & eucalipto & 172,89 & 3,14 & 1,62 & 4,87 & 12,99 & 7,99 & 0,09 \\
33 & capoeira & café & 35,73 & 1,73 & 2,77 & 7,11 & 6,67 & 7,61 & 0,04 \\
34 & mata & pasto & 63,18 & 2,34 & 12,01 & 3,81 & 19,19 & 10,09 & 0,00 \\
35 & capoeira & pasto & 16,83 & 1,18 & 1,64 & 4,71 & 15,46 & 22,72 & 0,00 \\
36 & mata & pasto & 23,67 & 1,85 & $2.380,85$ & 8,02 & 11,90 & 12,11 & 0,00 \\
\hline
\end{tabular}

Nota: Variáveis: C (classe), E (tipo predominante de uso da terra no entorno), T (tamanho), IF (índice de forma), IPF (índice de proximidade a outro fragmento), DC (distância mínima até a cidade mais próxima), DEEC (distância mínima até a Estação Ecológica dos Caetetus) e DD (distância mínima até um dormitório conhecido de maracanãs). 